\title{
PERFORMANCE STUDY OF A
}

\section{THERMAL-ENVELOPE HOUSE}

\section{PHASE II \\ COOLING PERFORMANCE}

FINAL REPORT

James M. Akridge

Charles C. Benton

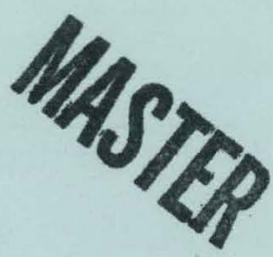

JANUARY 1981

Nint?

PORTTONS OF THTS RERORT ADE IIIER:BLE. It has been repraduced from the best availablo copy to permit the broadest possible avallo ability.

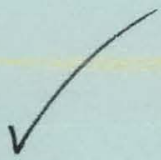

prepared by

The College of Architecture

GEORGIA INSTITUTE OF TECHNOLOGY

for

SOUTHERN SOLAR ENERGY CENTER

and the

\section{U.S. DEPARTMENT OF ENERGY}

under contract DE-AC02-79CS30166

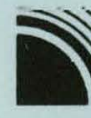




\section{DISCLAIMER}

This report was prepared as an account of work sponsored by an agency of the United States Government. Neither the United States Government nor any agency Thereof, nor any of their employees, makes any warranty, express or implied, or assumes any legal liability or responsibility for the accuracy, completeness, or usefulness of any information, apparatus, product, or process disclosed, or represents that its use would not infringe privately owned rights. Reference herein to any specific commercial product, process, or service by trade name, trademark, manufacturer, or otherwise does not necessarily constitute or imply its endorsement, recommendation, or favoring by the United States Government or any agency thereof. The views and opinions of authors expressed herein do not necessarily state or reflect those of the United States Government or any agency thereof. 


\section{DISCLAIMER}

Portions of this document may be illegible in electronic image products. Images are produced from the best available original document. 

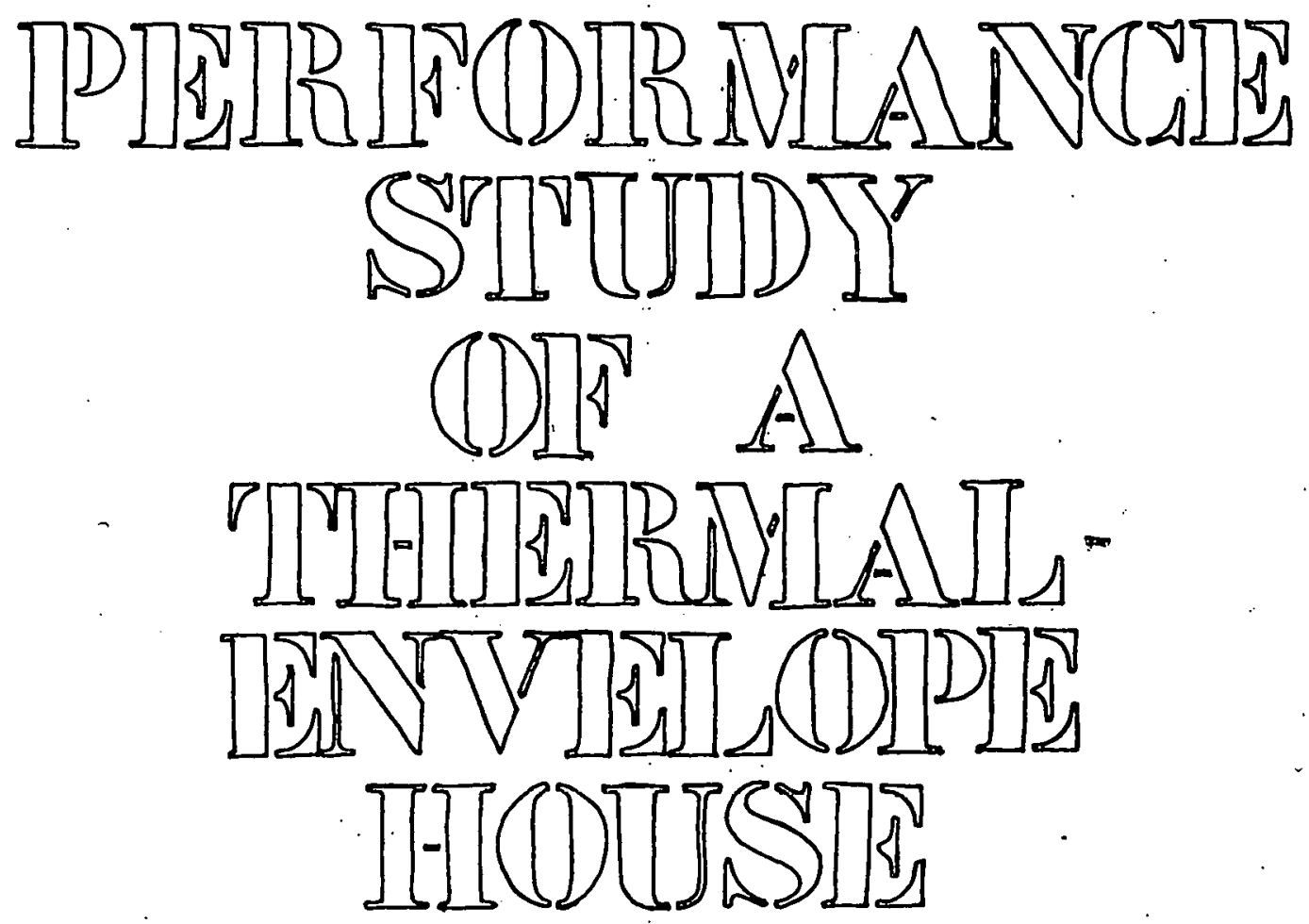

FINAL REPORT

Phase II

\section{COOLING PERFORMANCE}

James M. Akridge

This book was prepared as an accouns of work sponsored by an egency of the United States ciovernment.

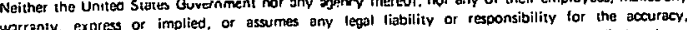

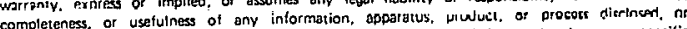
rearesents that its use would not inftinge privately ammed rights Reference herein to any specific commercial product. process, of service by trade name, tradenerk. mantacturer, or otherwse. does moi necessarty constiture or imply its endorsement, recommendotion, or lavang by the Unita

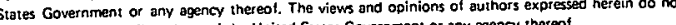

$$
\text { and }
$$

Charles C. Benton

Prepared for

The Southern Solar Energy Center

61 Perimeter Park

Atlanta, Georgia

By

The College of Architecture

Georgia Institute of Technology

Atlanta, Georgia 


\section{Disclaimer}

This work was prepared as an account of work sponsored by an agency of the United States Government. Neither the United States Government nor any agency thereof, nor any of their employees, makes any warranty, express or implied, or assumes any legal liability or responsibility for the accuracy, completeness, or usefulness of any information, apparatus, product, or process disclosed, or represents that its use would not infringe on privately owned rights. Reference herein to any specific commercial product, process, or service by trade name, trademark, manufacturer, or otherwise, does not necessarily constitute or imply its endorsement, recommendation, or favoring by the United States Government or any agency thereof. The views and opinions of authors expressed herein do not necessarily state or reflect those of the United States Government or any agency thereof. 


\section{ACKNOWLEDGEMENTS}

The authors wish to express their appreciation to Mr. and Mrs. C. A. Stokes, without whose assistance this program would have been impossible. 


\section{TABLE OF CONTENTS}

List of Figures

List of Tables

iv

Introduction

Summary

Instrumentation

Instrumentation Difficulties

Data Reduction

Analysis

Earth Cooling Tubes

Heating Performance Revisited

Conclusions

Appendices

Appendix A Sample Data Output/Files

Appendix B Additional Thermal Performance Curves

Appendix C Earth Cooling Tube Analytical Performance Model 


\section{LIST OF FIGURES}

Figure 1. Schematic Section of Thermal Envelope House

Figure 2. Schematic of Data Acquisition System . 6

Figure 3. Building Section Showing Thermocouple Location 7

Figure 4. Crawlspace Plan 8

Figure 5. First Floor Plan . 8

Figure 6. Second Floor Plan 9

Figure 7. Attic Plan 9

Figure 8. Sensor Locations for Earth Cooling Tubes 10

Figure 9. Aspirated Wetbulb Thermocouple 11

Figure 10. Thermocouple Radiant Shield $\quad 14$

Figure 11. Temperature Distribution in Greenhouse/Attic . 22

Figure 12. Temperature Distribution in Living Space 23

Figure 13. Temperature Distribution through West Wal1. 24

Figure 14. Temperature Distribution along Cooling Tube - Day 2S 25

Figure 15. Temperature Distribution down North Wal1 26

Figure 16. Temperature Lag in Master Bedroom 28

Figure 17. Temperature Distribution in Crawlspace 29

Figure 18. Temperature Distribution in Attic/Thermal Chimney 31

Figure 19. Thermal Chimney Driving Force Diagram 33

Figure 20. Thermal Loop Temperature Distribution 34

Figure 21. North Wall Temperature Distribution 35

Figure 22. Temperature Distribution along Cooling Tube - Day $35 \quad 37$

Figure 23. Temperature Distribution along Cooling Tube - Day 4S 38

Figure 24. Cooling Tube Inlet-Exit Temperatures on Psychrometric
Diagram

Figure 25. Ground Temperature Gradient Perpendicular to the Pipe Day $2 S$

Figure 26. Ground Temperature Gradient Perpendicular to the Pipe Day 3S

Figure 27. Ground Temperature Gradient Perpendicular to the Pipe Day 4S 43

Figure 28. Ground "Far Field" Temperature Gradient - Day 2S 44

Figure 29. Effect of Intermitent Operation on Ground Temperature Gradient

Figure 30. Effect of Fan Speed on Temperature Gradient along the Cooling Tube 


\section{LIST · OF FIGURES}

Page

Figure 31. Effect of Reduced Flow on Temperature Gradient along the Cooling Tube

Figure 32. Loop Equilibrium Temperature Schematic 


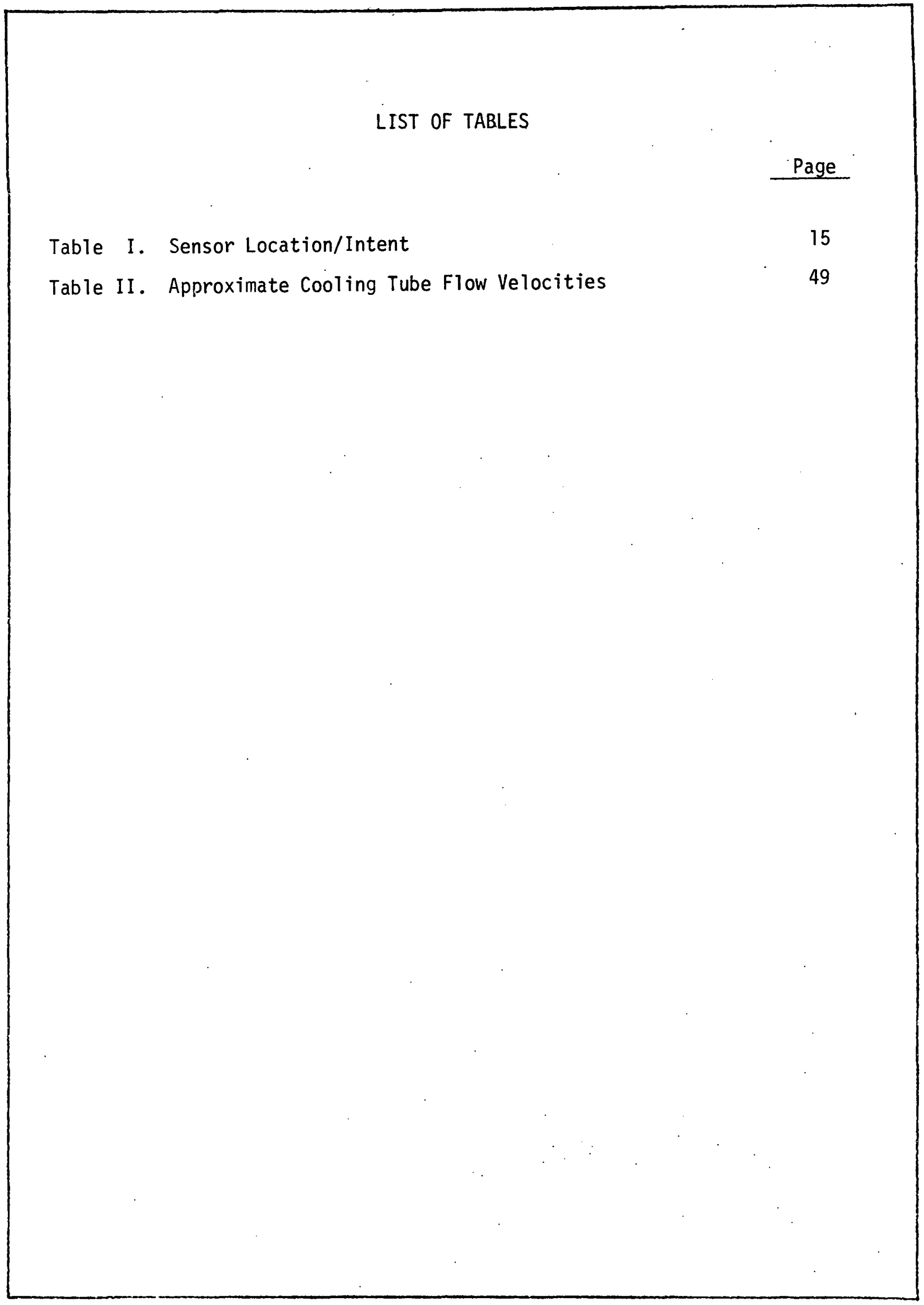

iv 


\section{INTRODUCTION}

Passive houses are currently receiving considerable attention throughout the world. They appear to offer significant potential for the reduction of energy required for space heating. One design, by California architect Lee Porter Butler, has received considerable publicity. This defisgn, which is essentially a house within a house, is called a thermal envelope house. This scheme has proponents who claim the design is the answer to many of our residential housing problems and critics who say it will not perform as claimed and that the design has significant problems.

The thermal envelope house is characterized by the presence of two insulating envelopes, one within the other, as shown in Figure 1. Between the two

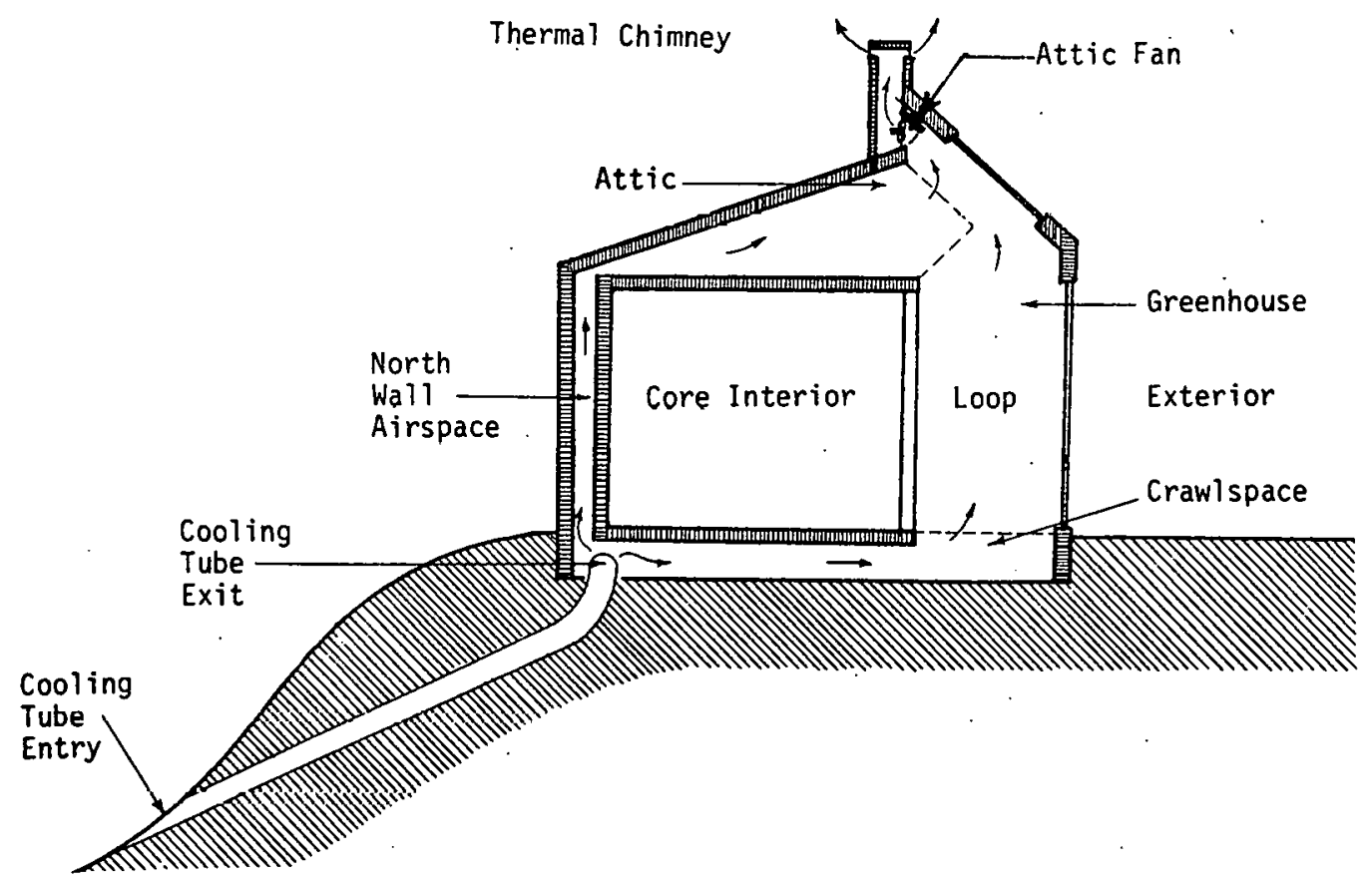

Figure 1. Schematic Section of Thermal Envelope House 
insulating envelopes, a continuous airspace is formed which allows air to circulate unimpeded between four spaces comprising a loop. These-four spaces include the south side greenhouse, the attic space, the air cavity between two insulated north walls and the crawlspace. Each of these areas is thermally insulated from the exterior environment as well as the core interior of the house. There is considerable speculation on the dynamics of both air flow and heat transfer within this loop.

The heating performance of one thermal envelope house was thoroughly evaluated in a PHASE I report. (1) The house, located in Canton, Georgia, demonstrated good performance in the heating mode. This report addresses the cooling performances of the same house.

This thermal envelope house uses two $21^{\prime \prime}$ diameter, 100' long earth cooling tubes (tubes buried beneath the ground surface) to supply earth-tempered air to the house envelope. Figure 1 shows how the earth-tempered air is circulated around the envelope and is exhausted through the thermal chimney. An attic fan is used to boost the flow on hot days. Ideally, the inner shell is not opened to the humid air circulating around the shell. In practice the inner space is frequently opened to the envelope to lower interior temperatures.

There has been considerable speculation concerning both the cooling potential of earth cooling tubes and driving potential of thermal chimneys. The thermal chimney shown in Figure 1 is a chimney-like structure running the length of the roof. In this particular design the greenhouse and the glazed section of the south roof act as part of the chimney. The object of the thermal chimney is to provide a relatively high vertical or near vertical (glazed or partially glazed) structure in which air can be heated by the sun. The bouyance caused by the heated air causes it to rise, exiting out the top of the chimney. The rising air is replaced by cooler air either coming from the cooling tubes or from outside the house. This report addresses both of these issues. 


\section{SUMMARY}

The investigation shows this thermal envelope house to perform much better than conventional houses without mechanical refrigeration and better than one would expect from most passively cooled houses in the hot-humid climate of Georgia. Peak temperatures inside the house were 8 to 15 of below peak ambient temperatures. Peak inside temperature measured during the test period was $800^{\circ} \mathrm{F}$ with an outside ambient peak of $930 \mathrm{~F}$.

The hot wire anemometers used to measure air flow rates showed velocities within the envelope to be quite low, being less than $1 \mathrm{ft} / \mathrm{sec}$ even when the attic fan was operating.

The earth cooling tubes provided noticeable sensible cooling to the house. Exit temperatures from the cooling tubes were between $72-76^{\circ} \mathrm{F}$, depending upon the air velocity through the tubes. These temperatures were only $4-8$ o F above the far field temperatures at the $4 \mathrm{ft}$. average depth of the tubes. "Far field" is used here to mean a position sufficiently distant from the cooling tube to be unaffected by the cooling tube.

The thermal chimney performed poorly as an air mover, especially when used to induce flow through the earth cooling tubes. If temperatures in the thermal chimney became too high, it increased the thermal load inside the house. If the thermal chimney was at moderate temperatures, the density of the air in the cooling tubes would sometimes cause outside air to flow in the thermal chimney and out the cooling tubes.

The performance of the earth cooling tube could be improved by using the 
attic fan to increase the air flow through the cooling tubes and to insure it flowed in the cooling tube, through the envelope and out the thermal chimney. While the attic fan was a satisfactory solution, it was not an optimum solution. Being an exhaust fan, the attic fan created a negative pressure in the house. While this increased air flow through the cooling tubes, it also increased air infiltration through the building shell, thus increasing load.

The largest problem encountered with the thermal envelope house in the cooling mode is problems with high humidity. The humidity level within the living space remains relatively high year-round due to low rates of air infiltration and water vapor transmission through the building skin. The problem is aggravated during the summer by the introduction of cool moist air from the cooling tubes to the envelope and frequently to the inner space. While the cooling tubes are able to reduce the sensible load, they are incapable of significantly reducing humidity or latent loads. This results in relatively comfortable air temperatures but uncomfortable humidities within the living space. 


\section{INSTRUMENTATION}

The data acquisition system used for the cooling performance evaluation, while similar to that used in the heating performance evaluation, was modified to permit evaluation of the earth cooling tubes. Figure 2 schematically shows the data acquisition system layout. Copper-constantan thermocouples (26 gauge premium grade NBS reference) were routed to 69 positions within the house, greenhouse, crawlspace, thermal chimney and cooling tubes. Since the heating performance evaluation had shown little temperature variation between the east and west sections compared to the center section and the data logger was limited to 60 data stations, nine thermocouples along the east and west sections were not connected for the cooling evaluation. Those thermocouples within the living space and those measuring temperatures of the double concrete block west wall were connected for the cooling evaluations. Figure 3 is a section through the centerline of the house showing those thermocouples located along this section.

Figure 4 is a plan view of the crawlspace showing thermocouples positions within this space. Figure 5 is a plan view of the first floor showing thermocouple positions used to establish the temperature distribution in this space. Figure 6 shows the thermocouple locations on the second floor and Figure 7 shows the thermocouple locations in the attic.

Figure 8 shows those thermocouples added to monitor temperatures within the cooling tube. Thermocouples 1 and 2 measure the cooling tube inlet dry-bulb and wet-bulb temperatures respectively. Thermocouples 3-8 measure the dry-bulb temperature along the cooling tube. Thermocouple 9 measures the wet-bulb 

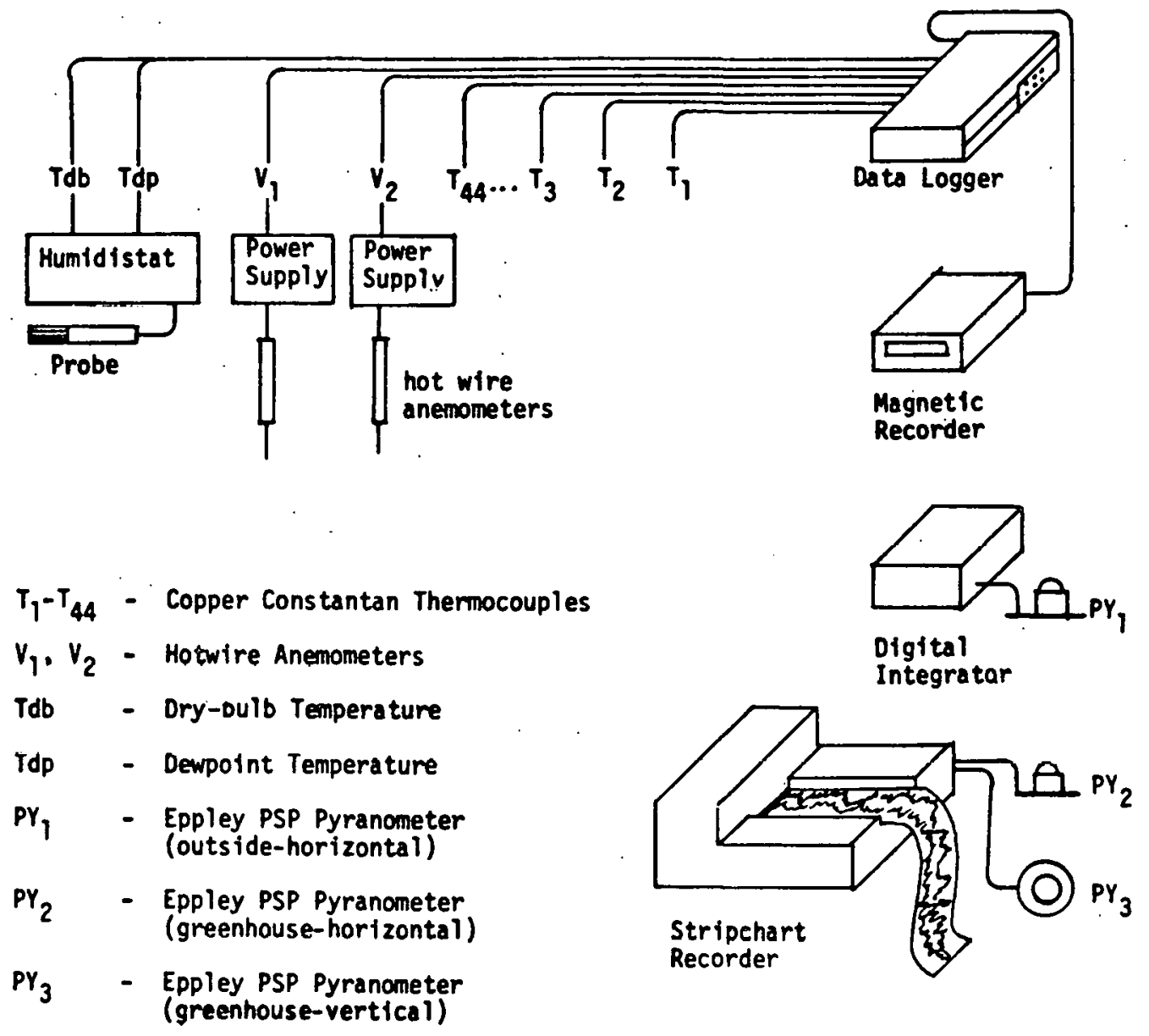

Figure 2. Schematic of Data Acquisition System 


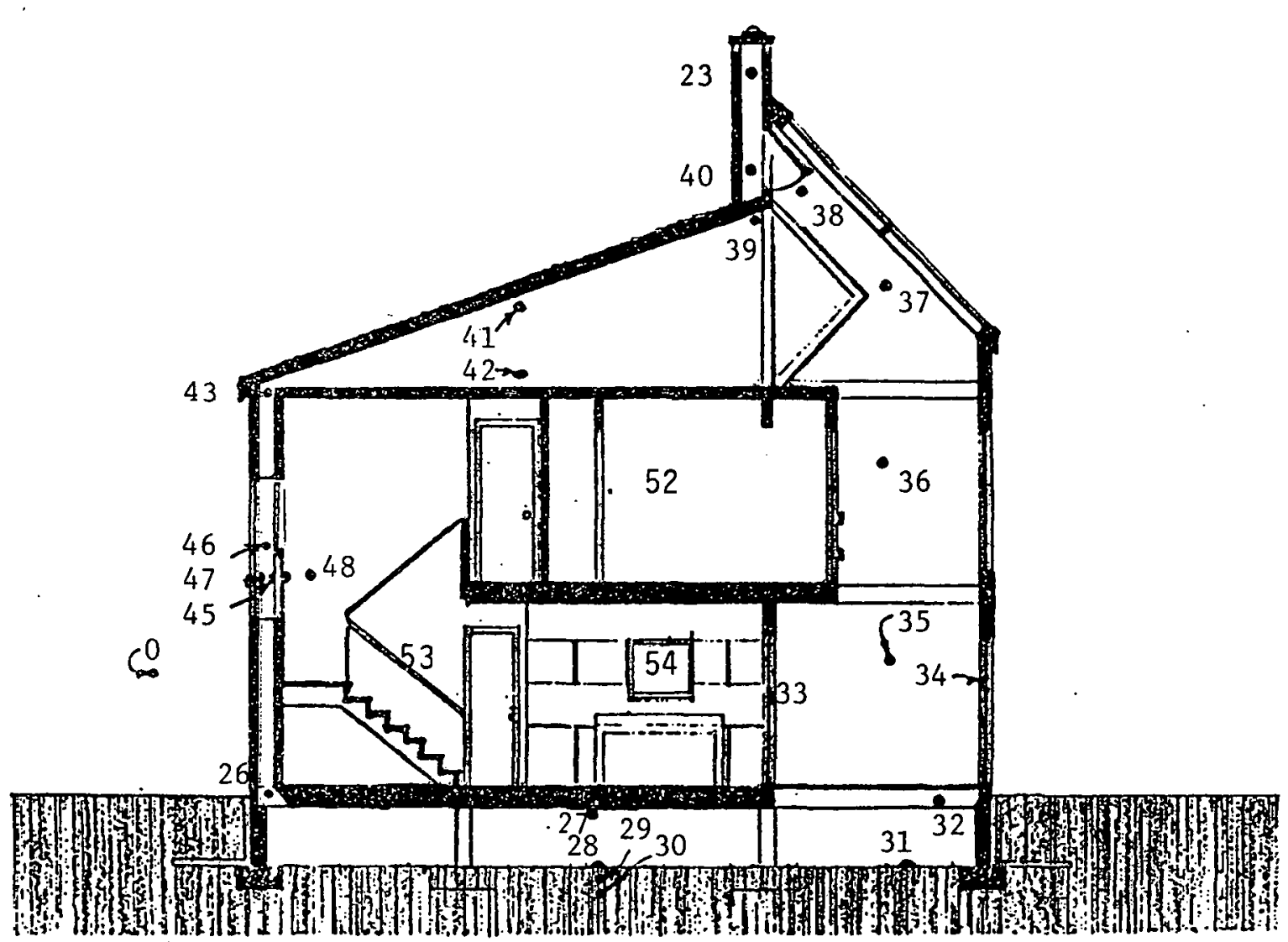

THERMOCOUPLE LOCATION - SECTION THRU STAIR

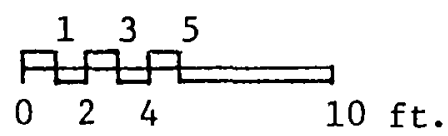

Figure 3. Building Section Showing Thermocouple Location 


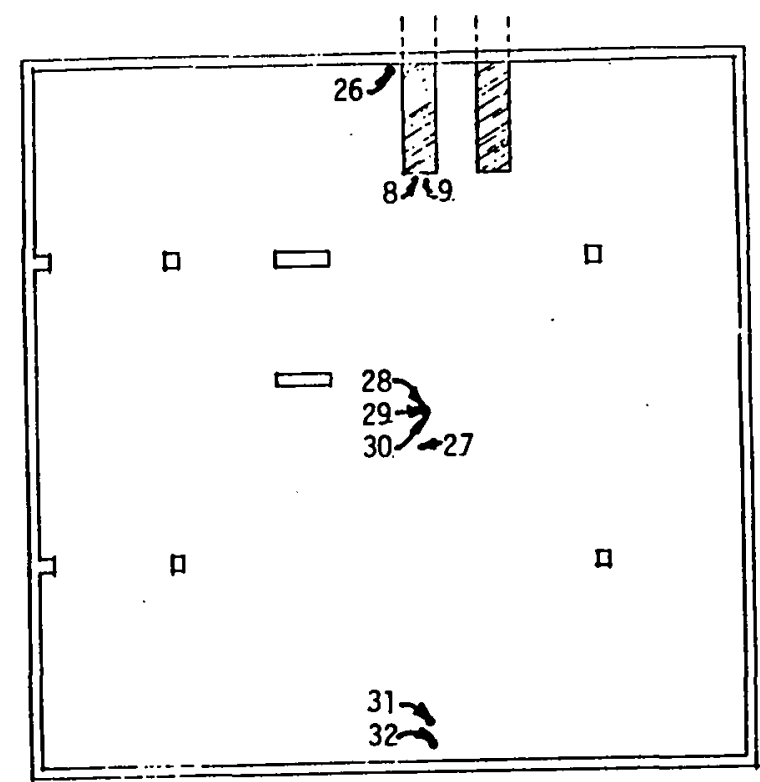

crawlepace

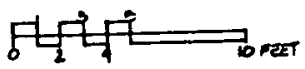

Figure 4. Crawlspace Plan

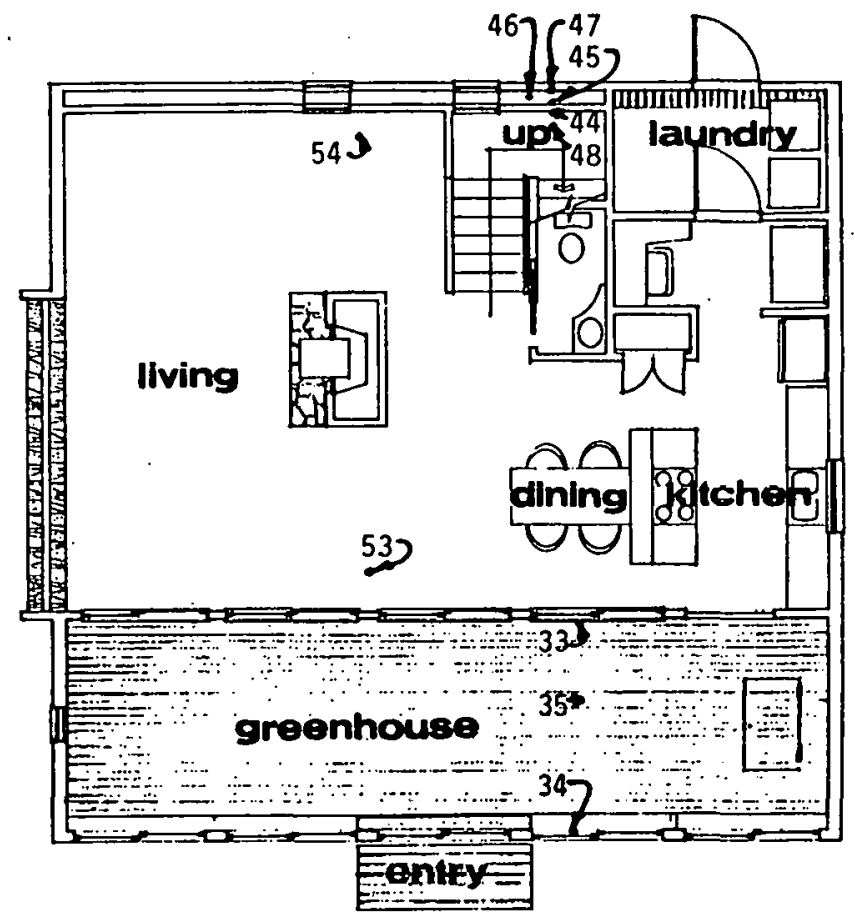

lower level

मfti

Figure 5. First Floor Plan 


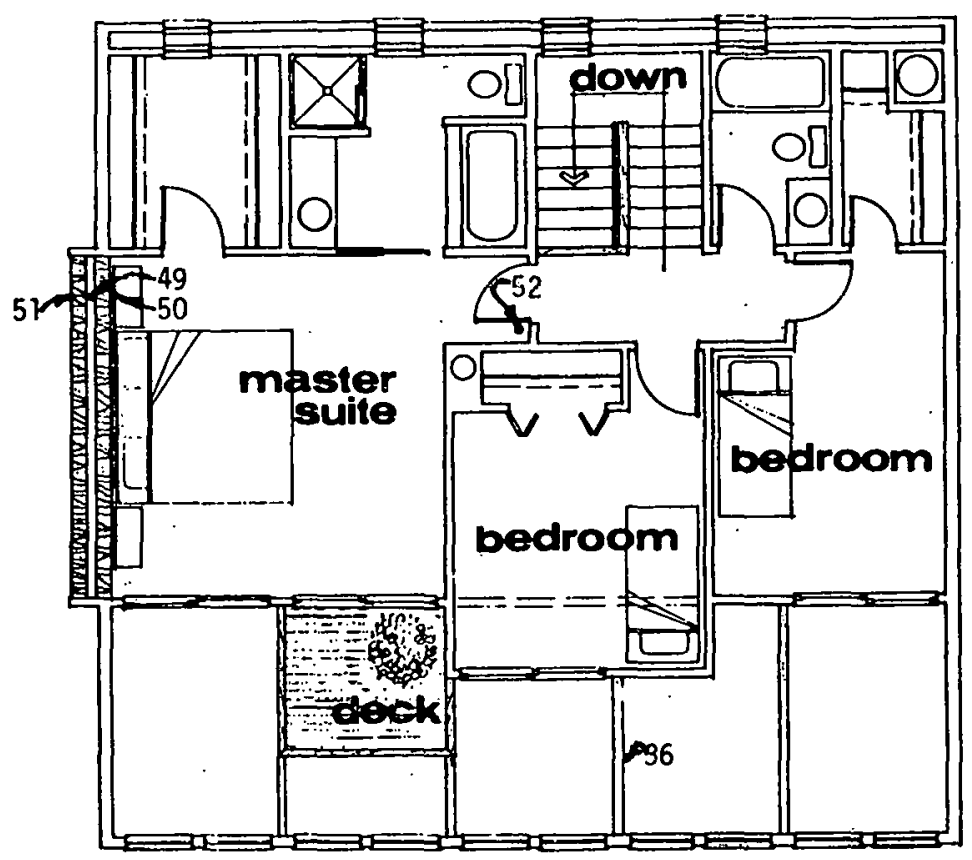

upper level

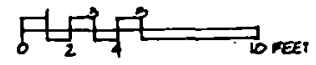

Figure 6. Second Floor Plan

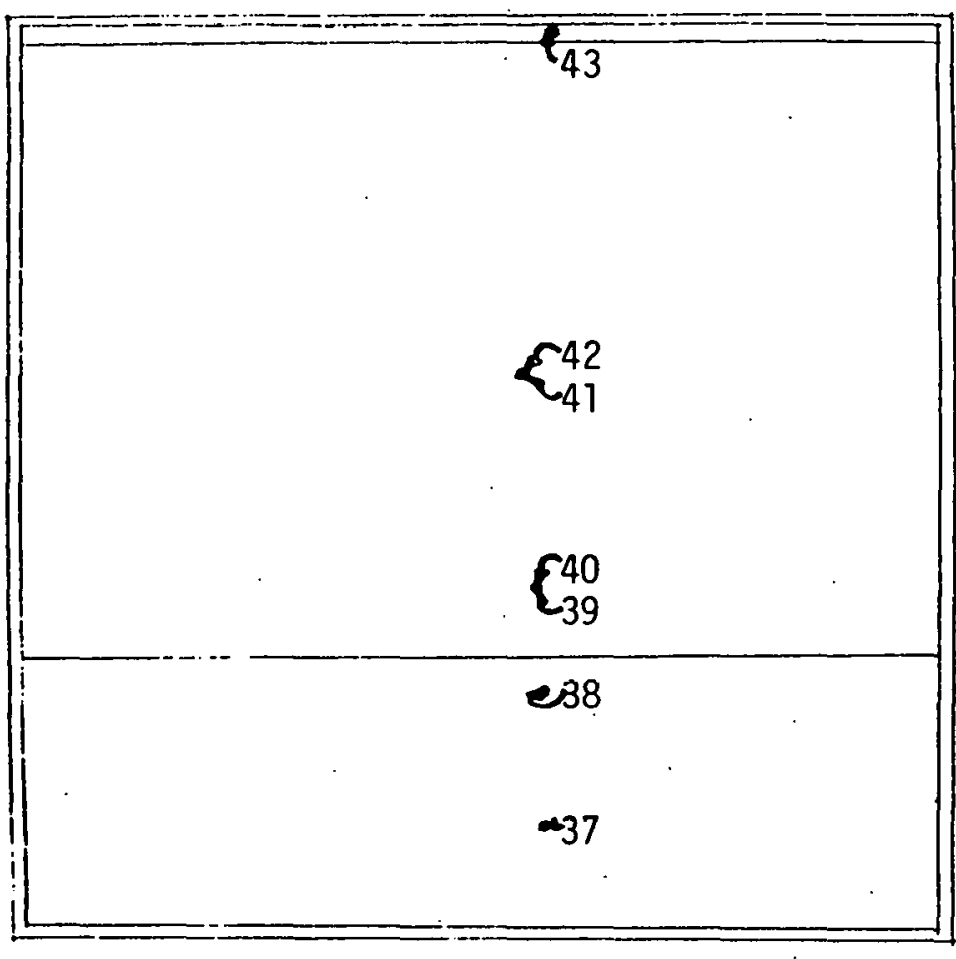

attic

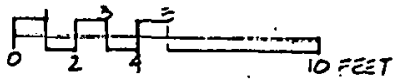

Figure 7. Attic Plan 


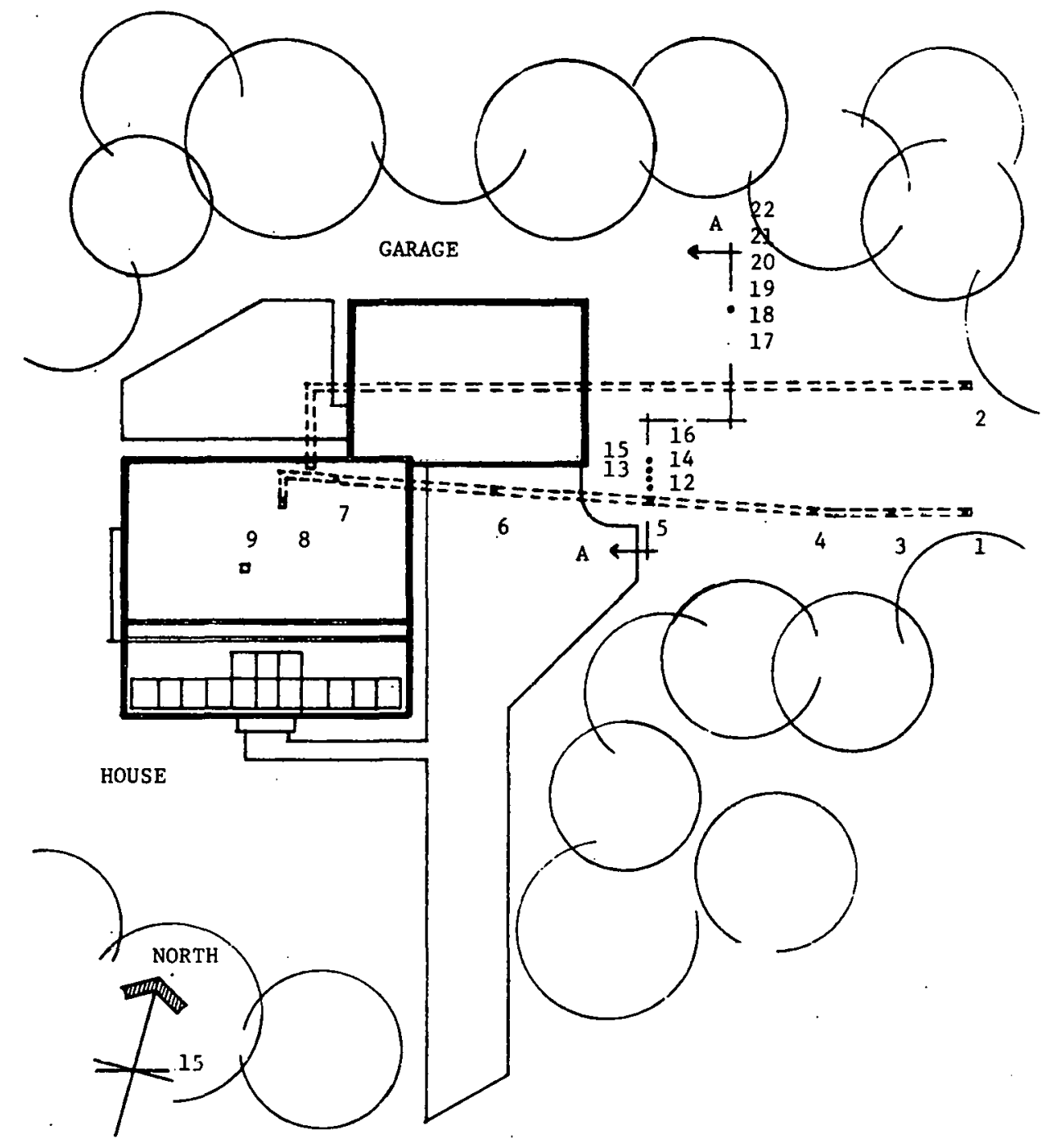

PLAN SHOWING COOLINC TUBE LAYOUT AND TEMPERATURE SËNSUR LAYOUT STOKES ' HOUSE

* Circled numbers indicate thermocouples inside tube.

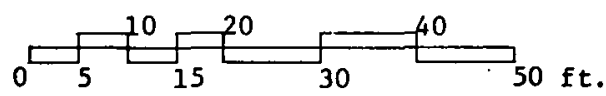

Figure 8. Sensor Locations for Earth Cooling Tubes 


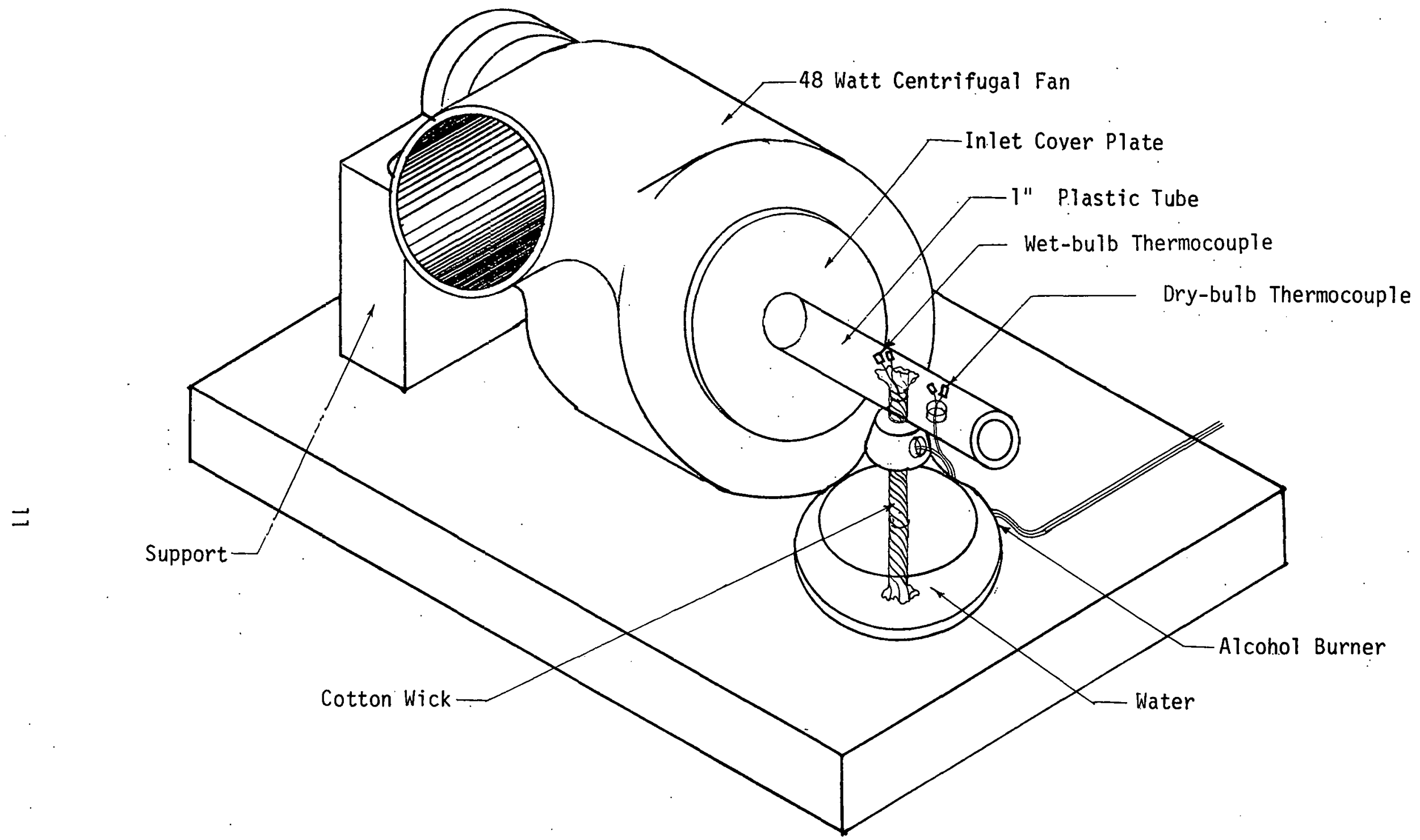

Figure 9. Aspirated Wet-bulb Thermocouple 
temperature of the cooling tube exit air.

Thermocouples $10,11,12$ measure the ground temperature adjacent to the tube at positions along the tube. Thermocouples 12-16 measure the ground temperature at the cooling tube depth at five distances away from the tube. These measurements were made at a position $40^{\prime}$ from the tube inlet (outside opening). Thermocouples 17-21 measure the far field (undisturbed) ground temperature from the surface to a depth of $4 ' 8^{\prime \prime}$.

An Eppley PSP Pyronometer was mounted horizontally on top of the thermal chimney to measure total horizontal radiation. Eppley PSP Pyranometers were also mounted in vertical and horizontal positions along the south side of the greenhouse adjacent to and inside the greenhouse glazing to measure radiation levels within this space.

A hot wire anemometer was positioned along the centerline of one of the earth cooling tubes, 2' from its exit (inside opening) and about 2' from a $90^{\circ}$ elbow. The flow measurements were obviously adversely affected by the exit and elbow. Unfortunately, no long, straight section of the tube could be reached for flow measurements due to the tube being buried.

The use of commercially available, saturated salt humidistats during the heating performance study proved unsatisfactory due to excess maintenance requirements and pnor arcuracy. This experience prompted a change to aspirated dry-and wet-bulb thermocouples for the cooling performance studies. Figure 9 shows the small 48-watt fan used for measuring the dry- and wet- bulb temperaures at the inlet and outlet of the southernmost cooling tube.

Output from all thermocouples, the humidistat, and both hot wire anemometers were routed to a Fluke Model 2240B Datalogger. The datalogger provided a cold junction reference for the thermocouples, linearized their output and converted the output to a reading in $\mathrm{OF}$. The datalogger was programmed to sample 
all connected channels once each hour. The datalogger printed the date, time, channel number, the reading, and the units for each of the inputs onto a paper tape. Figure Al in Appendix A gives a sample paper tape output.

The datalogger also wrote all the data printed on the paper tape onto a Columbia Model 300C four-channel magnetic type recorder through a standard Rs232C interface. One four-channel, 300-ft. cartridge was capable of storing data for 60 channels sampled once each hour for two months.

The outputs from the pryanometers in the greenhouse were recorded on Houston Instrument Omni-Scribe two-channel stripchart recorders. The output from the horizontal pyranometer mounted on the roof was routed to an electronic integrator calibrated to read in $\mathrm{Btu} / \mathrm{Ft}^{2}$. This integrator was manually read and logged with daily weather observations at the end of each'day, and then reset. Figure A2 in Appendix A shows a typical stripchart for a clear day.

All thermocouples which were exposed to direct solar radiation or high mean radiant temperatures were shielded with double radiation shields, as shown in Figure 10 .

Table I gives the channel number, location and intent for each of the channels used. 


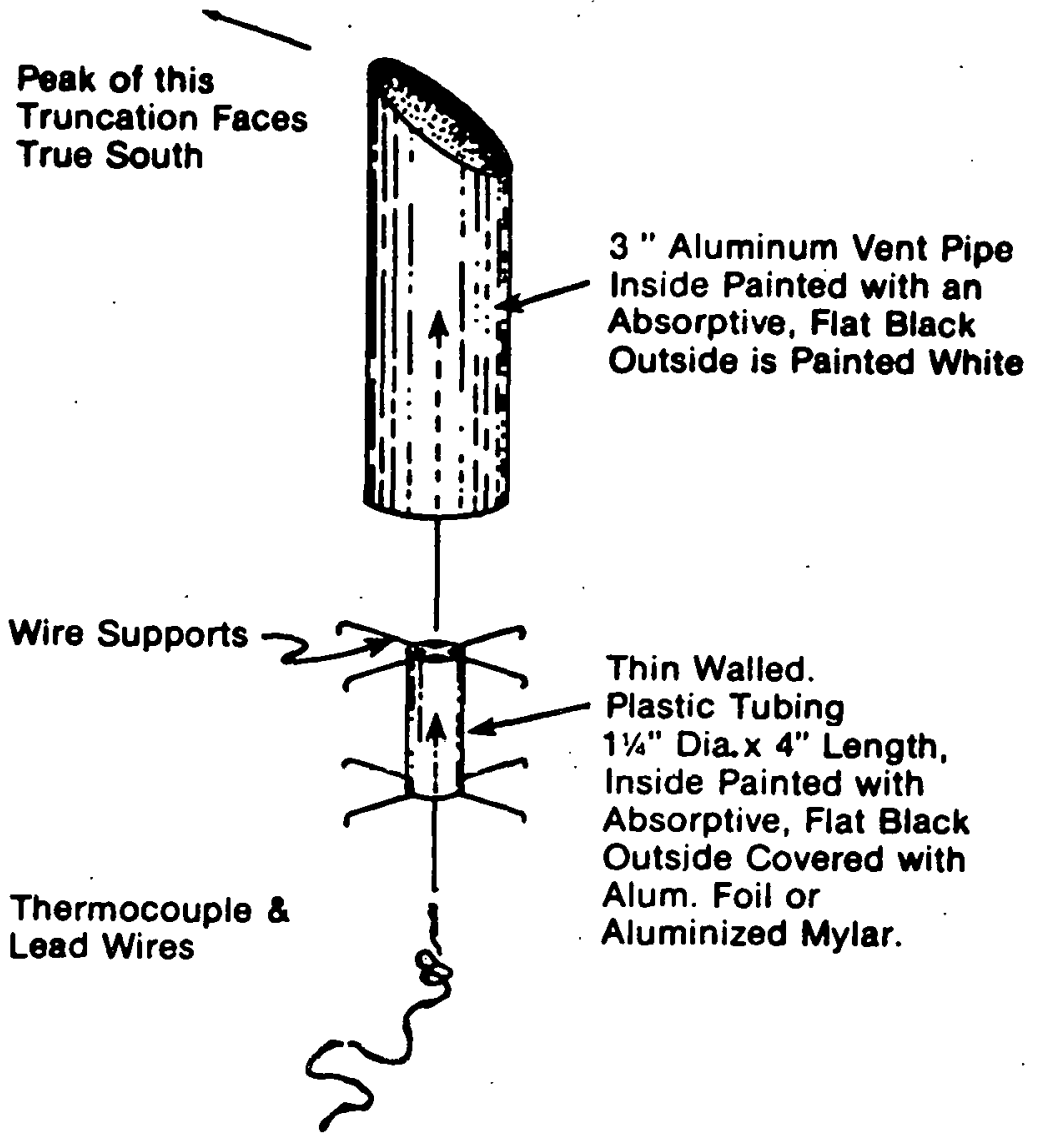

Figure 10. Thermocouple Radiant Shield 
TABLE I

SENSOR LOCATION AND DESCRIPTION

CHANNEL

LOCATION/INTENT

0

1

2

3

4

5

6

7

8

9

10

11

12

13

14

15

16

17

18

19

20

21

22

23

24

25

26

27

28

29

30
OUTSIDE AIR

DRY-BULB-inlet tube

WET-BULB-inlet tube

DRY-BULB-10' up tube

DRY-BULB-20' up tube

DRY-BULB-40' up tube

DRY-BULB-60' up tube

DRY-BULB-80' up tube

DRY-BULB tube exit

WET-BULB-tube exit

GROUND TEMP.-adjacent tube $10^{\prime}$

GROUND TEMP.-adjacent tube 20'

GROUND TEMP.-adjacent tube $40^{\prime}$

GROUND TEMP. $-1^{\prime}$ from tube $40^{\prime}$

GROUND TEMP. $-2^{\prime}$ from tube $40^{\prime}$

GROUND TEMP. $-3^{\prime}$ from tube $40^{\prime}$

GROUND TEMP. -4 ' from tube $40^{\prime}$

GROUND TEMP. - 4' 8 " deep

GROUND TEMP. - $3^{\prime} 8^{\prime \prime}$ deep

GROUND TEMP. - 2' 8 " deep

GROUND TEMP. -1'8" deep

GROUND TEMP. - -8" deep

GROUND TEMP.-surface ( $\left.\frac{1}{2} "\right)$

ATTIC-extreme peak

NORTHWALL-cavity bottom

CRAWLSPACE-mid.

CRAWLSPACE-mid ground

CRAWLSPACE-2" below ground

CRAWLSPACE-5" be low ground 
31

32

33

34

35

36

37

38

39

40

41

42

43

44

45

46

47

48

49

50

51

52

53

54

55

56

57

58

59

73
CRAWLSPACE-south greenhouse

GREENHOUSE-below floor

GREENHOUSE-external-internal glass

GREENHOUSE-internal-external glass

GREENHOUSE-5' above finished floor

GREENHOUSE-13" above finished floor

GREENHOUSE-peak

GREENHOUSE-extreme peak

ATTIC-peak

THERMAL CHIMNEY-lower

ATTIC-mid. rafter

ATTIC-mid. floor

NORTHWALL-cavity top

NORTHWALL-internal room surface

NORTHWALL-internal cavity surface

NORTHWALL-mid. cavity

NORTHWALL-cavity

NORTHWALL-at 6" from surface

WESTWALL-interior

WESTWALL-cavity

WESTWALL-externa 1

INTERNAL-master bedroom

INTERNAL-south 1 ivingroom

INTERNAL-center north livingroom

PYRANOMETER

TUBE-exit air velocity

NORTHWALL-air velocity

INTERIOR-dewpoint

INTERIOR-dry-bulb

CRAWLSPACE-north ground 


\section{INSTRUMENTATION DIFFICULTIES}

Although modifications to the instrumentation had been made to correct problems encountered during the heating performance studies, several problems persisted and one very major new problem was encountered.

The heating performance report pointed out the difficulty of installing 1500 feet of thermocouple wire without an esthetic impact on the residence. An additional 3000 feet of thermocouple wire was used to document the cooling performance. Installation of the additional wire was very time consuming because of the location of the wire. Several trips through the cooling tubes were required to install the wire used to monitor the air temperatures through the tube. This did permit a visual inspection of the cooling tube showing no condensed water in the tube and little evidence that much, if any, condensation had occurred.

The problem of rather frequent power interruptions at the site was not solved. Time limitations forced the program to use the Columbia magnetic cartridge recorder used during the heating performance evaluation because the magnetic data recorder furnished by the sponsor would not work properly.

Two significant problems resulted from rather frequent power interruptions at the site. While one would not expect to have any power interruptions in a onemonth period, three interruptions were experienced during the test period. The Fluke datalogger has a battery backup for the program which assigns channel, channel functions, sampling rate, etc. Unfortunately, the date and time clock is not connected to the battery. When the power was interrupted, the clock would reset to 0 and would begin at that time when the power came back on. This was a minor 
inconvenience, only requiring that the correct time be noted the next time the datalogger was checked and the date/time clock reset. It could have been eliminated by connecting the clock to the battery. The datalogger was modified by Fluke following these tests to eliminate this problem.

A more serious problem was experienced with the Columbia magnetic cartridge recorder. When power came back on after an interruption, the recorder would rewind to the start of tape position and record over data previously recorded. This erased portions of the earlier data. The problem was lessened by stepping the recorder to the next track as soon as the power was restored. This was not always possible. This method minimized data loss but resulted in much more recording tape being used in the tests than actually was required. If no one was present when the power came back on, some data were lost from the magnetic recorder. A subsequent model of the Columbia recorder which does not rewind has been purchased.

A data file for the lost data can be created by transcribing from the paper tape backup provided by the datalogger. This process proved to be a very time consuming job. Approximately four (4) hours were required of two people to read and record on disc the sixty (60) channels of data for a twenty-four (24) hour period. This is roughly half the time required for the heating data because data were taken only once each hour rather than twice as in the heating study.

The most serious instrumentation problem had not been encouritered during the heating performance study. With thermocouples ranging from a high point at the peak of the house to a low point buried near the cooling tubes, a significant voltage potential existed when thunderstorms approached the site. Unfortunately, thunderstorms are rather frequent in this area. During the four week period this monitoring was occuring, three very expensive dataloggers were damaged and made inoperative by lightning or voltage potentials due to lightning. Although the monitoring period covered almost one month, only six days of data were taken due to time required to 
repair, replace, and check out dataloggers.

Two problems due to lightning were encountered. The fírst problem resulted from large voltage spikes occuring along the power line. This has been corrected for subsequent programs by installing a crystal-controlled clock in the datalogger and powering the datalogger with a battery-driven, 60 cycle inverter. A battery charger keeps the battery charged when power is available. This modification corrects two problems: it isolates the datalogger from line spikes, and it eliminates the loss of a time reference when power losses occur. In addition, the battery and inverter can power the Columbia recorder and thus eliminate the rewind problem.

The voltage spike coming along the thermocouple wire proved to be more difficult to correct. A satisfactory solution was found by connecting the negative side of the thermocouple to both the negative terminal and the ground terminal. This effectively shorts voltage spikes to ground. A 4- to 40- volt zener diode connected between the positive thermocouple terminal and ground is being investigated as a means of protecting the positive side of the thermocouple circuit.

The datalogger was not the only instrumentation affected by lightning. A saturated salt humidistat was damaged and a hot wire anemometer was destroyed during these tests. Both of these can be protected by powering them with a batterydriven inverter. 


\section{DATA REDUCTION}

Once the data acquisition system was installed and working satisfactorily, a computer program for data reduction and curve plotting was written and checked out.

At the end of the test period, the magnetic cartridge recorder and the magnetic tapes used during the test were connected in series with a computer terminal on a direct line to the Tech Cyber $70 / 74$ computer. The data were then read directly onto a computer disc. One file was created for each day data were available.

A computer program written for data reduction would plot up to 10 curves from any data file selected. All curves in Appendix B and those used to describe the house performance were plotted from stored data by the Cyber Versatec plotter. 


\section{ANALYSIS}

Due to the instrumentation difficulties discussed earlier, our analysis of the cooling performance was limited to six days. Fortunately, these six days were hot, humid, and clear, and thus are typical of this region.

Figure 11 shows the moderating effect of the thermal envelope. It also shows the extreme temperatures being reached at points in the greenhouse. Although the outside air temperature reached about 90\% $\mathrm{F}$ at 2:30 p.m., the inside temperature in the master bedroom reached a peak of only $80^{\circ}$ at 7:00 p.m.

The master bedroom was strongly affected by the uninsulated west wall, thus reaching temperatures higher than one would have expected. The inside temperatures along the west side of the house were slightly cooler than other interior temperatures during the early portions of the day. This is illustrated in Figure 12, showing temperatures at several locations within the living space. Figure 12 also shows the south living room temperature running 1-3 of higher than the master bedroom until the temperatures in the greenhouse begin to fall. This Figure shows the effect of the high mass on the west side of the house. The master bedroom temperature runs lower than other internal temperatures until about 5:00 p.m. The reason for this delay can be seen in Figure 13 which shows the temperature distribution through the west wall. Note the delay and dampening due to the mass of the double concrete block west wall. The double concrete block is shown in section on Figure 13.

Surprisingly, the internal temperatures do not reflect the significant. decrease in envelope temperatures when the attic fan is turned on. Figure 14 shows 

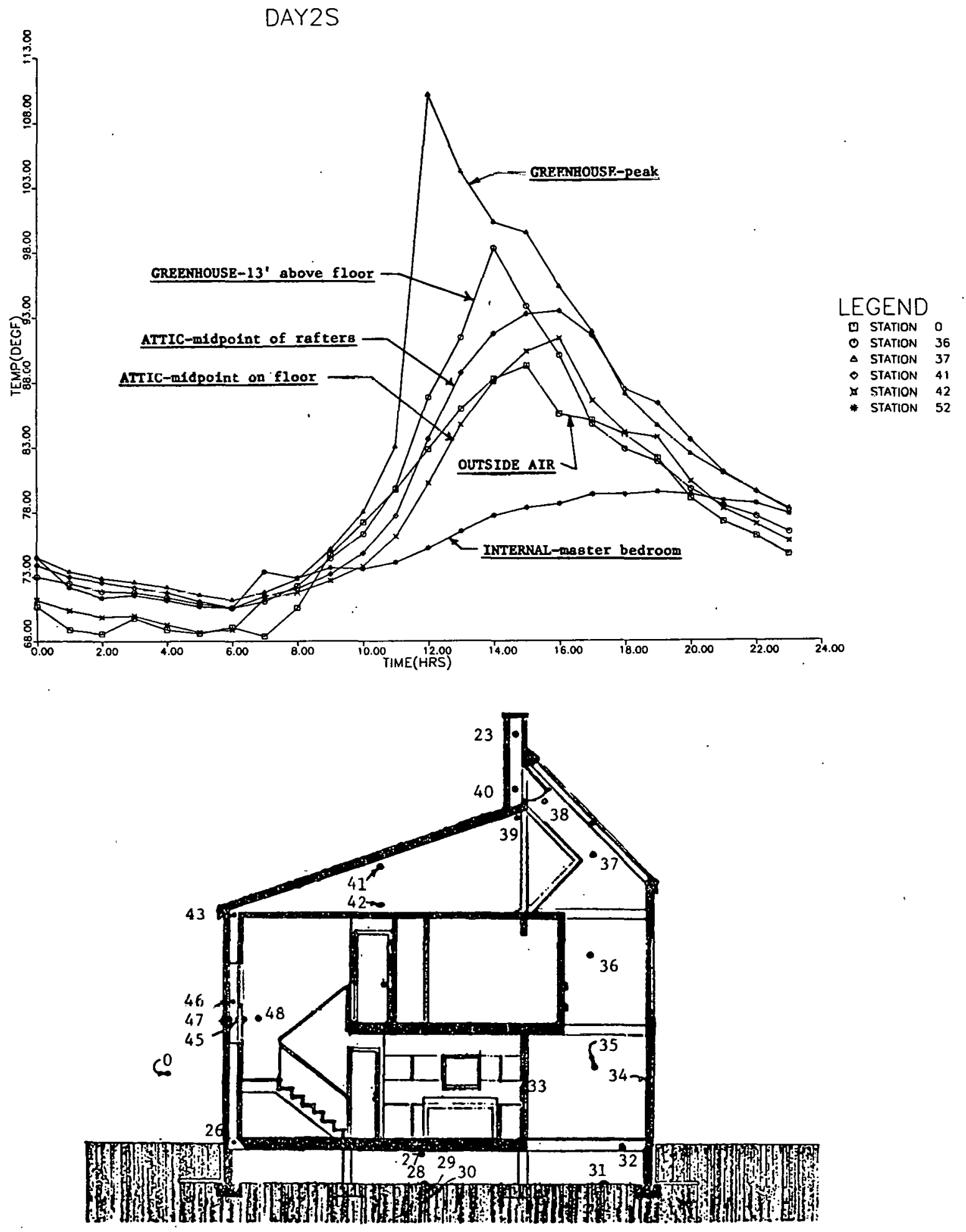

THERMOCOUPLE LOCATION - SECTION THRU STAIR

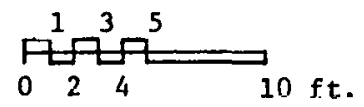

Figure 11. Temperature Distribution in Greenhouse/Attic 

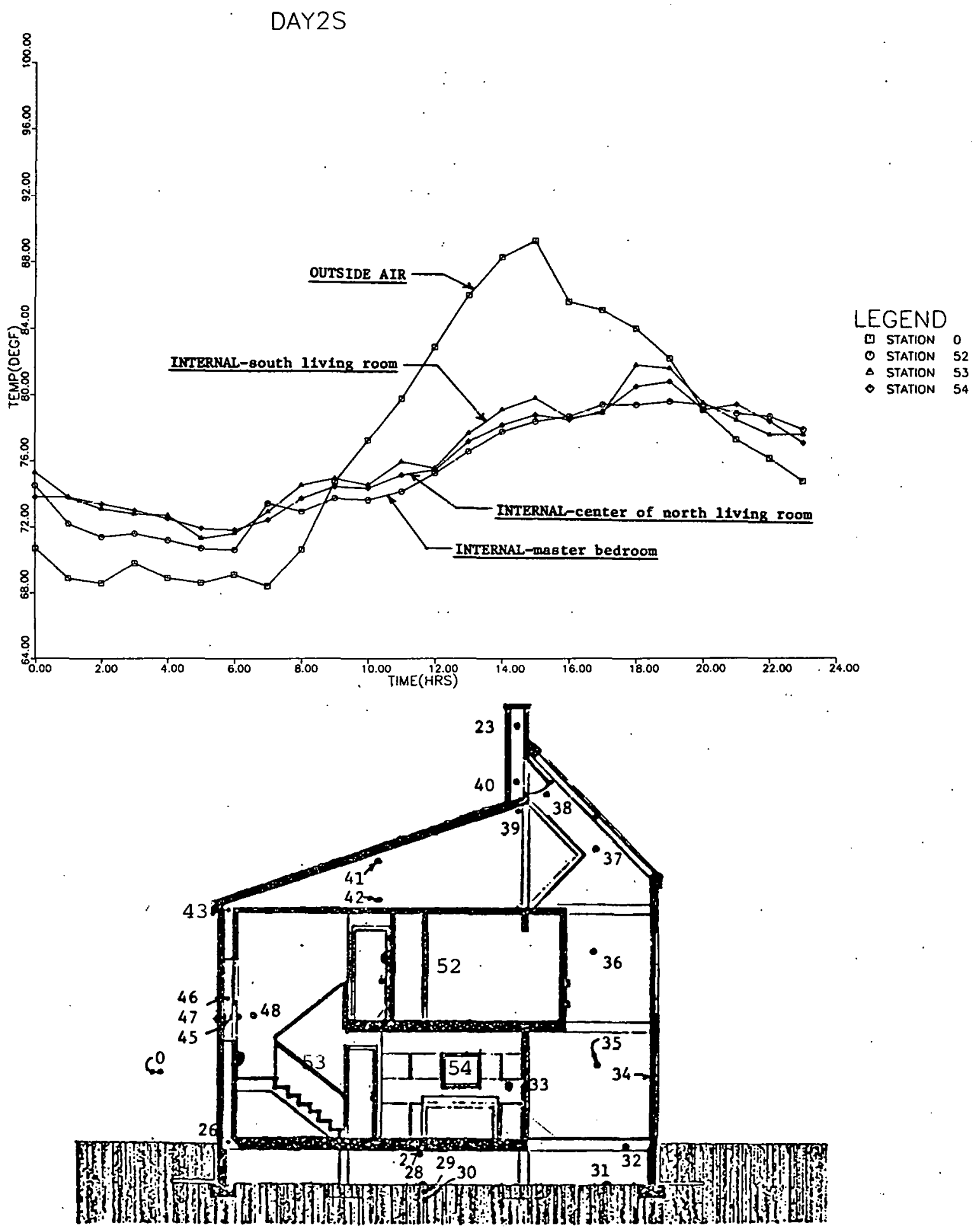

THERMOCOUPLE LOCATION - SECTION THRU STAIR

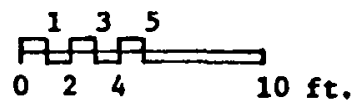

Figure 12. Temperature Distribution in Living Space 

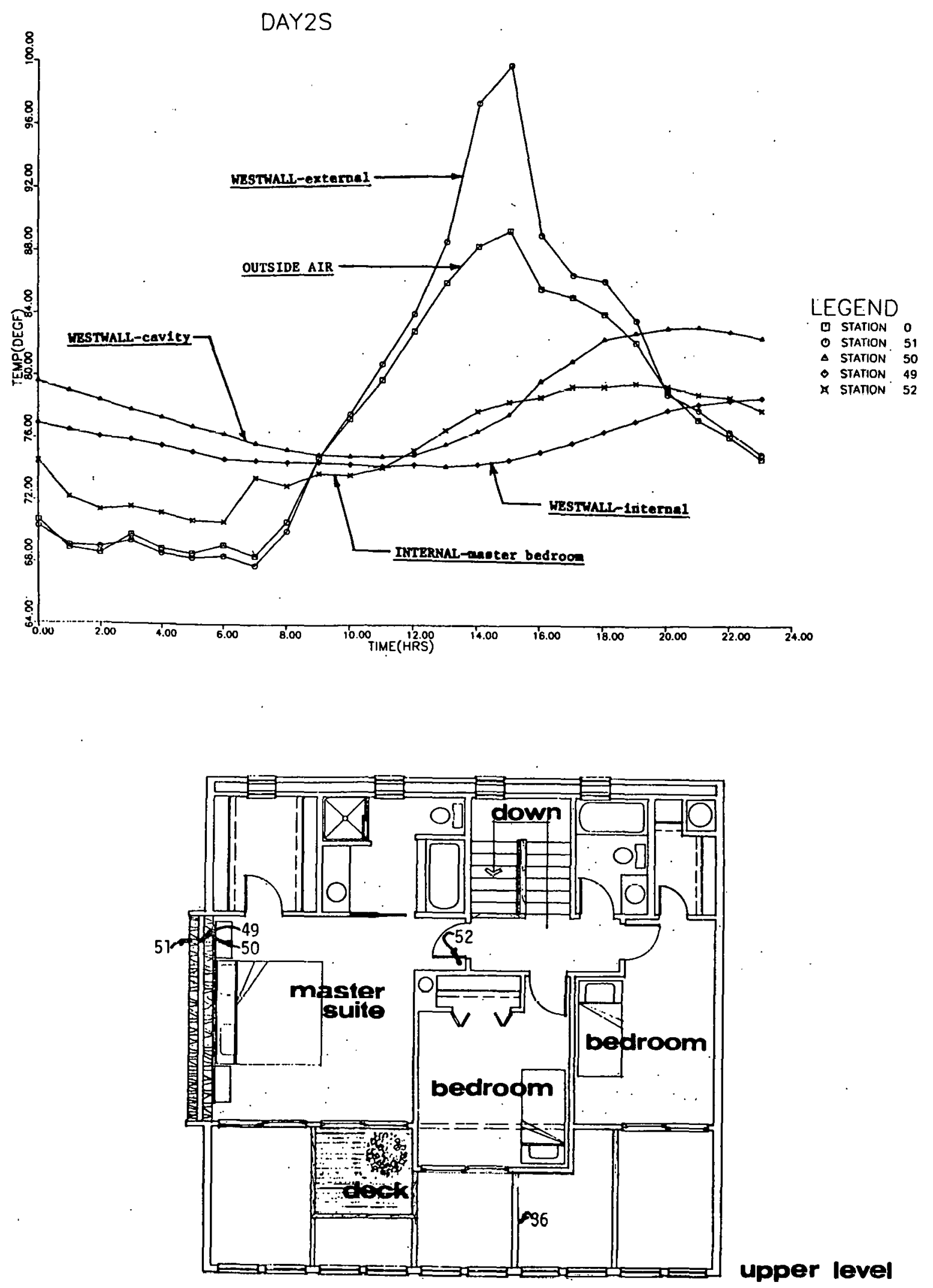

upper level

DofeEI

Figure 13. Temperature Distribution through West Wall 


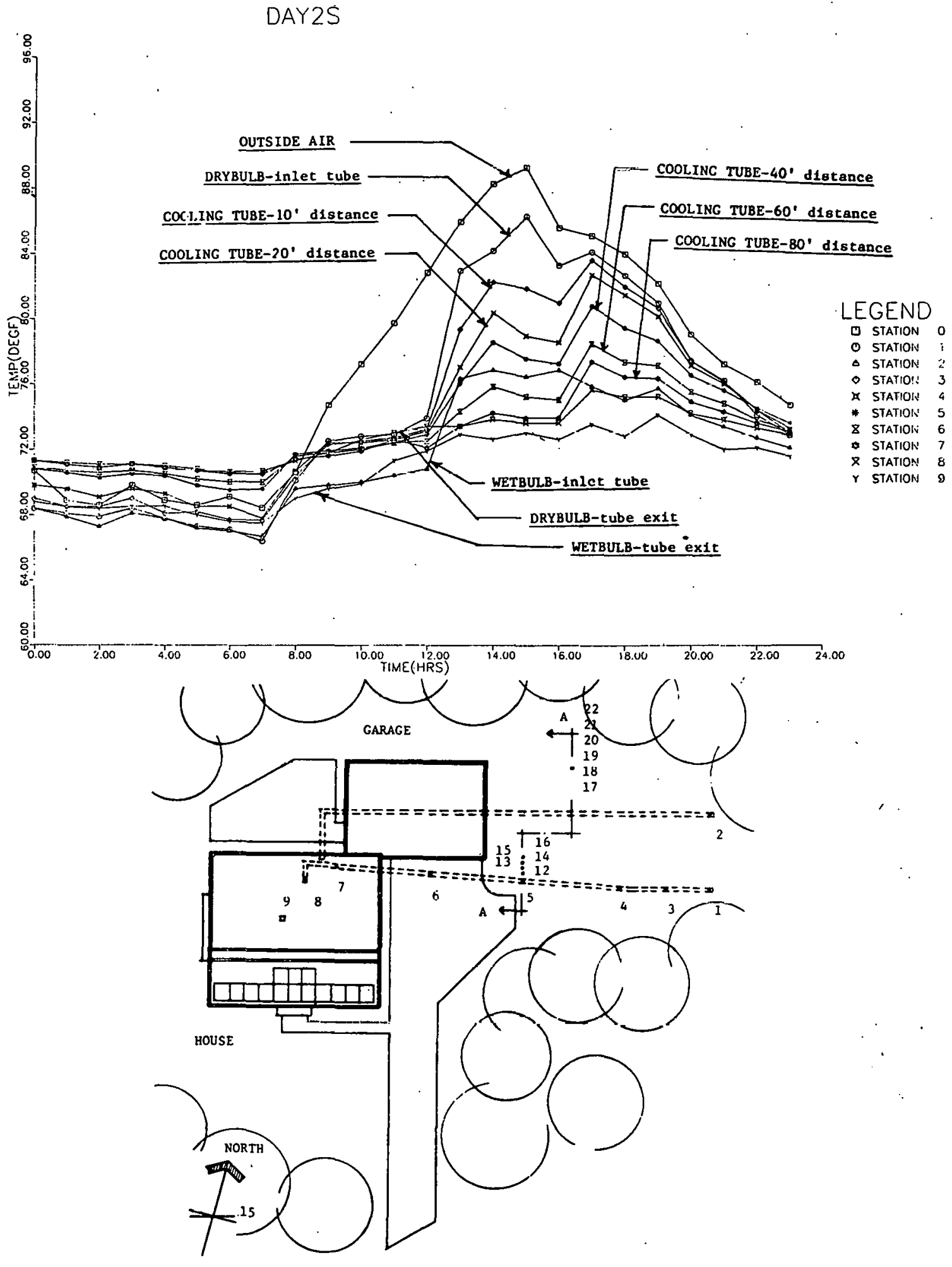

PLAN SHONING COOLING TUBE LAYOUT AND TERPERATURE SENSOR IAYTYT -

STOKes' hOUSE

- Circled aumbers Indicate thermocouples faside tube.

${ }_{0} \underbrace{20}_{15} \underbrace{20}_{30} \underbrace{0}_{50}$ 


\section{DAY2S}
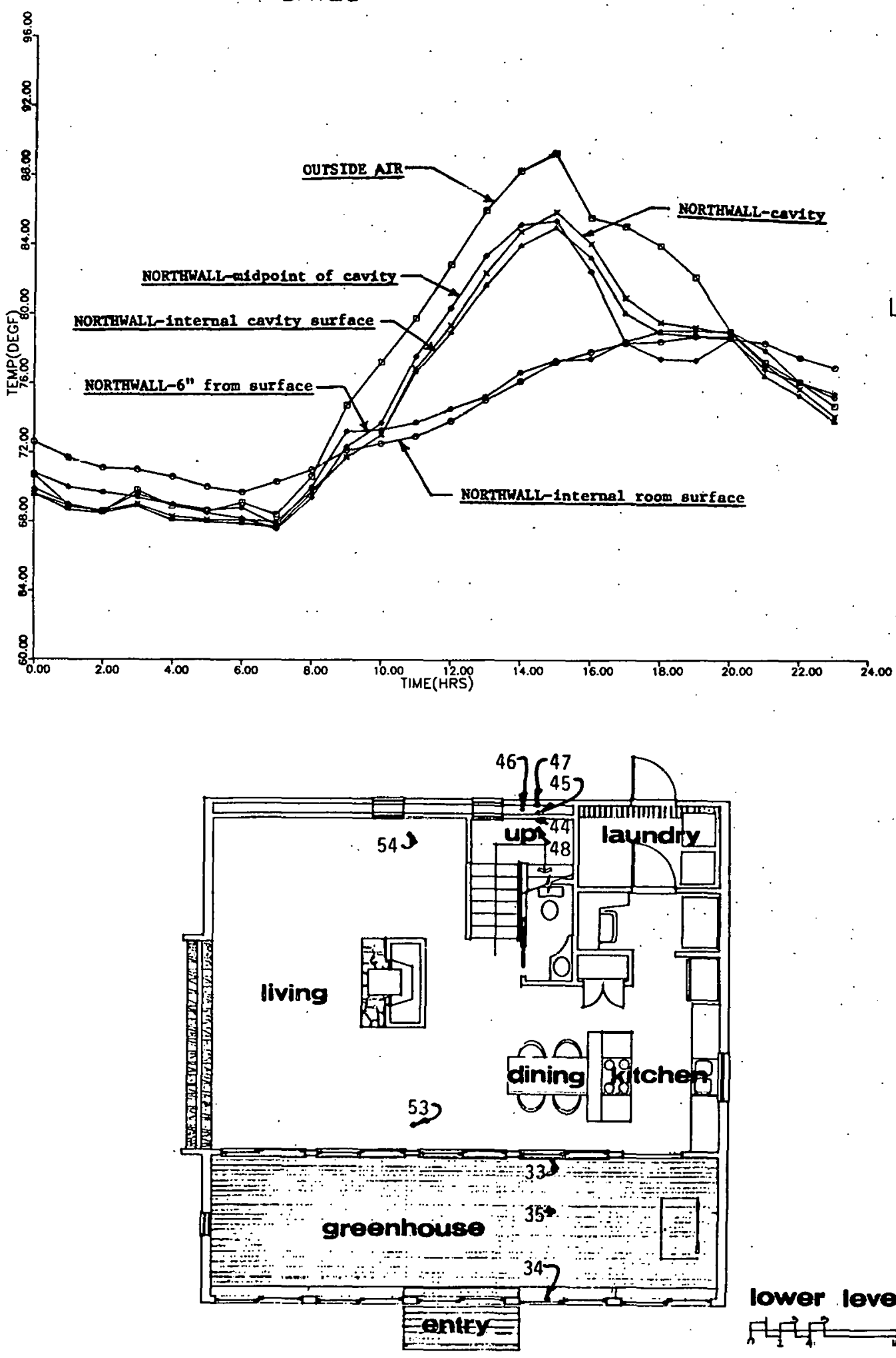

lower level

Hfit?

Figure 15. Temperature Distribution Down North: Wal1 
temperatures in the earth tube on the same day as the previous Figure. One will notice that the outside air temperature is about the same as the temperature in the cooling tube until about 9:00 a.m. Also notice that when the attic fan is off all temperatures down the length of the cooling tube are relatively uniform. Although there is a minor airflow through the tubes, it is so low that the air quickly reaches ground temperature. The temperatures along the cooling tube spread out quite quickly when the attic fan is turned on at 12:00 noon. One can see the temperatures decrease as the air moves along the tube; exiting at a temperature $170 \mathrm{~F}$ below ambient temperature at noon and $80 \mathrm{~F}$ below ambient temperature at 6:00 p.m. Notice that the abrupt change in temperature when the fan is turned on is not obvious or evident in interior temperatures shown in Figure 11. It also is not evident in the north wall temperatures shown in Figure 15. Apparently flow in the north wall is downward even when the attic fan is running.

Figure 16 shows internal temperature distribution on day $7 \mathrm{~S}$ when the external temperature reached $930 \mathrm{~F}$ from 1:00 p.m. to 5:00 p.m. The highest interior temperature was $840 \mathrm{~F}$ at 6:00 p.m. in the master bedroom.

Figure 17 shows the temperature in the crawlspace for the same day. Notice that crawlspace air temperature, which is measured near the top of the crawlspace, climbs until the fan is turned on at about 1:00 p.m. The crawlspace air temperature drops once the attic fan is turned on and additional air is being pulled through the cooling tubes.

As in the heating performance evaluation, we found this thermal envelope house to perform better in the cooling mode than one would have expected for a conventional house without mechanical cooling. The margin of difference is not nearly as great as it was in the heating mode. It is apparent from the interior temperatures along the south side of the house and the very high temperatures in the greenhouse that the cooling performance is being compromised by the very large 

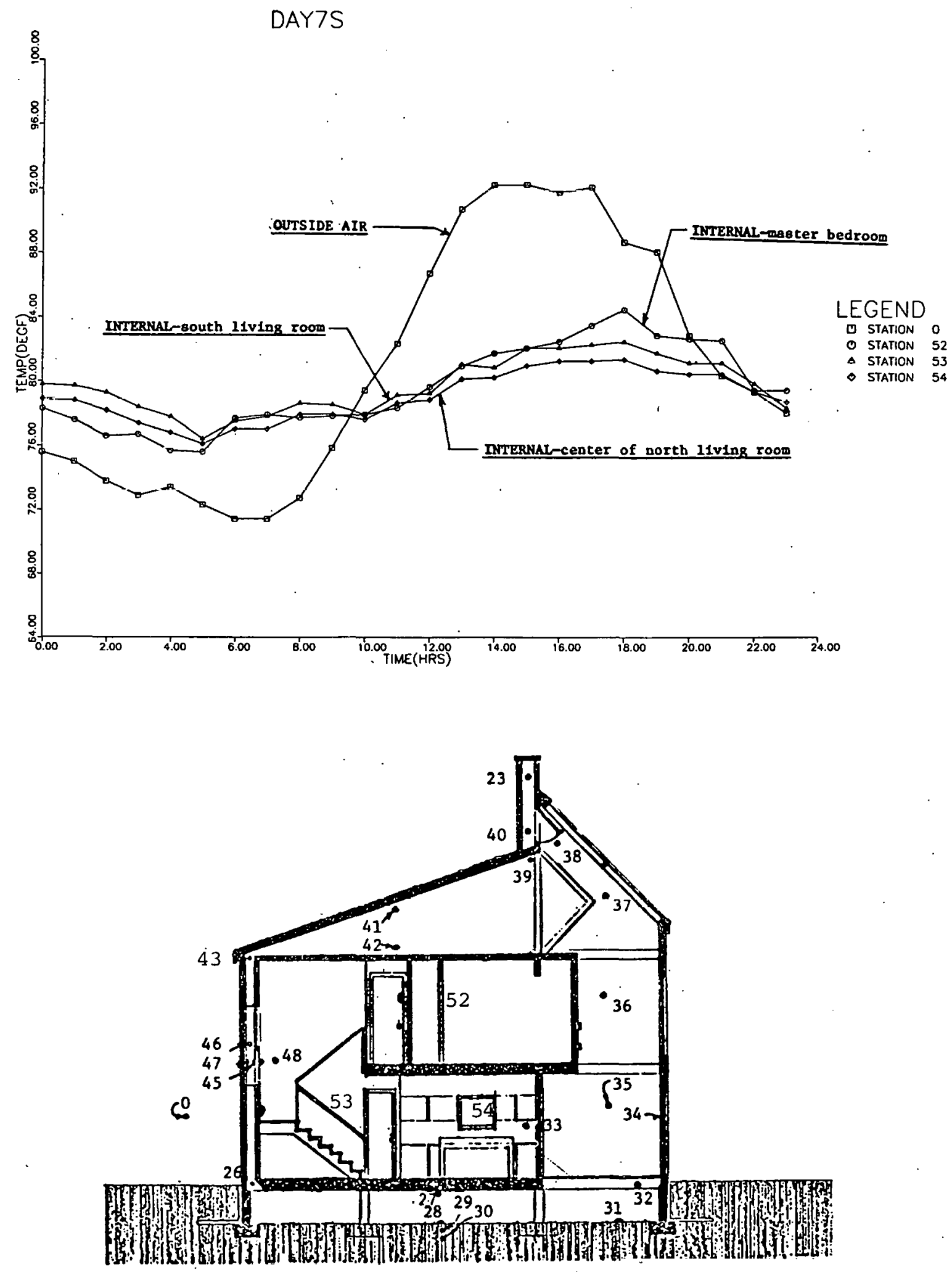

THERMOCOUPLE LOCATION - SECTION THRU STAIR

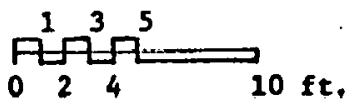

Figure 16. Temperature Lag in Master Bedroom 

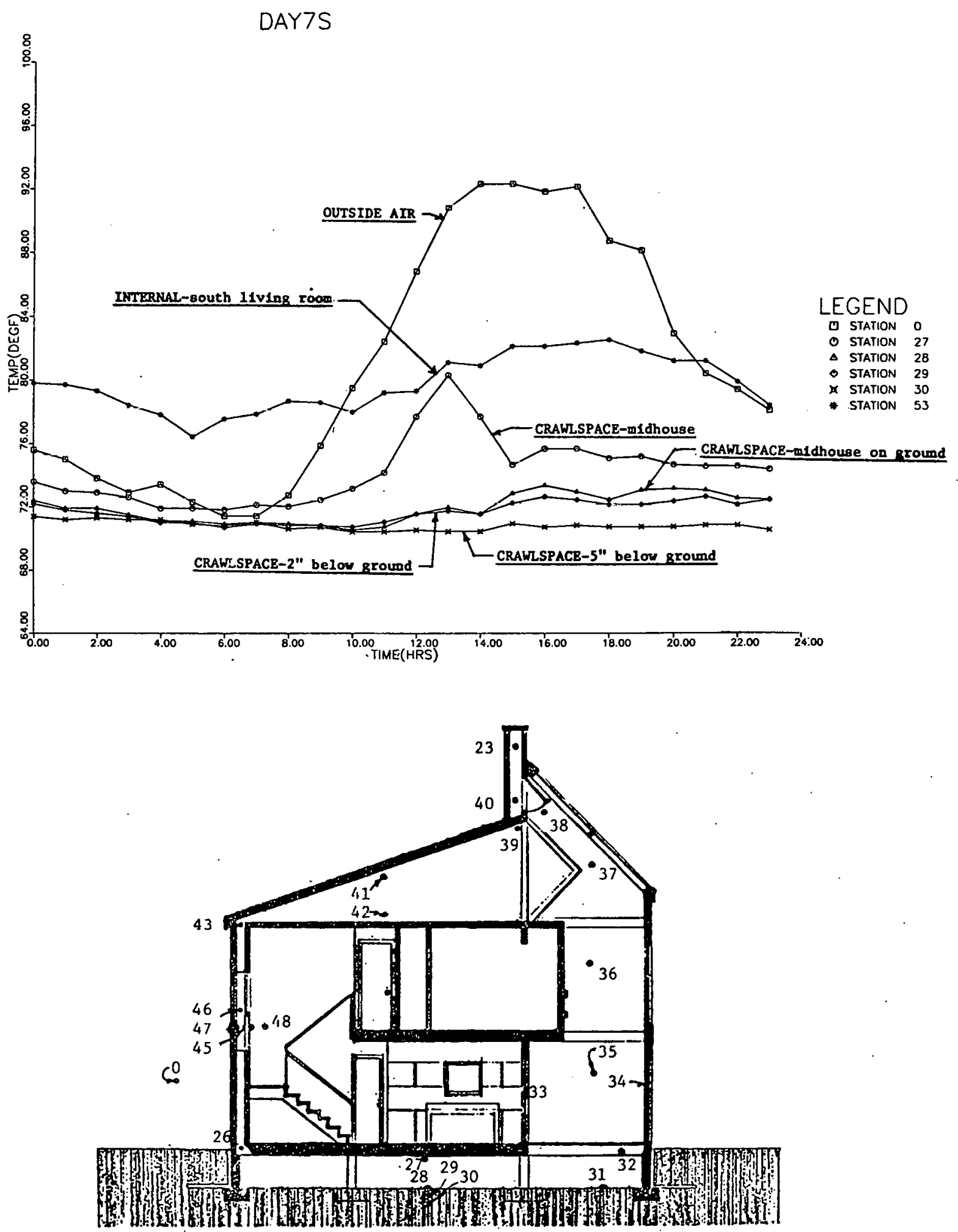

THERMOCOUPLE LOCATION - SECTION THRU STAIR

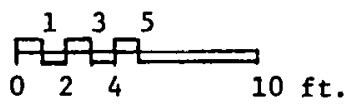

Figure 17. Temperature Distribution in Crawlspace 
quantities of glass in the greenhouse. It is also evident, as will be discussed in some detail in the next section, that the greenhouse and thermal chimney are not effective as air circulators. One must question the wisdom of using thermal chimneys to induce air flow in regions with hot-humid climates, such as the Southeast. Probably, this recommendation should apply to any location. Thermal chimneys work best when the sun is brightest. Unfortunately, outside temperatures are also the highest when the sun is the brightest. This means the chimney works best during those time periods when one would prefer to keep the hot ambient air outside.

One must analyze how a thermal chimney works to fully appreciate why they don't offer satisfactory solutions in most cases. The chimney depends upon a difference in buoyancy between the air within the chimney and the outside air to cause flow, i.e., the air within the chimney must be higher in temperature than the air outside for the air to flow. If the outside air temperatures are above $100^{\circ} \mathrm{F}$ as they were several days this summer in Atlanta, then the air within the chimney must be well above $100^{\circ} \mathrm{F}$. These high temperatures were observed in the greenhouse and thermal chimney and are shown in Figure 18.

Since one obviously doesn't wish to pull outside air at a temperature above 100 F through the house or even the envelope, the air must be cooled first. The cooling tubes serve the purpose of cooling the air before it reaches the envelope or living space. Unfortunately, for the purpose of inducing flow, the cooling tubes must be considered part of the thermal chimney loop. If we now look at Figure 19 we see that we have an outside air column $50 \mathrm{ft}$. high at an average temperature of $1000 \mathrm{~F}$ and two inside air columns, one $25^{\prime}$ high with an average temperature of $75^{\circ} \mathrm{F}$ and one with an average temperature of 1100 . We find that the average temperature per $\mathrm{ft}$. outside is $1000 \mathrm{~F}$ and the average temperature per $\mathrm{ft}$. inside is 950F (a lower temperature). This means the air will flow into the house at what was supposed to be the thermal chimney exit and will exit at what was supposed to be the cooling tube 

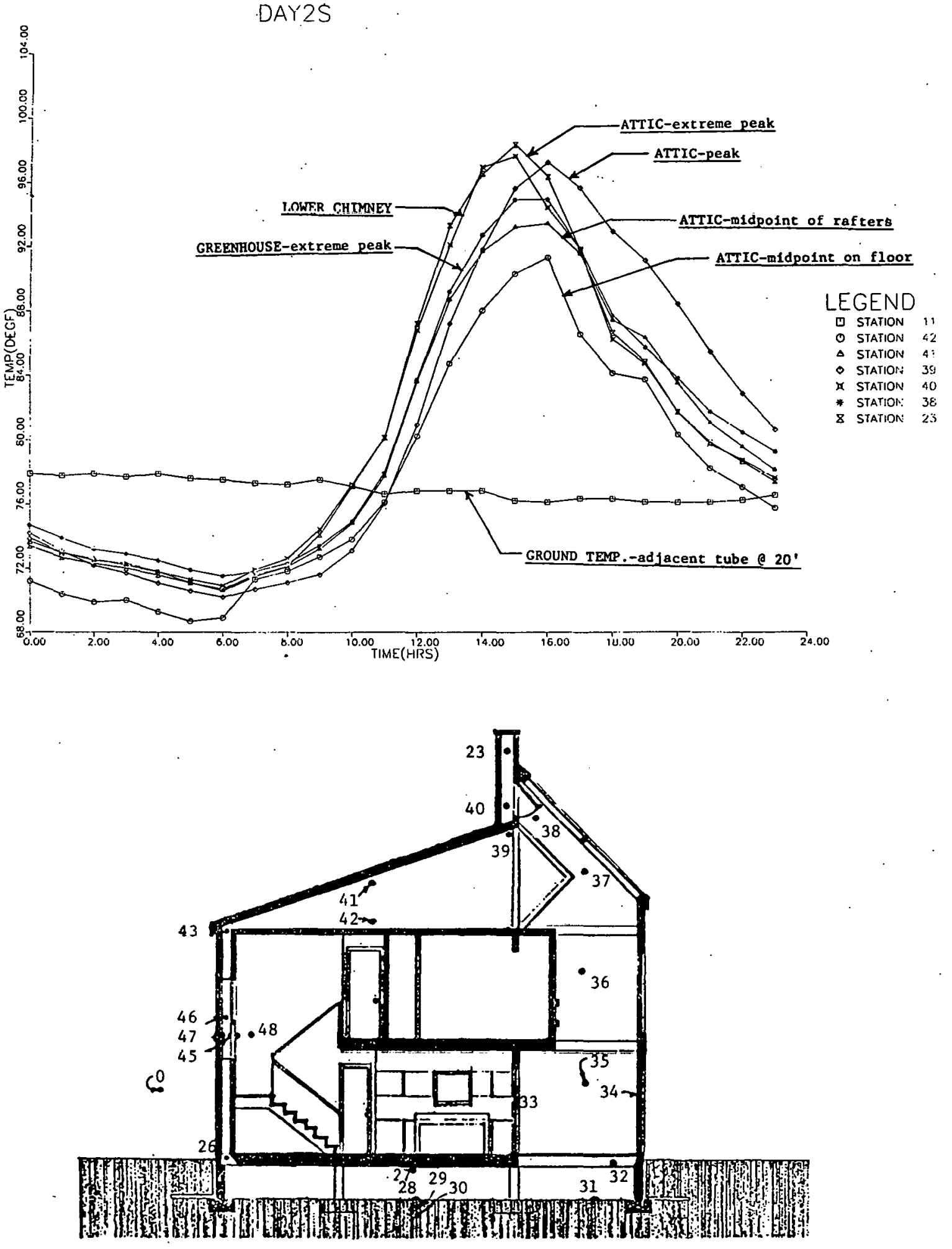

THERMOCOUPLE LOCATION - SECTION THRU STAIR

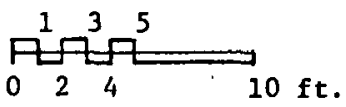

Figure 18. Temperature Distribution in Attic/Thermal Chimney 
inlet. This reverse flow was observed in this thermal envelope house and as would be predicted, became worse during the afternoon hours when the outside air temperatures were the highest and the direct radiant load on the thermal chimney had begun to decrease. These observations will apply to most designs which depend upon thermal effects to induce flow through cooling tubes. It was aggravated in this particular house because the house faced about 150 east of south, resulting in a low thermal chimney temperature in the afternoon when the ambient temperatures are the highest.

A secondary effect was also observed to come into play. The air along both the north and south roofs becomes much hotter than the ambient air due to solar absorption on the roof. It also reaches temperatures higher than those measured in the greenhouse and thermal chimney.

If one now looks at a cross section of the house shown in Figure 20, one sees a thermal loop much like what was desired in the heating mode. All of the temperatures along the south side of the loop are higher than those along the north side of the loop, thus hot air flows out of the greenhouse across the attic and down the north wall. This results in higher envelope temperatures than one would have expected if the envelope had been blocked. The temperature shown in Figure 21 supports this theory.

Due to the location and exit directions of the cooling tubes, it appears that the greenhouse-to-attic-to-north wall flow direction may continue even after the attic fan is turned on. Since the hot wire anemometer is not direction sensitive, we were unable to determine the flow direction, but the north wall temperatures do not reflect the drop in temperature one would have expected when the fan was turned on.

It was difficult to separate the performance of the thermal envelope house from the performance of a thermal envelope house with cooling tubes. The cooling tubes certainly improved the performance of the house, although not to the extent 
they could have, had the air volume and flow direction been better. The comments made in this report are based on tests made on a thermal envelope house with earth cooling tubes. The comments and subsequent conclusions may nat be applicable to a thermal envelope house without earth cooling tubes.

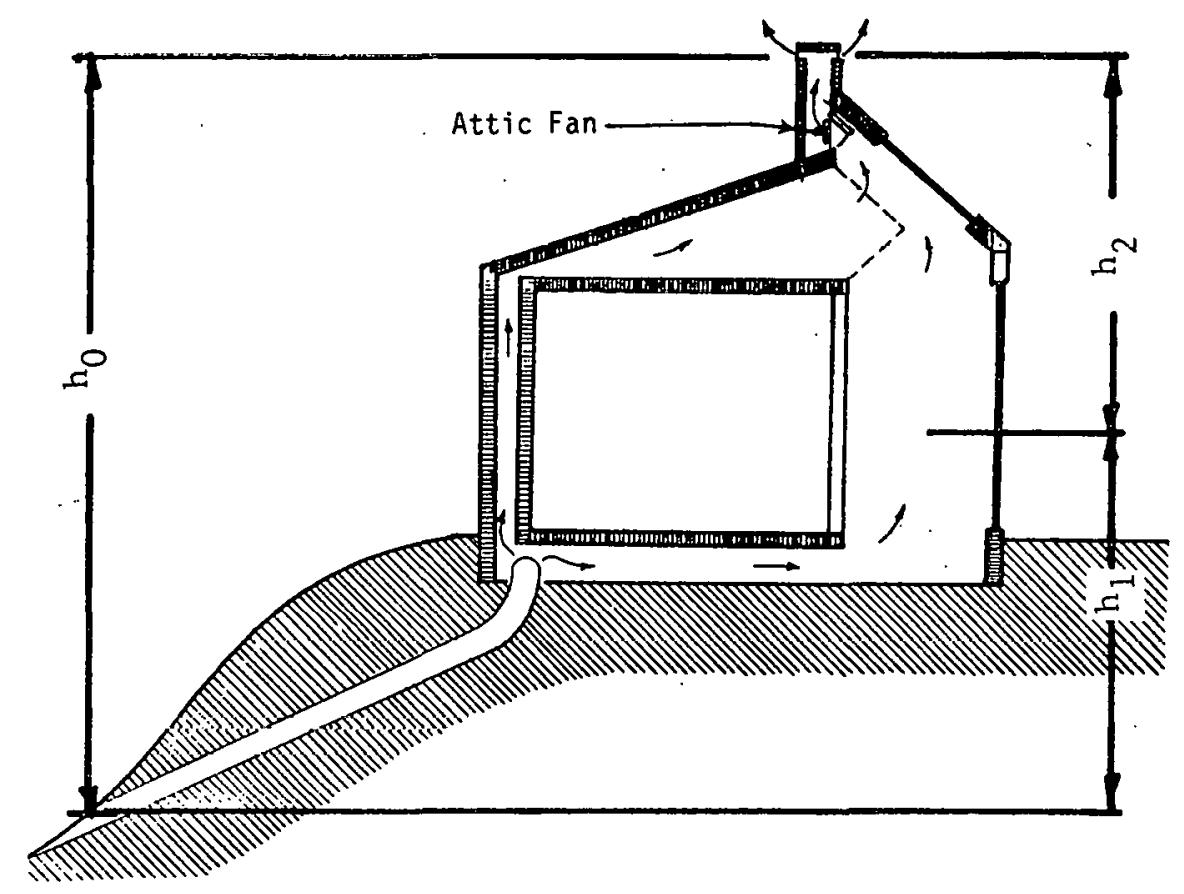

Figure 19. Thermal Chimney Driving Force Diagram 

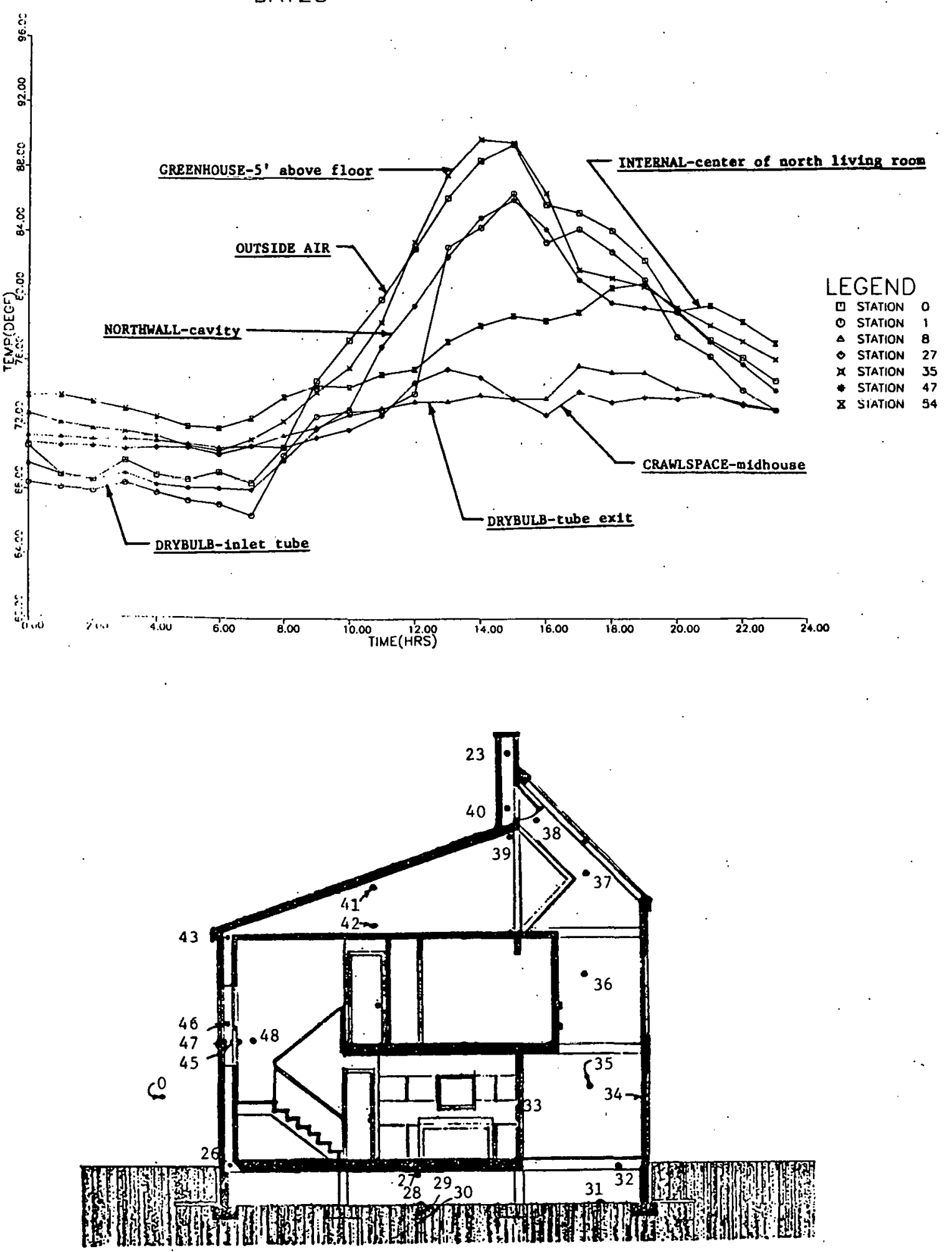

THERMOCOUPLE LOCATION - SECTION THRU STAIR

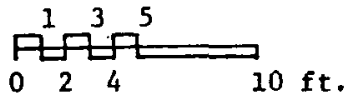

Figure 20. Thermal Loop Temperature Distribution 
DAY2S

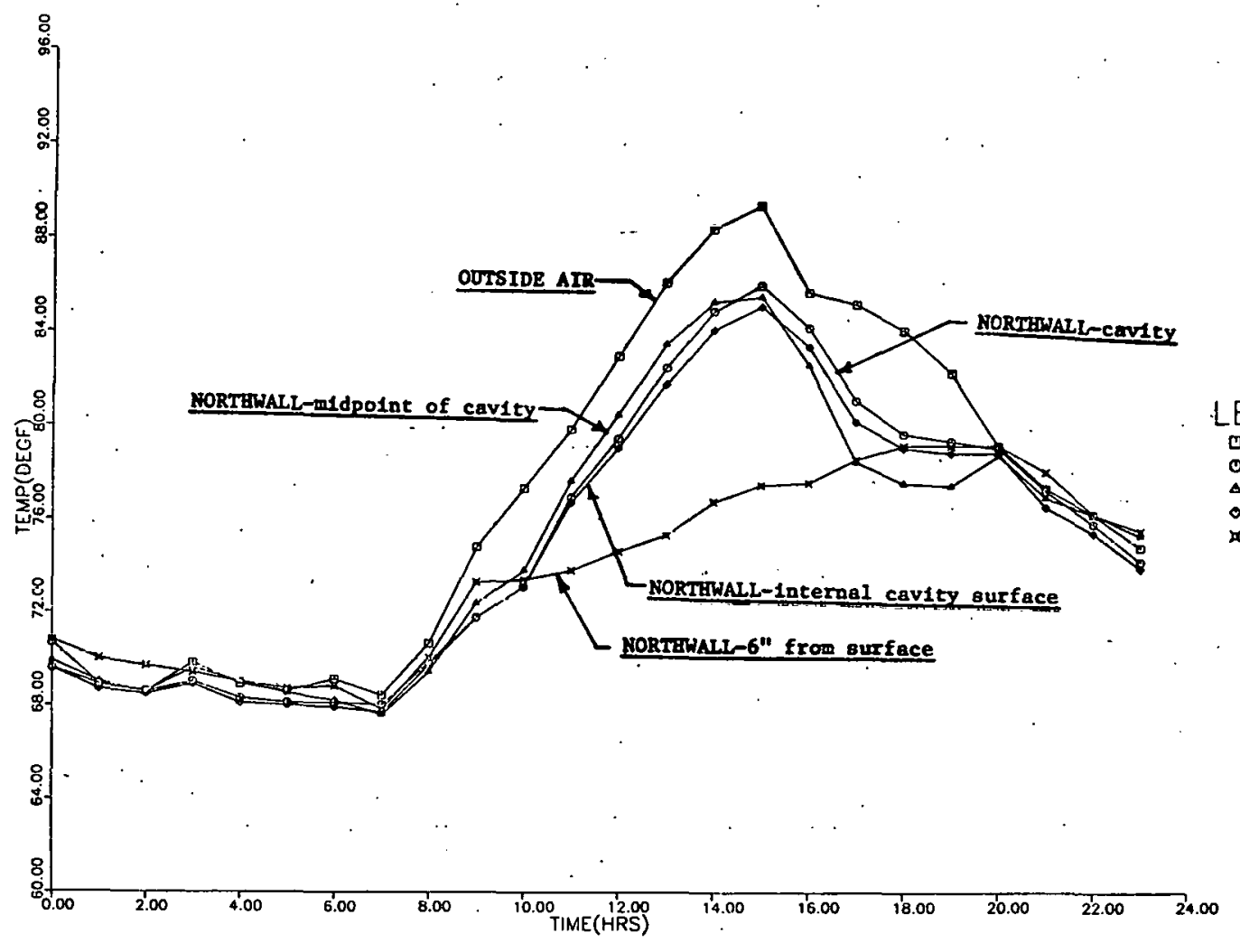

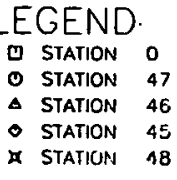

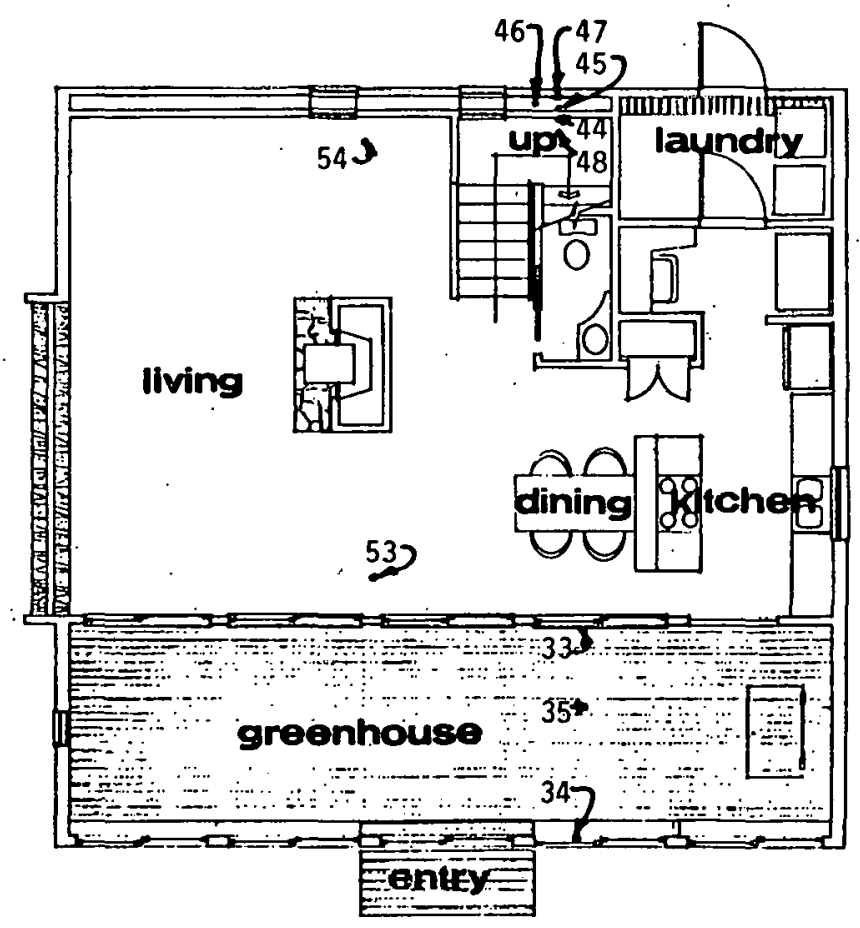

lower level

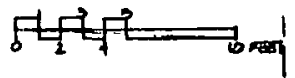

Figure 21. North Wal1 Temperature Distribution 


\section{EARTH COOLING TUBES}

Since the only cooling device available to this thermal envelope house was the earth cooling tubes, much of the effort during this phase of the program was directed toward evaluating the performance of the earth cooling tubes. Three approaches were taken in this evaluation. First, the cooling tubes and adjacent ground were heavily instrumented with thermocouples. Both wet- and dry-bulb thermocouples were located at the tube inlet and exit and were monitored hourly throughout the test. Second, one complete day was spent varying the flow rate and monitoring the tube performance. Third, a mathematical model was developed which can be used to estimate the performance of earth cooling tubes and predict the effect of various changes. The cooling tube mathematical model is described in Appendix C.

While some data from the continuous monitoring of the earth cooling tubes were presented in the earlier section on the performance of the thermal envelope house, additional data are given here. Figures 22 and 23 show temperatures along the tube on $3 \mathrm{~S}$ and $4 \mathrm{~S}$. As shown in Figure 14, all temperatures along the tube become essentially the same until the attic fan is turned on (10:00 a.m. in Figure 22 and 12:00 noon in Figure 23). The temperatures develop the decaying logarithmic profile expected once the attic fan begins to move air through the tube. Notice that both the wet-bulb and dry-bulb temperatures decrease as the air moves from the inlet to the exit. Figure 24 shows the inlet and exit conditions plotted on a psychrometric chart. Notice that the exit conditions are above saturation and that the cooling has been at a constant moisture level, i.e., moisture was not condensed out. This was confirmed 


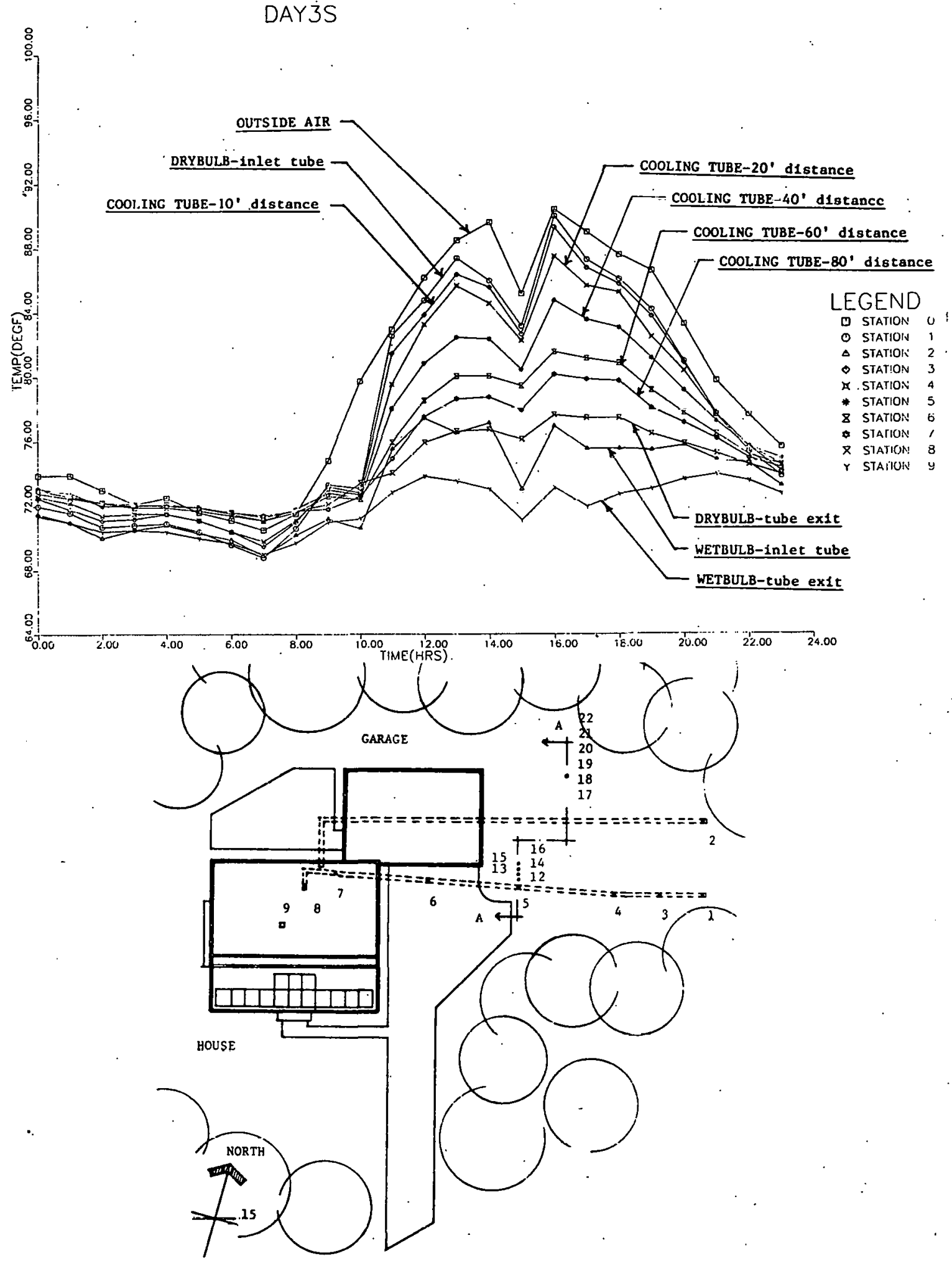

PLAN SHONTNG COOLING TUBE IAYOOT AND TEMPERATURE SENSOR LAYOUT STOKES' HOUSE

- Circled mubera Indicate thermocouples instde tube.

${ }_{0} \overbrace{15}^{10} \overbrace{50}^{20} \overbrace{5 t}^{n}$

Figure 22. Temperature Distribution Along Cooling Tube - Day 3S 


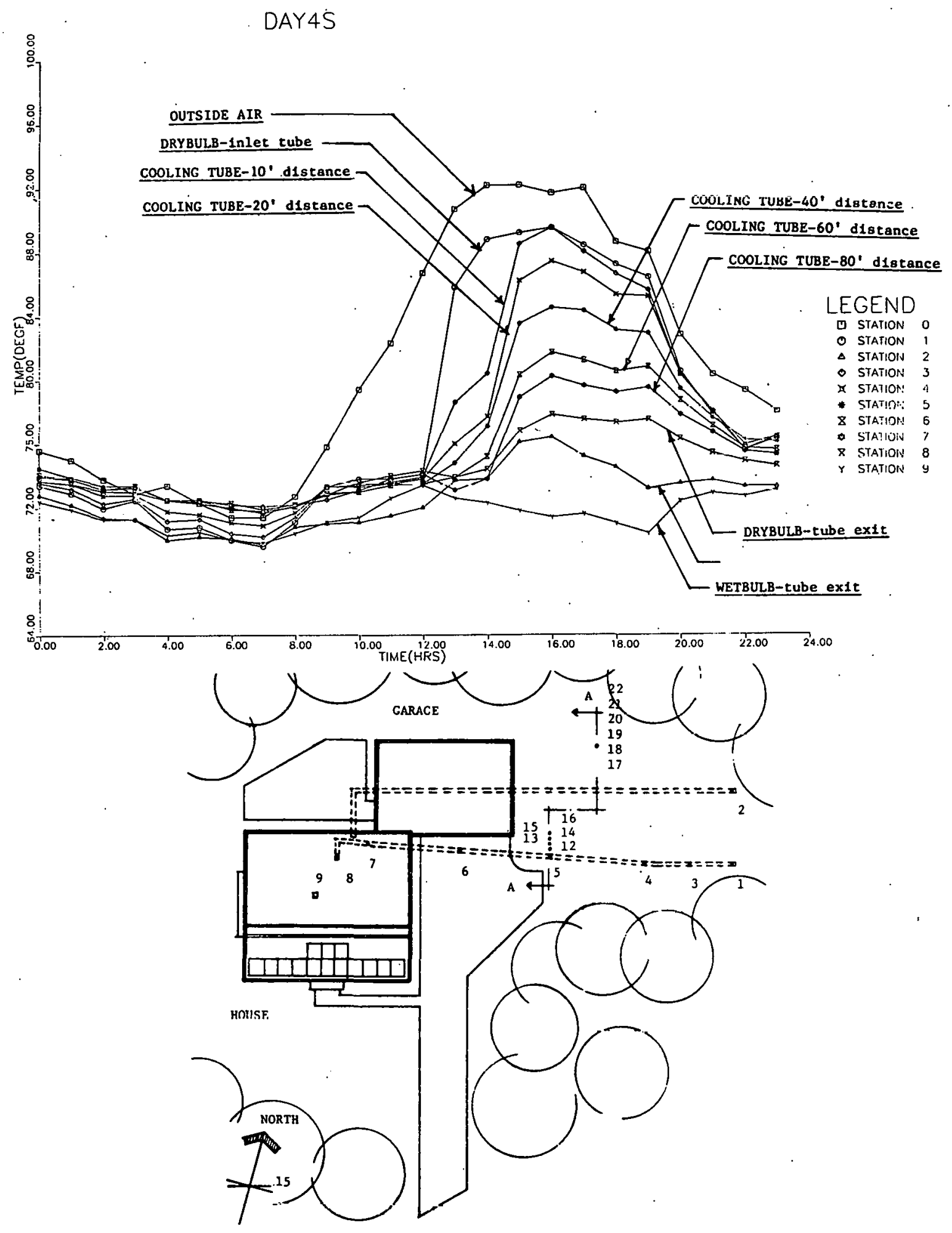

PLAN SHONTAG COOLING TUBE LAYOUT AND TEMPERATURE SENSOR LAYOUT STOKES' HOUSE

* Circled mubers indicate thermocouples inside tube.

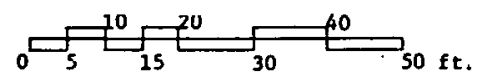

Figure 23. Temperature Distribution Along Cooling Tube - Day 4S 


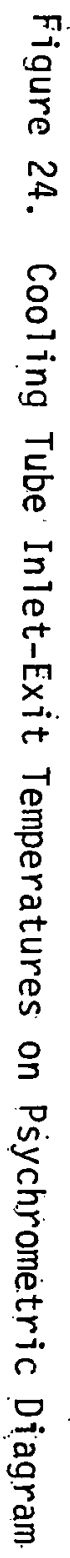

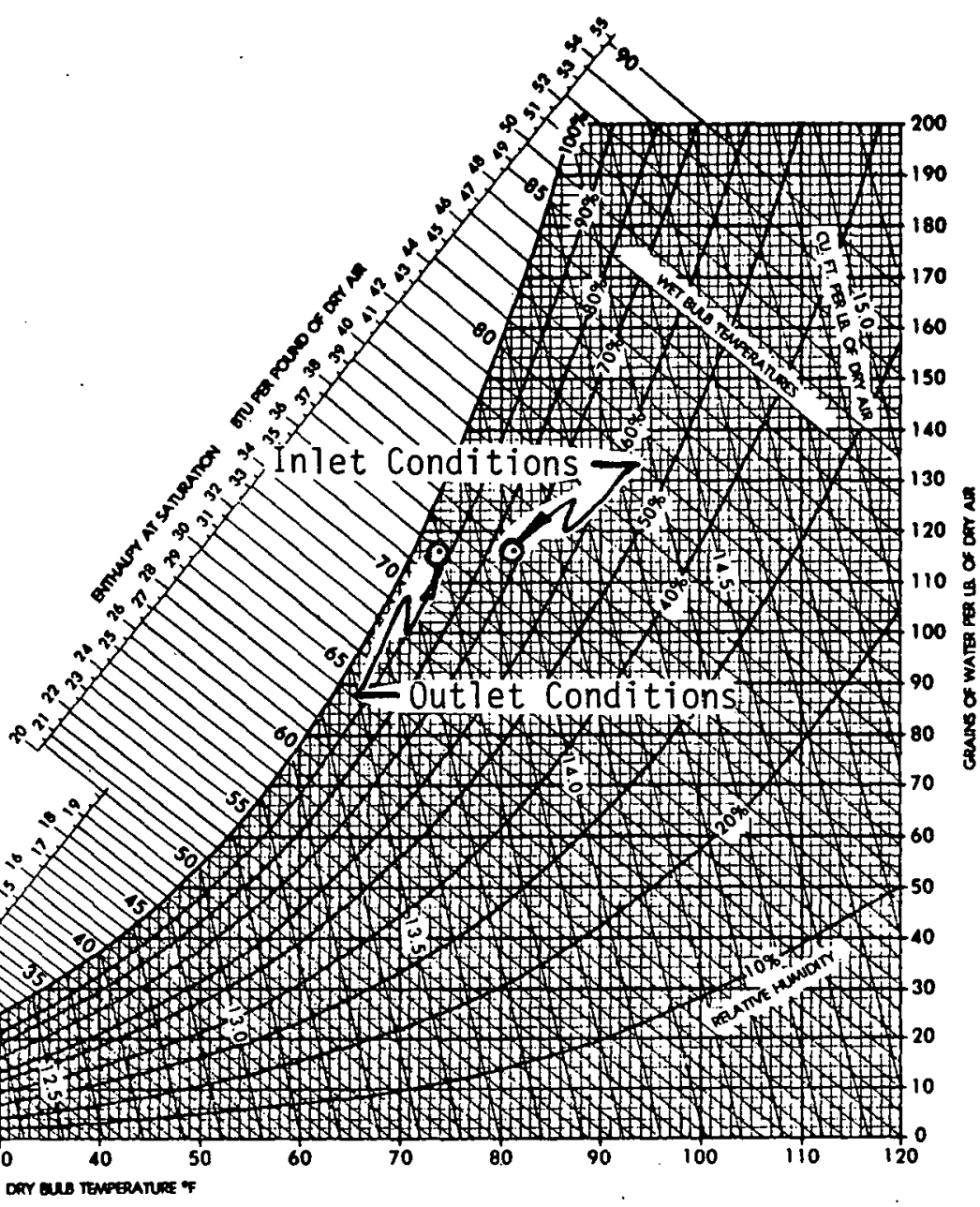


with a visual inspection of the earth cooling tube while installing the thermocouples. There was only a slight powdering of the inside of the tube indicating that little if any liquid had been present in the tube.

Figures 25, 26 and 27 show ground temperature perpendicular to the tube forty (40) feet from the inlet. Notice the distinct difference in the ground temperature adjacent to the tube in each case while the temperatures 1,2 , and 3 feet from the tube show little effect from the different air temperatures flowing through the tubes.

Figure 28 shows the far field (undisturbed) ground temperature at various depths. Notice that the ground temperature 1/2" down shows a marked effect of ambient temperatures, that at 8 " shows only a minor effect, while that 1 ' 8 " or deeper shows little daily effect due to ambient temperatures. It should be noted that the cooling tubes and the far field ground temperature probe were located in heavily tree-shaded areas.

Comparison of the ground temperature at $3^{\prime} 8^{\prime \prime}$ on Figure 28 with the ground temperature 4 ' from the tube (at approximately the same depth) in Figure 25 shows the far field (undisturbed) temperature to be about 1.- $1.5 \mathrm{~F}^{\circ}$ lower than the ground temperature four feet from the tube. This appears to result from two factors. First, the ground adjacent to the tube receives slightly more radiant energy due to less tree shading. Secondly, the ground adjacent and at least up to four feet from the tube has been affected by the tube. This is more evident in Figure 29. There has been much discussion about how ground temperatures vary around an earth cooling tube used intermittently (as is the case with these tubes). Figure 29 shows the gradient to be quite steep in the first foot and to vary with the time of day. It also shows the gradient to be very small beyond the first foot. The tubes monitored during these tests are on approximately eight hours and off sixteen hours. It appears that under these operating conditions, the energy diffuses at least through the first 3 or 4 feet, 

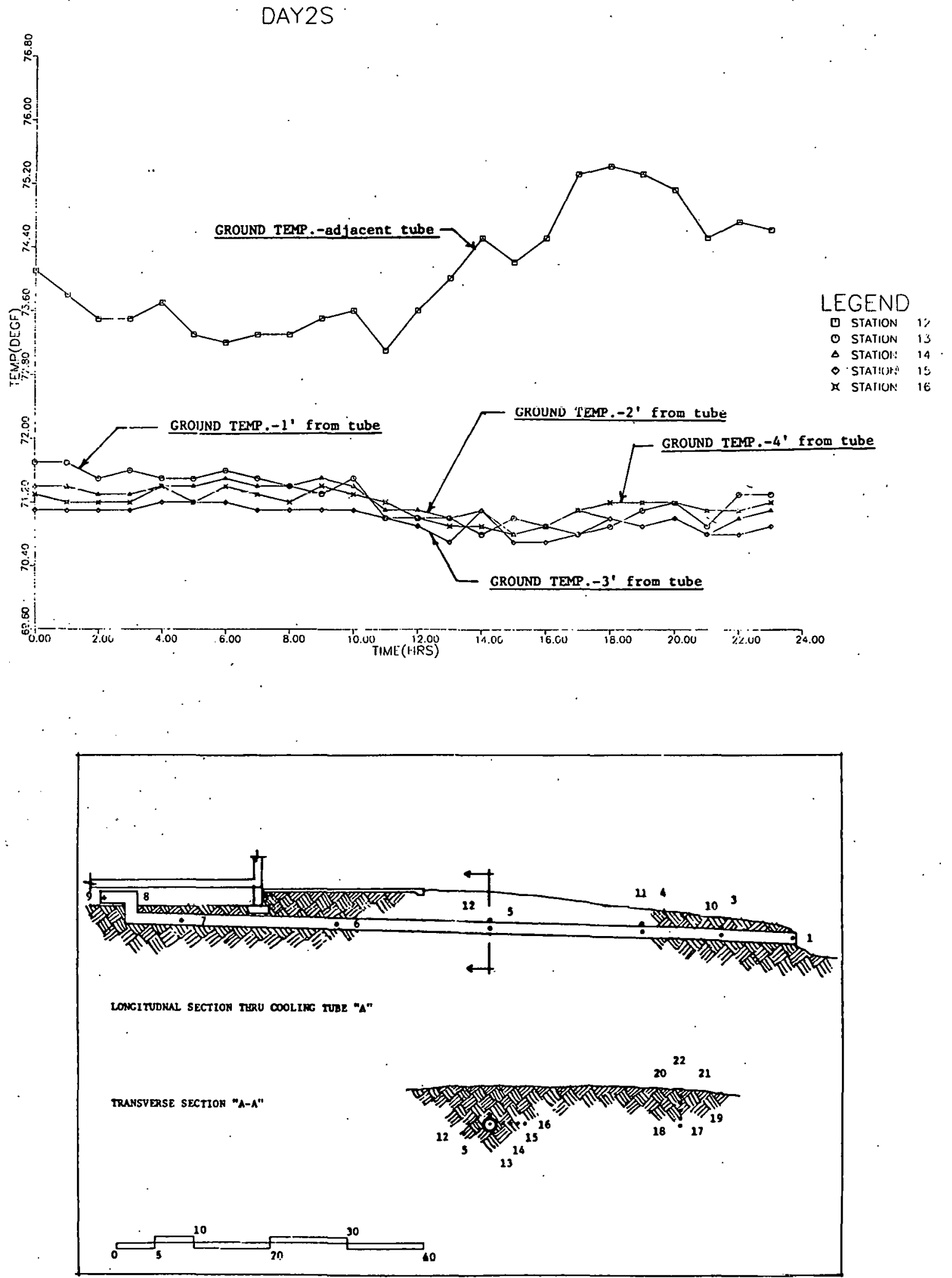

Figure 25. Ground Temperature Gradient Perpendicular to the Pipe - Day $2 S$ 

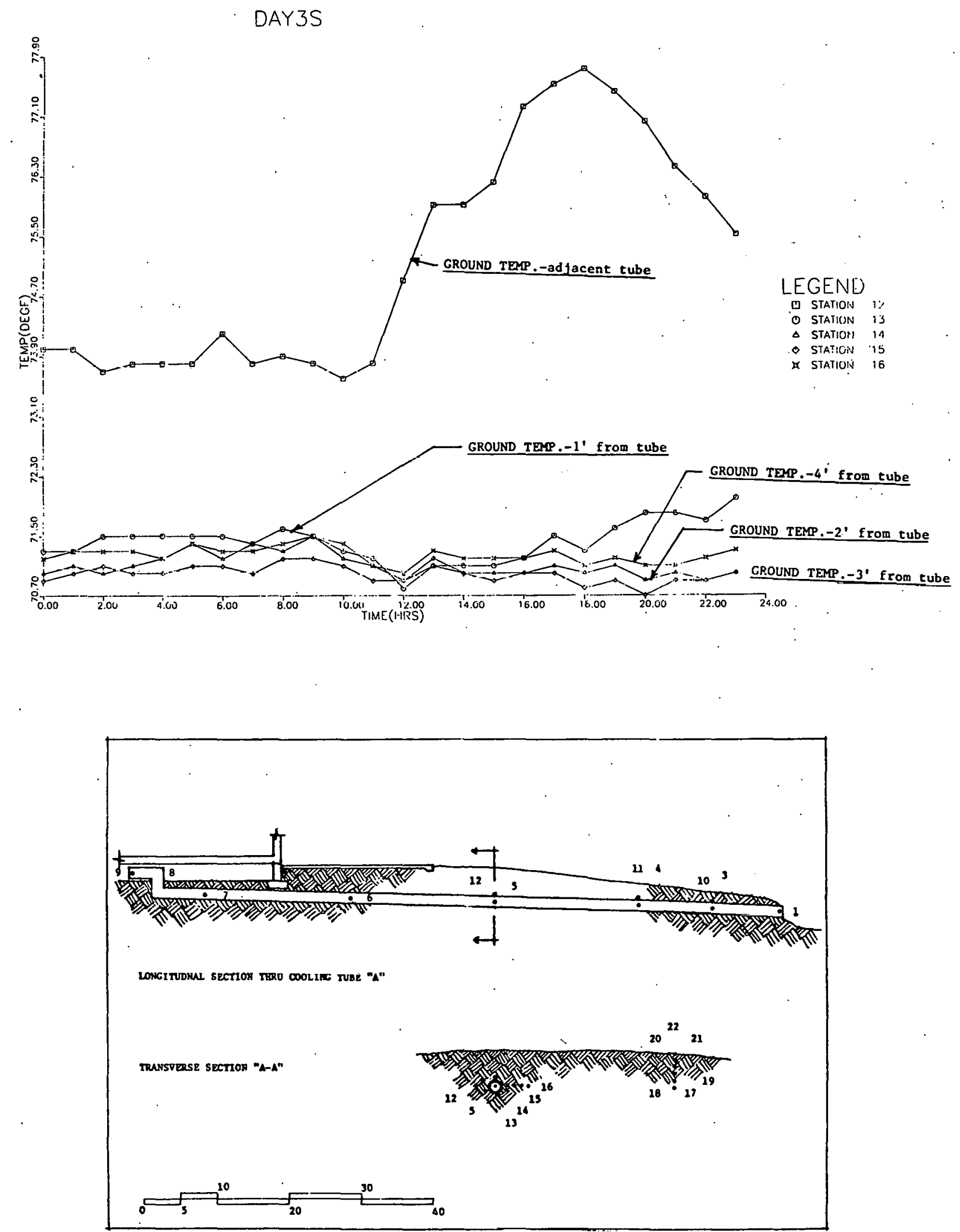

Figure 26. Ground Temperature Gradient Perpendicular to the Pipe - Day 35 

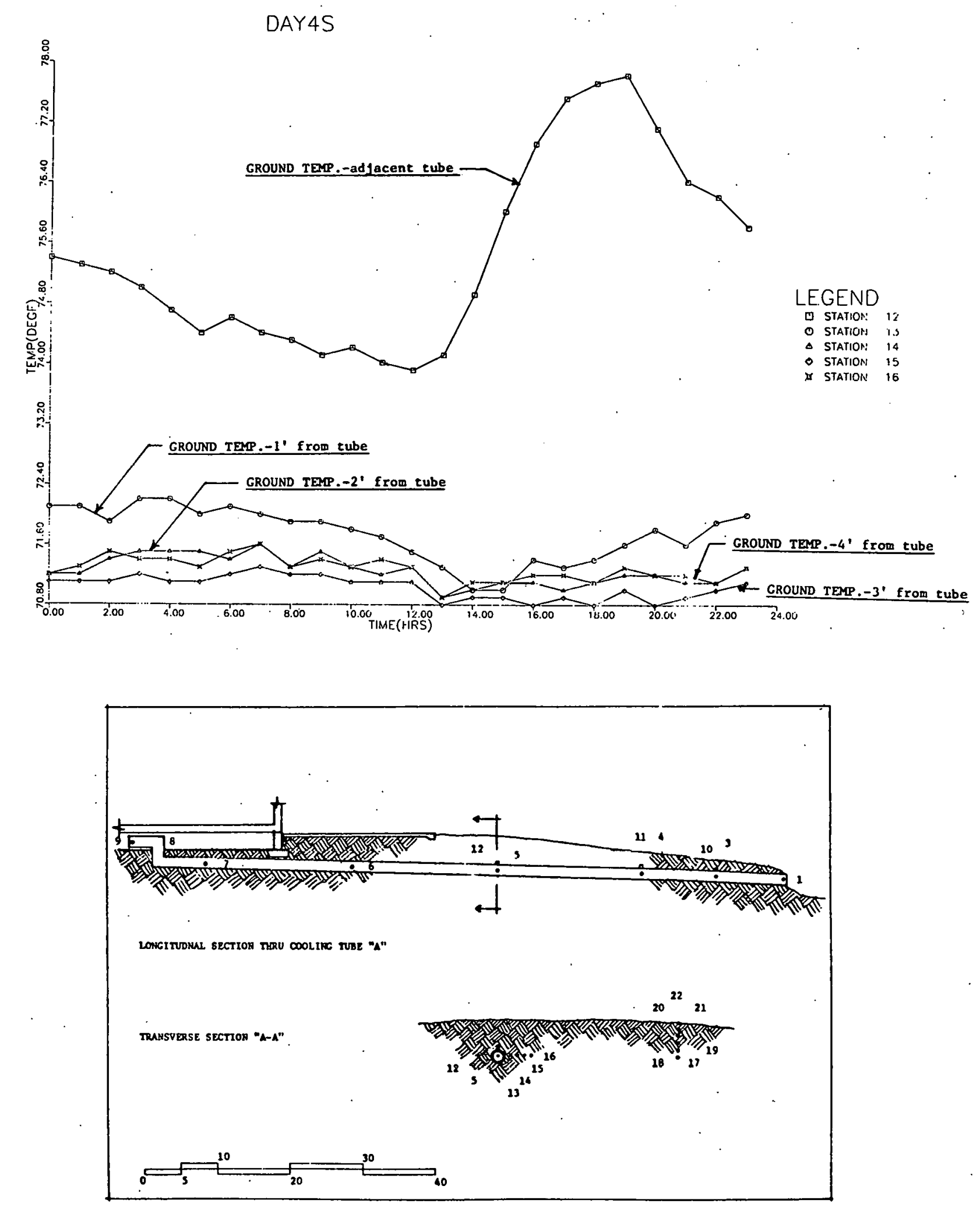

Figure 27. Ground Temperature Gradient Perpendicular to the Pipe - Day 4S 

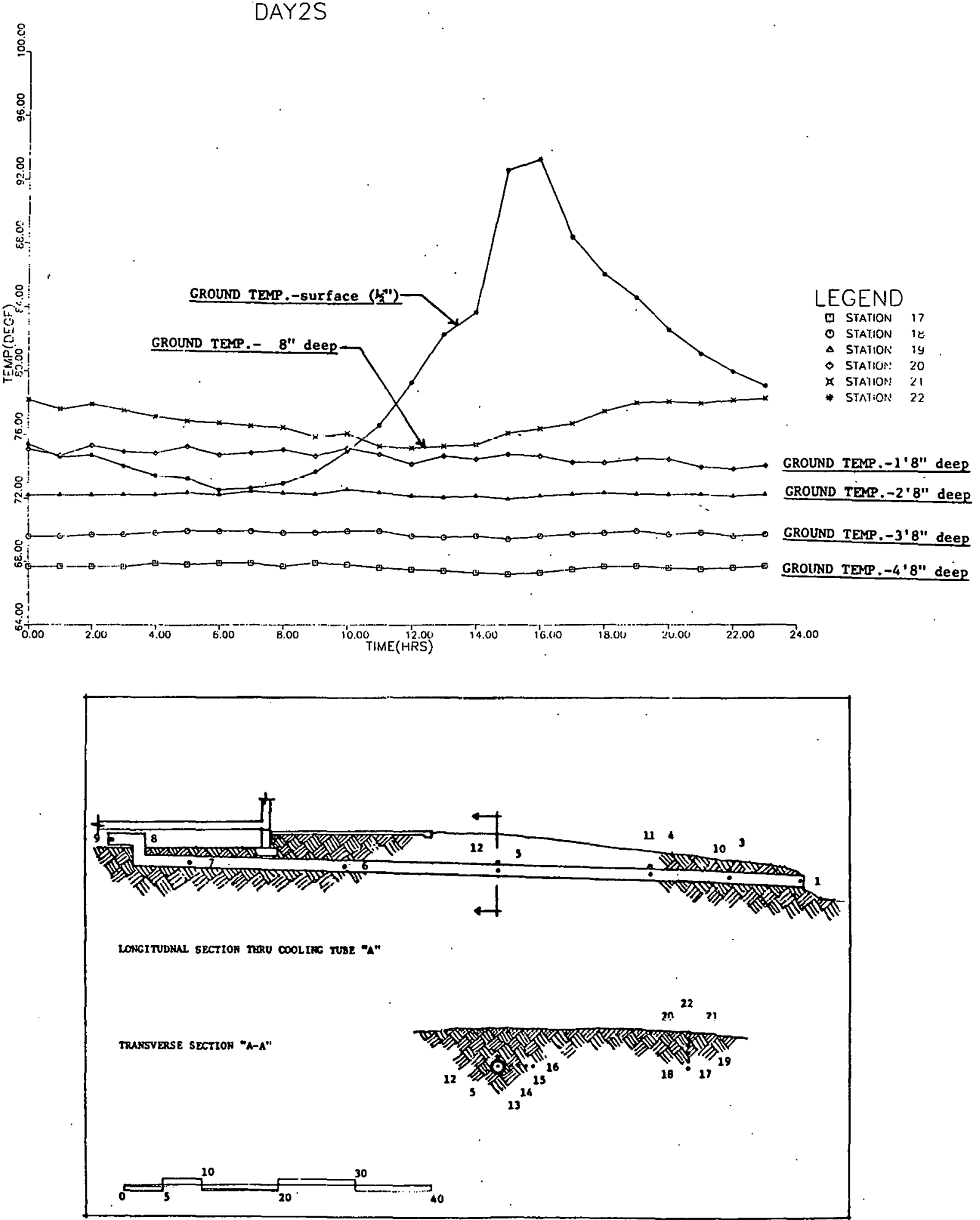

Figure 28. Ground "Far Field" Temperature Gradient - Day 2S 

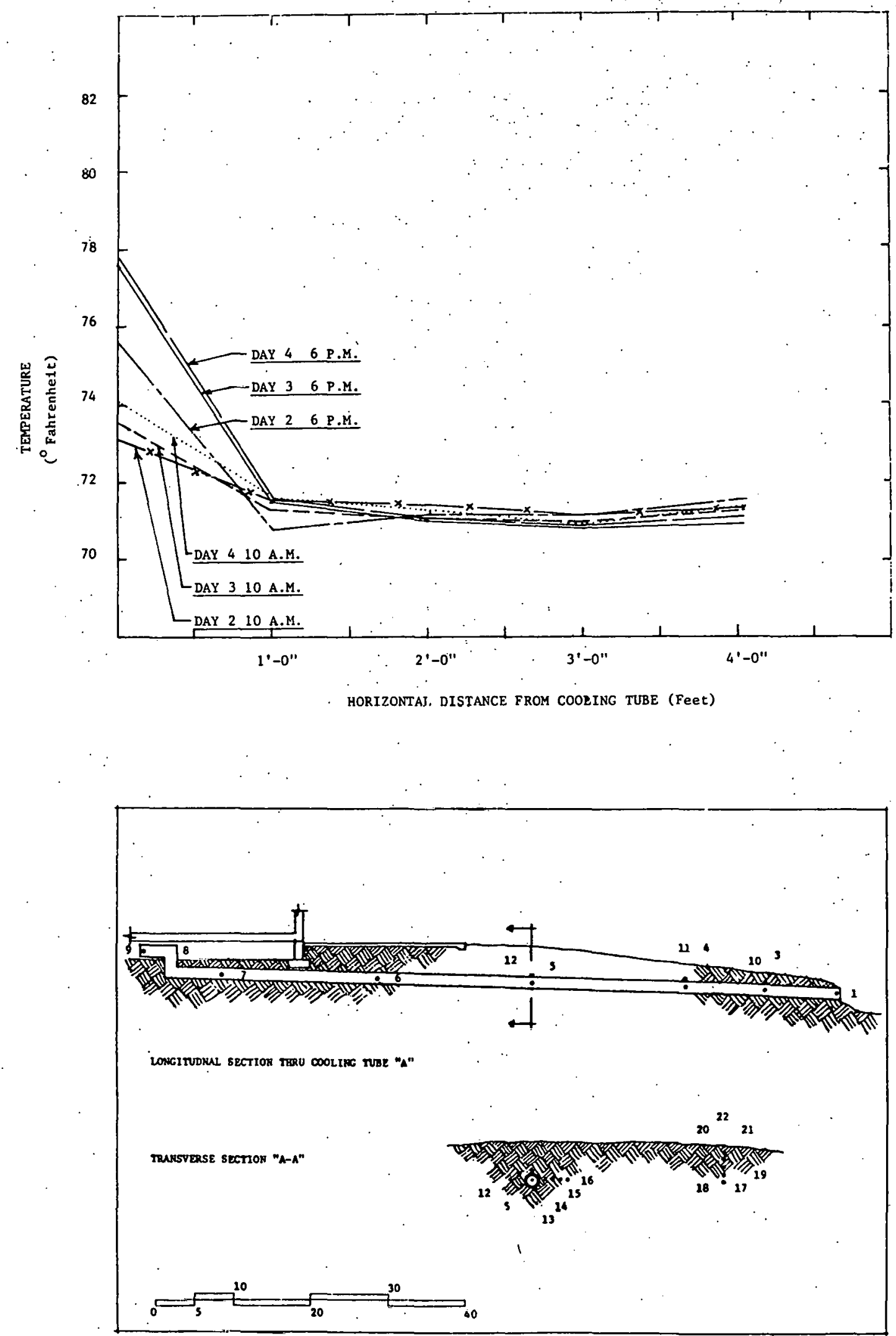

Figure 29. Effect of Intermitent Operation on Ground Temperature Gradient 
raising that much earth approximately $10 \mathrm{~F}$ above the far field temperature.

Since the attic fan had only an off, slow speed, and high speed switch, it was necessary to resort to other means to investigate the effect of airflow rate on the cooling tube performance. Flow adjustments were made by blocking one of the cooling tubes, and by putting various size orifices over the inlet of the remaining tube for measurements.

Figure 30 shows the temperature distribution along the tube for three conditions. The high fan speed and low fan speed curves with a $15^{\prime \prime}$ orifice show a steady decrease in temperature as air moves through the tube while the natural ventilation curves show a random temperature distribution. Due to turbulence at the. inlet, the inlet temperature must also be questioned. The inlet temperature should be the same for all speeds since they were measured within 10 minutes of each other. Since it is difficult to determine whether there was flow under natural ventilation conditions and, if so, in which direction, it appears the curve merely represents the ground temperature with little if any flow.

Figure 31 shows the temperature distribution for two different speeds with two different orifices. Again, the location of the inlet thermocouple immediately behind the orifice causes one to question the inlet temperature. All inlet temperatures should be approximately $830 \mathrm{~F}$ since all measurements were made within a very short time period.

Table II gives approximate flow velocities for each of the flow conditions. "Approximate" is used here because flow measurements are difficult even under ideal conditions. A hot,wire anemometer should have a straight section of pipe 5-10 pipe diameters in length preceeding and following the anemometer. Unfortunately, with the earth cooling tube under investigation, the ideal placement was not available. The only locations where airflow measurements could be made were at at the inlet, exit, and about $2^{\prime}$ from the exit. The position approximately 2 ' from the exit was 


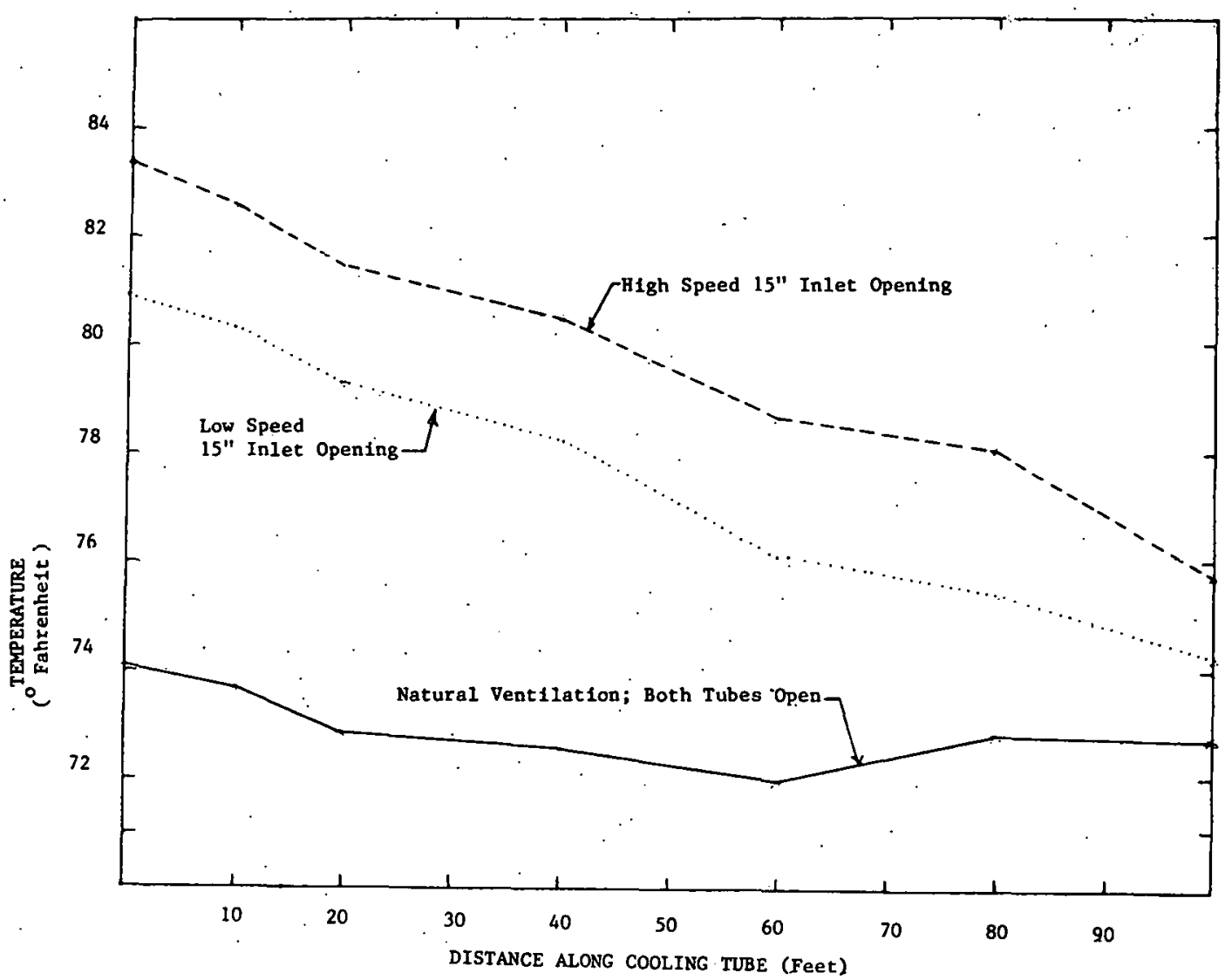

THERMal PERFormance OF 2l" DLAMETER COOLING TUBE

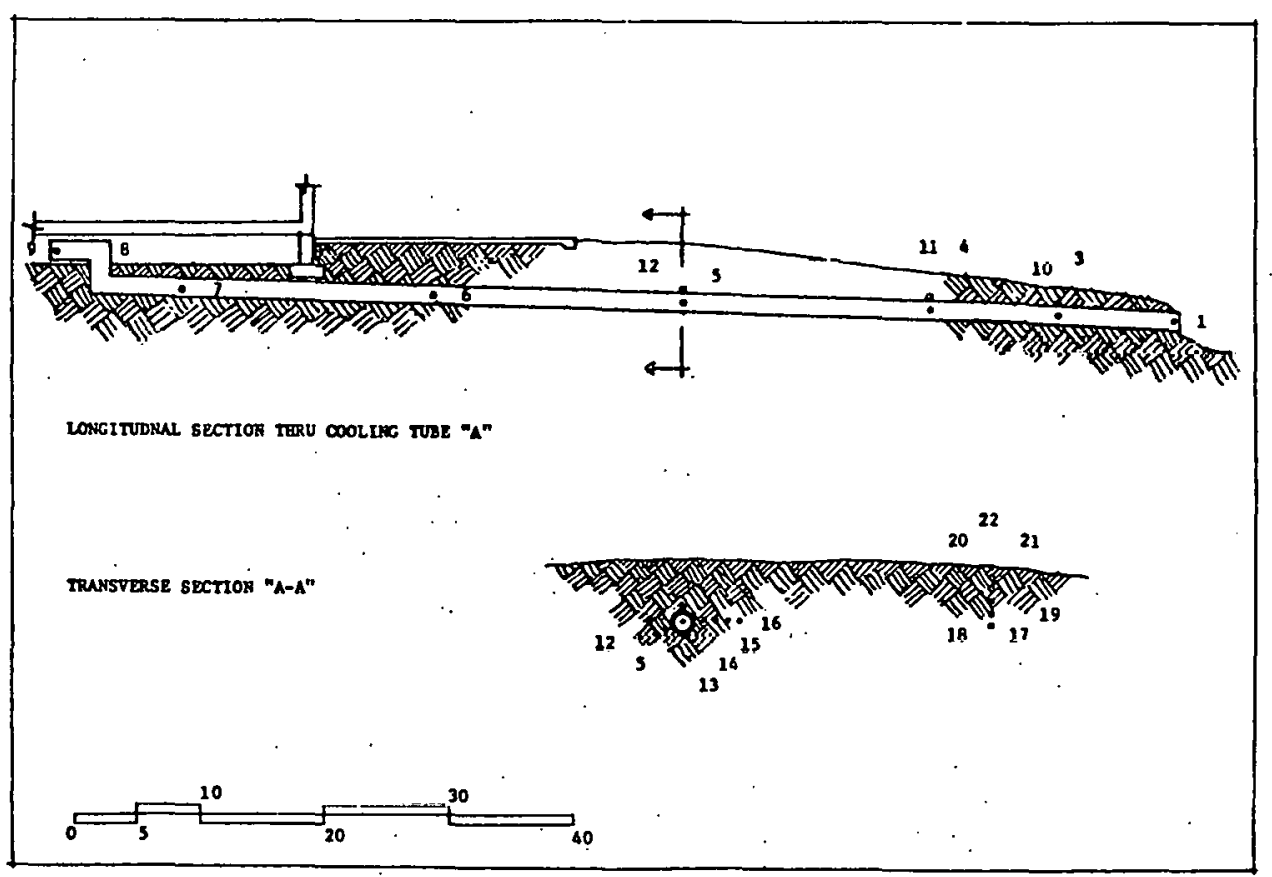

Figure 30. Effect on Fan Speed on Temperature Gradient àlong the Cooling Tube 


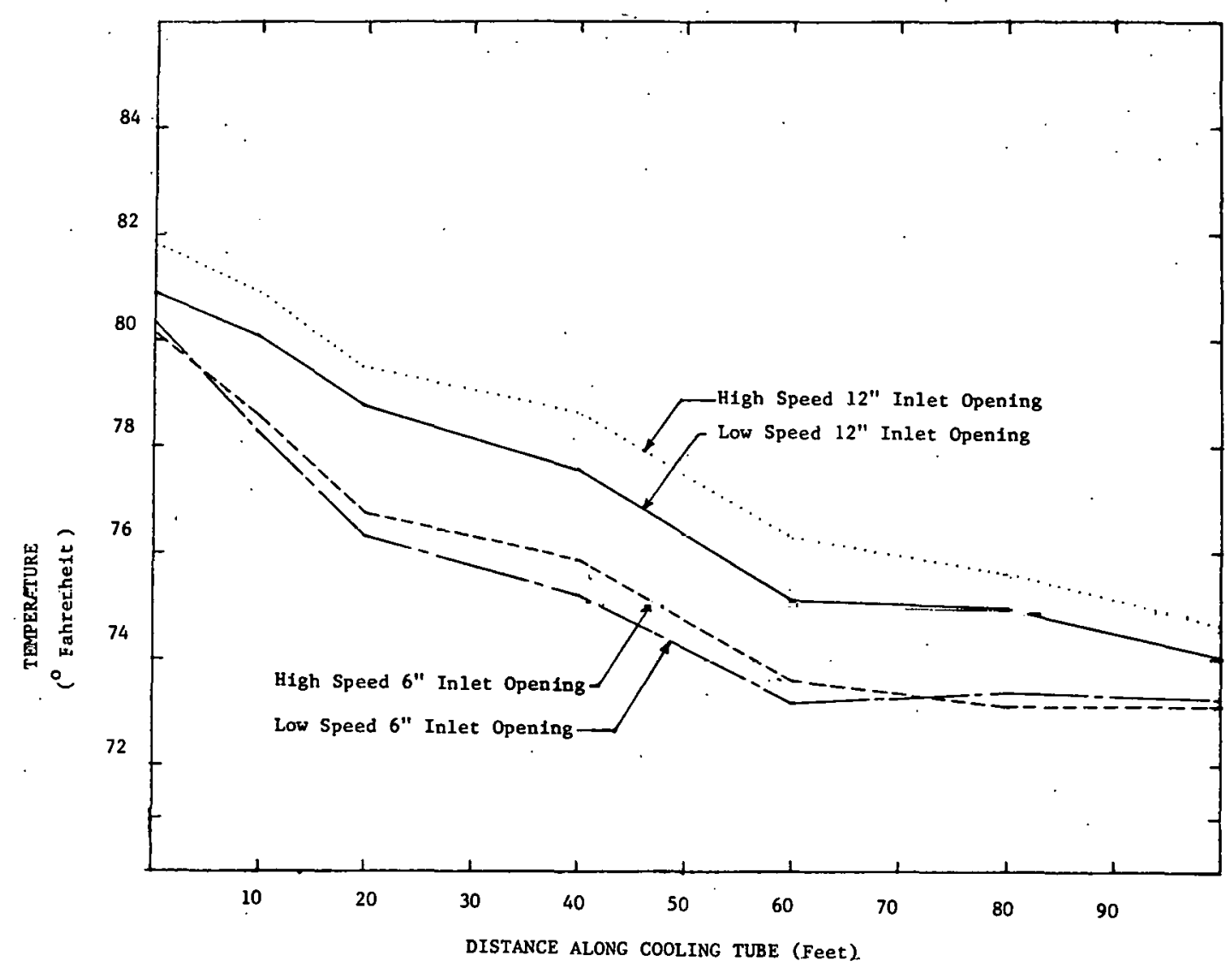

THERMAL PERFORMANCE OF 21" DIAMETER COOLING TUBE

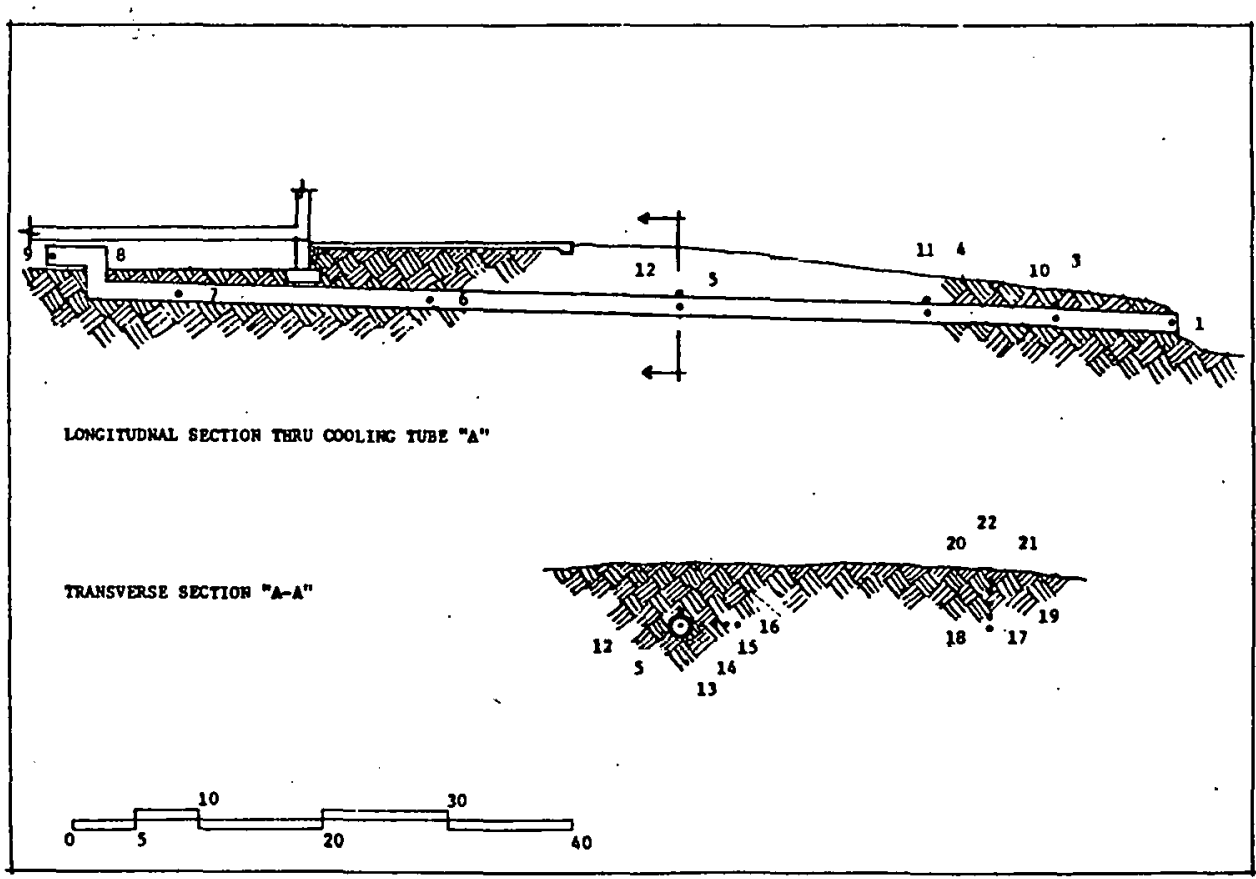

Figure 31. Effect of Reduced Flow on Temperature Gradient along the Cooling Tube 
TABLE II

COOLING, TUBE AIR VELOCITY

DESCRIPTION

FAN SPEED

VELOCITY (FT/SEC)

Both tubes open

Low speed

$2.6 \mathrm{ft} / \mathrm{sec}$

Both tubes open

High speed

$6.0 \mathrm{ft} / \mathrm{sec}$

Opposite tube blocked

Low speed

$5.0 \mathrm{ft} / \mathrm{sec}$

Opposite tube blocked

High speed

$6.9 \mathrm{ft} / \mathrm{sec}$

Natural Ventilation

$0.2 \mathrm{ft} / \mathrm{sec}$

15" Inlet opening

Low speed

$4.4 \mathrm{ft} / \mathrm{sec}$

15" Inlet opening

High speed

$7.3 \mathrm{ft} / \mathrm{sec}$

12" Inlet opening

Low speed

$1.6 \mathrm{ft} / \mathrm{sec}$

12 "Inlet opening

High speed

$3.7 \mathrm{ft} / \mathrm{sec}$

6" Inlet opening

Low speed

$0.1 \mathrm{ft} / \mathrm{sec}$

6" Inlet openiny

High speed

$6.5 \mathrm{ft} / \mathrm{sec}$ 
chosen for these measurements, but this position was influenced by a 900 turn $2^{\prime}$ upstream and the exit $2^{\prime}$ downstream. Severe turbulence was obviously present and the readings measured are considered only rough approximations.

Additional Figures are given in Appendix B for both the thermal envelope house and the earth cooling tube for those interested in pursuing the performance further. 


\section{HEATING PERFORMANCE REVISITED}

There has been considerable discussion about the heating performance reported in the Phase I performance report. The most controversial topics appear to be whether energy is being stored in the ground and rereleased to the envelope and the related area of why our measurements did not indicate flow reversal while several other studies have measured flow reversal. This section attempts to address both of these questions.

We can address more analytically the second quiestion of flow reversal and why it occurs in some houses and not in others. If one refers to Figure 32 , one can show that under steady state conditions the temperatures in the greenhouse $\left(\mathrm{T}_{\mathrm{gh}}\right)$ and the north wall cavity $\left(\mathrm{T}_{\mathrm{nw}}\right)$ can be calculated by:

$$
T_{g h}=\frac{T_{0} U_{1} A_{1}+T_{i} U_{2} A_{2}}{U_{1} A_{1}+U_{2} A_{2}}
$$

and

$$
T_{n w}=\frac{T_{0} U_{4} A_{4}+T_{i} U_{3} A_{3}}{U_{3} A_{3}+U_{4} A_{4}}
$$

where: ' $T_{g h}=$ equilibrium temperature in the greenhouse

$\mathrm{T}_{\mathrm{nw}}=$ equilibrium temperature in the north wall cavity

$\mathrm{T}_{0}=$ outside temperature 


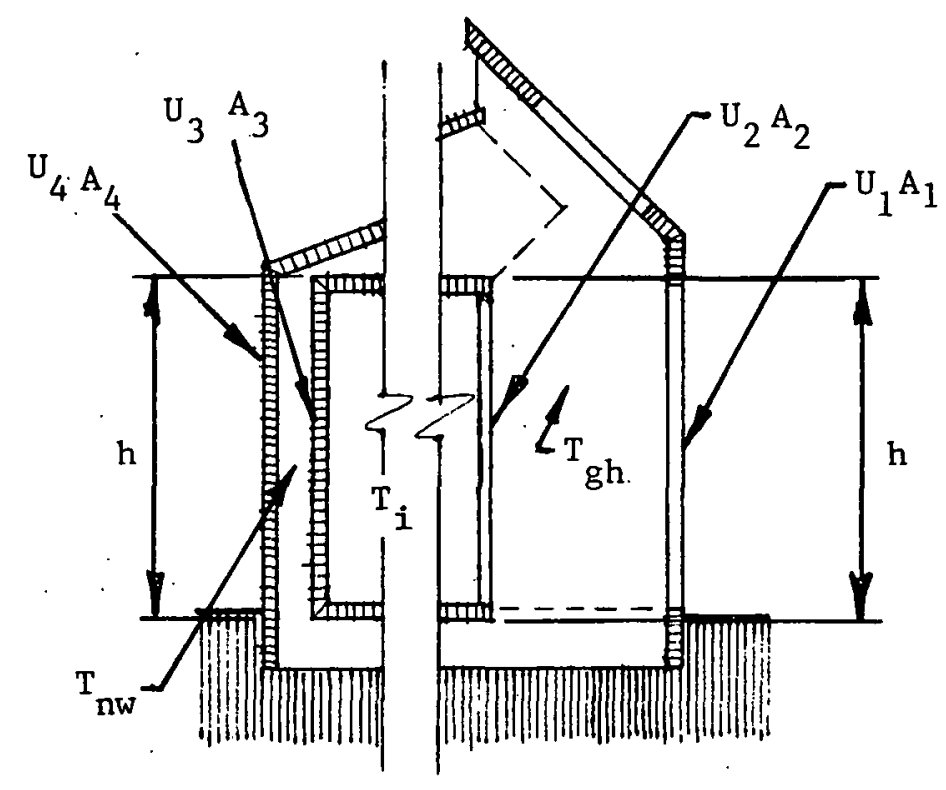

$$
\begin{aligned}
& T_{g h}=\frac{T_{0} U_{1} A_{1}+T_{i} U_{2} A_{2}}{U_{1} A_{1}+U_{2} A_{2}} \\
& T_{n w}=\frac{T_{0} U_{4} A_{4}+T_{i} U_{3} A_{3}}{U_{3} A_{3}+U_{4} A_{4}}
\end{aligned}
$$

Figure 32. Loop Equilibrium Temperature Schematic 
$\mathrm{T}_{\mathrm{i}}=$ inside temperature

$U_{1} A_{1}, U_{2} A_{2}, U_{3} A_{3}, U_{4} A_{4}=$

the product of the wall conductivities and areas for the respective walls

The term UA is used in these calculations as the total loss coefficient including conductive losses to outside air and the earth plus infiltration loads.

For the case white:

$$
\mathrm{U}_{1} \mathrm{~A}_{1}=\mathrm{U}_{2} \mathrm{~A}_{2}
$$

and

$$
\mathrm{U}_{3} \mathrm{~A}_{3}=\mathrm{U}_{4} \mathrm{~A}_{4}
$$

Equations (1) and ( 2 ) reduce to:

$T_{g h}=\frac{T_{i}+T_{0}}{2}$

$$
T_{n w}=\frac{T_{i}+T_{0}}{2}
$$


In this case, the equilibrium temperature in the greenhouse and north wall would be identical. Since each side has the same column height and the same equilibrium temperatures, there is no driving force to cause reverse flow at night. The Stokes house met the conditions stipulated above and therefore would not be expected to have flow reversal; none was measured. Many of the other thermal envelope houses have different UA ratios due to thicker, more heavily insulatéd outside north walls or much less glass areas on the greenhouse inside than on the greenhouse outside. Flow reversal is entirely possible and probable in these cases. Since the Stokes house performs quite well without flow reversal and since there is little energy being stored in the ground, one must question whether flow reversal is either necessary or desirable.

Others have attempted to take the crawlspace air temperatures and the ground surface temperature and apply a horizontal heat transfer coefficient to calculate energy transfer rate to and from the ground. This is obviously in error since the air temperature measurement was approximately $40^{\prime \prime}$ above the ground surface with a very steep temperature gradiant between the ground and the air where its temperature was being measured. Without a more detailed. knowledge of the temperature gradient, it is impossible to accurately estimate the convective heat transfer coefficient, thus convective transfer calculations are difficult.

The authors are frequently asked why the envelope stabilizes at some particular temperature if the house experiences several very cloudy days unless the ground has stored energy during sunny days which is given up on cloudy days. One only need refer to equations (1) and (2) to answer these questions. If one assumes:

$$
\mathrm{U}_{1} \mathrm{~A}_{1}=\mathrm{U}_{2} \mathrm{~A}_{2}
$$

and

$$
\mathrm{U}_{3} \mathrm{~A}_{3}=\mathrm{U}_{4} \mathrm{~A}_{4}
$$




$$
\begin{aligned}
& \mathrm{T}_{\mathrm{i}}=700 \mathrm{~F} \\
& \mathrm{~T}_{\mathrm{O}}=100 \mathrm{~F} \\
& \mathrm{~T}_{\mathrm{gh}}=\frac{70+10}{2}=400 \mathrm{~F} \\
& \mathrm{~T}_{\mathrm{nW}}=\frac{70+10}{2}=400 \mathrm{~F}
\end{aligned}
$$

The $40^{\circ} \mathrm{F}$ equilibrium temperature is almost exactly the temperature measured in the Stokes house after several cloudy days. If one assumes a different set of relative UA values in either the south or north walls different equilibrium temperatures result as shown below:

$$
U_{1} A_{1}=U_{2} A_{2}
$$

and

$$
\begin{aligned}
\mathrm{U}_{3} \mathrm{~A}_{3} & =1.7 \mathrm{U}_{4} \mathrm{~A}_{4} \\
\mathrm{~T}_{\mathrm{i}} & =70 \mathrm{~F}^{\circ} \\
\mathrm{T}_{0} & =10^{\circ} \mathrm{F} \\
\mathrm{T}_{\mathrm{gh}} & =\frac{700+100}{2} \\
\mathrm{~T}_{\text {gh }} & =40 \mathrm{~F}^{*} \\
\mathrm{~T}_{\mathrm{nw}} & =\frac{70 * 1.7 * \mathrm{U}_{4} \mathrm{~A}_{4}+10 * \mathrm{U}_{4} \mathrm{~A}_{4}}{1.7 * \mathrm{U}_{4} \mathrm{~A}_{4}+\mathrm{U}_{4} \mathrm{~A}_{4}} \\
\mathrm{~T}_{\mathrm{nw}} & =\frac{1.7 \times 70+10}{2.7} \\
\mathrm{~T}_{\mathrm{nw}} & =47.8 \mathrm{OF}
\end{aligned}
$$


Again, these temperatures are very close to those being measured in several of the other thermal envelope houses.

Note! These are equilibrium temperatures where the inside temperature is maintained at some fixed temperature. The equations will permit envelope equilibrium temperatures to be calculated for any combination of temperatures. We have not measured a series of cloudy days without occupants. There are no data on long time temperatures without internal gain. The one cloudy day measured with no occupants did not show a steady equilibrium temperature. It decreased until the sun again became a factor.

The envelope equilibrium temperature is frequently given as proof that energy has been stored in the earth and is being used to temper the envelope temperature. We see from the above that realistic envelope equilibrium temperatures are reached without any contributions from the ground. The equilibrium temperatures calculated are almost exactly those being measured. If the ground was contributing significant quantities of energy, the equilibrium temperature would be much higher. 


\section{CONCLUSIONS}

The thermal envelope house with earth cooling tubes that was monitored on this program performed well relative to other naturally cooled houses in Georgia:" It was capable of keeping temperatures inside the house within the comfort range the majority of the time. It was not capable of keeping humidity levels within the comfort range.

The earth cooling tubes did provide beneficial, sensible cooling to the building throughout the summer. The cooling tubes did not provide latent cooling, i.e., they were able to lower temperatures but were not capable of lowering moisture levels. While the humidity levels were high, they did not adversely affect comfort as long as the cooling tube-tempered air was kept out of the living space. In practice this inner space was usually opened to the envelope, resulting in high humidity levels within the living space.

The thermal chimney was found to be a poor method for inducing flow through earth cooling tubes. Little flow was established through the tubes unless an attic fan was used to induce flow. Unfortunately, the attic fan also increased infiltration into the house by creating a negative pressure inside the house.

The performance was, adversely affected in both the heating and cooling modes by several factors which should not be repeated in subsequent designs. The "dehumidification" west wall increased the thermal load in both the winter and summer due to its low thermal resistance. Since its performance as a dehumidifier is doubtful at best, it should be replaced with a well-insulated wall similar to the east wall.

The house also contained obstructions (plumbing, etc.) in the north wall 
envelope which provided some restriction to air movement. While the effect of these restrictions may be small, they should be eliminated in subsequent designs.

The earth cooling tubes used in this house were open to the outside (open loop). This results in hot humid outside air having to be cooled before reaching the house. This caused the ground around the tubes to be heated more than necessary and also resulted in very humid air in the envelope. It would be preferable to arrange the cooling tubes in a closed loop fashion with air being pulled from the house, through the earth cooling tubes, into the house envelope and back to the tubes. This would result in the cooling tubes having to carry only the house sensible load, not ambient sensible loads. Air going into the cooling tubes would be approximately $800 \mathrm{~F}$ in the closed loop mode and between $90-105 \circ \mathrm{F}$ in the open mode. With the cooler air inlet temperatures in closed loop systems one might experience problems with moisture accumulation. This needs further investigation. 
APPENDIX A

Sample Datalogger Output

Sample Insolation Chart

Sample Computer Disc File 


\begin{tabular}{|c|c|c|c|c|c|c|c|c|c|c|c|}
\hline C.HANNEL & \multicolumn{2}{|c|}{ READING } & CHANNEL & \multicolumn{2}{|c|}{ READING } & CHANNEL & \multicolumn{2}{|c|}{ READING } & CHANNEL & \multicolumn{2}{|c|}{ READING } \\
\hline 47 & $3,31 ه 8$ & $v$ & & & & 47 & 3,3219 & $v$ & 47 & 3,3194 & $v$ \\
\hline 46 & 3,0280 & $v$ & 47 & 33125 & $\mathbf{v}$ & 46 & 3,5777 & $v$ & 46 & $3,0 \cap 27$ & $\checkmark$ \\
\hline 45 & $\bullet \bullet \bullet \bullet$ & $r$ & 46 & 29691 & v & 43 & $-\cdots$ & 4 & 45 & 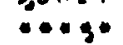 & $\checkmark$ \\
\hline 44 & 784 & 1 & 45 & -45 & 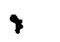 & 44 & 682 & $\gamma$ & 44 & 683 & 4 \\
\hline 43 & 750 & $\checkmark$ & 44 & 76 & 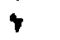 & 43 & 73,2 & $r$ & 43 & 123 & $i$ \\
\hline 42 & 741 & $y$ & 4 & 720 & 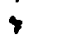 & $4 ?$ & 728 & $r$ & 42 & 135 & + \\
\hline 41 & 184 & 7 & 42 & 766 & $r$ & 41 & 481 & $r$ & 41 & $\Delta 7,0$ & 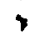 \\
\hline 40 & 450 & 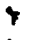 & 41 & $\triangle 86$ & 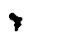 & 40 & 446 & $r$ & 40 & 444 & 7 \\
\hline 39 & $5 q 2$ & 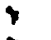 & 40 & 653 & $i$ & 39 & 497 & 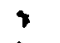 & 39 & 49,4 & $r$ \\
\hline 38 & 166 & $\checkmark$ & 39 & 532 & + & 30 & 666 & 3 & 38 & 406 & + \\
\hline 37 & 439 & 7 & 38 & 420 & $r$ & 37 & 474 & $r$ & 37 & 467 & + \\
\hline 36 & $1,7,4$ & 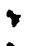 & 37 & 480 & $i$ & 36 & 47,2 & $r$ & 36 & 47,0 & $r$ \\
\hline 35 & 443 & 3 & 36 & 479 & 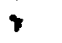 & 33 & $4 \$ 4$ & 7 & 33 & 480 & $r$ \\
\hline 34 & 420 & 7 & 35 & 180 & $\checkmark$ & 34 & 45,1 & 7 & 34 & 452 & 3 \\
\hline 33 & 47,7 & 7 & 34 & 466 & 4 & 33 & 47,0 & 8 & 33 & 43,0 & 1 \\
\hline 32 & 4,5 & $\checkmark$ & 33 & 47,5 & 4 & 32 & 45,0 & 1 & 32 & 451 & $r$ \\
\hline 31 & 472 & $r$ & 32 & 470 & 7 & 31 & 42,0 & 7 & 31 & 470 & $r$ \\
\hline 30 & 47,0 & $r$ & 31 & 470 & 4 & 30 & 469 & $T$ & 30 & 469 & 1 \\
\hline 29 & 43,3 & 1 & 30 & 469 & : & 29 & 153 & 2 & 29 & 43,3 & 7 \\
\hline 20 & 45,2 & $T$ & 29 & 461 & 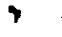 & 20 & 43,2 & $r$ & 28 & 440 & $r$ \\
\hline 27 & $\triangle 8 \cap$ & $?$ & 28 & 45,9 & 4 & 27 & 477 & $r$ & 27 & 467 & $*$ \\
\hline 26 & 168 & $?$ & 27 & $18 \theta$ & 1 & 26 & 167 & 7 & 26 & 165 & 4 \\
\hline 23 & 461 & 4 & 26 & 17,6 & 4 & 25 & 458 & 7 & 25 & 45,3 & 1 \\
\hline 24 & 63,9 & 7 & 25 & 466 & 4 & 24 & 63,7 & 3 & 24 & 63,3 & 7 \\
\hline 23 & 664 & 3 & 24 & 60,8 & 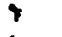 & 23 & 680 & 5 & 23 & 65,5 & $\checkmark$ \\
\hline 22 & 646 & 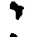 & 23 & 669 & $t$ & 22 & 642 & 3 & 22 & 63,8 & 1 \\
\hline 21 & 482 & $r$ & 22 & 65,0 & 7 & 21 & 47,9 & 7 & 21 & 420 & $r$ \\
\hline 20 & 4,3 & 1 & 21 & 486 & 4 & 20 & 454 & 1 & 70 & 45,2 & 1 \\
\hline 19 & 523 & 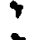 & 20 & 45,6 & 1 & 19 & $32:$ & $y$ & 19 & 522 & 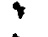 \\
\hline 18 & 380 & 3 & 19 & 324 & 7 & 1 月 & 498 & 1 & 10 & 49,7 & + \\
\hline 17 & คค ค & 3 & 18 & 30.2 & $r$ & 17 & 454 & 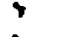 & 17 & 483 & 7 \\
\hline 16 & 50,5 & 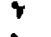 & 17 & $+9,0$ & $\checkmark$ & 16 & $\leq 92$ & 7 & 16 & 521 & 1 \\
\hline$\therefore 3$ & 498 & 3 & 26 & 595 & 1 & 15 & 497 & 2 & 15 & 49,7 & 4 \\
\hline 14 & 487 & + & 15 & 49,7 & 1 & 14 & 463 & 1 & 14 & 482 & 7 \\
\hline 13 & 47,4 & 3 & 14 & 488 & 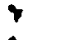 & 13 & 472 & 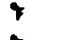 & 13 & 4,3 & 7 \\
\hline 12 & 470 & 1 & 13 & 477 & 1 & 12 & $4 Z^{2}$ & t & 12 & 472 & 7 \\
\hline 11 & 0.65 & 7 & 12 & 429 & 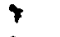 & 14 & 439 & + & 11 & 45,9 & 7 \\
\hline 10 & 446 & 3 & 11 & $46 \theta$ & 7 & 10 & 496 & 3 & 10 & 452 & 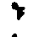 \\
\hline 9 & 660 & $?$ & 10 & 472 & $r$ & 9 & 45,9 & 4 & 9 & 4,6 & r \\
\hline 8 & 392 & 3 & 9 & 467 & 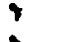 & 8 & $\begin{array}{l}301 \\
50\end{array}$ & 3 & 8 & 49,9 & $r$ \\
\hline 7 & $: 62$ & 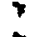 & 8 & 592 & 1 & 7 & 45,9 & $?$ & 7 & 45,9 & + \\
\hline 6 & 587 & $?$ & 7 & 468 & 3 & 6 & 586 & 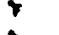 & 6 & $5 \mathrm{Qg}$ & 4 \\
\hline 5 & 494 & 3 & 6 & 389 & 1 & 3 & 42,9 & ? & 3 & 479 & $r$ \\
\hline 4 & 47,8 & 1 & 5 & 484 & + & 4 & 436 & 2 & 4 & 474 & t \\
\hline 3 & 446 & 3 & 4 & A 81 & $\checkmark$ & 3 & 444 & 1 & 3 & 493 & \% \\
\hline 2 & 483 & 1 & 3 & 150 & 8 & 2 & 426 & 2 & 2 & 4,3 & 2 \\
\hline 1 & 0.10 & $?$ & 2 & 483 & 1 & 2 & -1.54 & 2 & 1 & 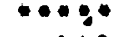 & $?$ \\
\hline 0 & 142 & 1 & $\begin{array}{l}1 \\
0\end{array}$ & 18 & t & 0 & 140 & 7 & 0 & 150 & 4 \\
\hline & & & & & & & $\therefore$ & & & & \\
\hline $\mathrm{D} \wedge \mathrm{Y} 12$ & . & & DAY 1 & 2 & & $\mathrm{D} \wedge \mathrm{Y} 1$ & 2 & & DAY & 2 & \\
\hline $00: 00$ & hrs & . & $00: 30$ & hrs & & $01: 00$ & hrs & & $01: 30$ & hrs & \\
\hline
\end{tabular}

l:IGURE: A1 - SAMPLE DATALOGGER OUTPUT' 


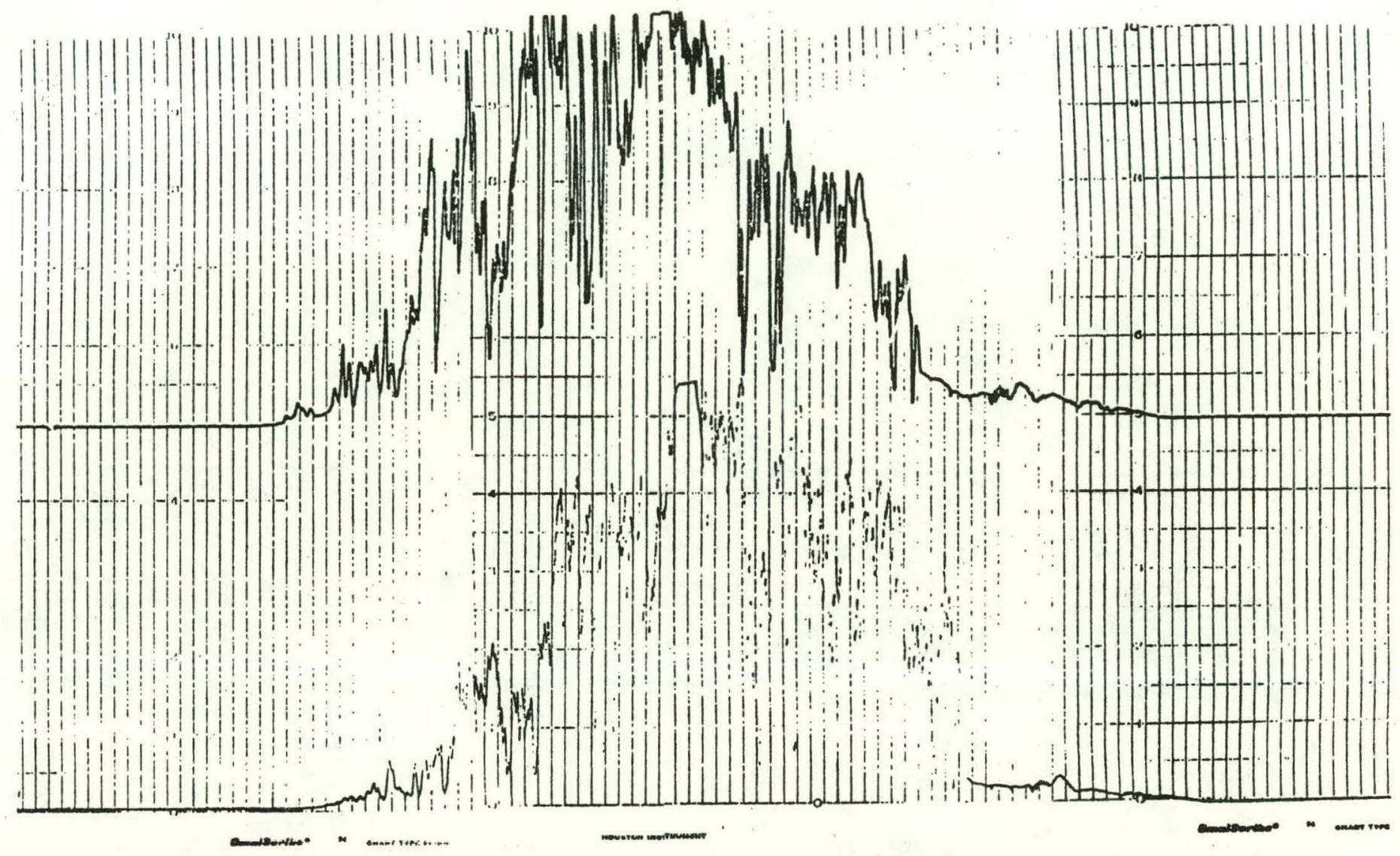

FIGURE A2 - SAMPLE INSOLATION CHART FROM EPPLEY PSP PYRANOMETER AND OMNISCRIBE STRIP CHART RECORDER. 
$Y 225 \div 01: 29 \div 59$

$\times 080480$

\begin{tabular}{|c|c|c|c|c|c|c|c|c|c|c|c|c|c|}
\hline 0 & 68.9 & $F$ & $A$ & 1 & 68.1 & $F$ & A & 2 & 67.9 & $F$ & A & 3 & 68.5 \\
\hline 4 & 69.6 & $F$ & & 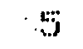 & 70.6 & $F$ & & 6 & 70.7 & $F$ & & 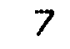 & 1. \\
\hline 8 & 71.2 & $F$ & & 9 & 68.5 & $F$ & & 10 & -7.777 .9 & $* * \mathrm{ET}$. & $A$ & 11 & 8 \\
\hline 12 & 73.8 & $F$ & $A$ & 13 & 71.7 & $F$ & & 14 & 71.4 & $F$ & A & 5 & - 1. \\
\hline 16 & 71 & $F$ & & 17 & .7 & $F$ & & 8 & $t$ & $F$ & $A$ & 9 & \\
\hline 20 & 74 & $F$ & $A$ & 21 & 77.6 & $F$ & & 2 & + & $F$ & A & 3 & \\
\hline 24 & +7777 & $k * \mathrm{BT}$ & $A$ & 25 & $+7777.7 x$ & $* * \mathrm{BT}$ & A & 26 & + & $F$ & $A$ & 27 & .7 \\
\hline 28 & + & $F$ & $A$ & 29 & 70.0 & $F$ & & 30 & $t$ & $F$ & $A$ & 31 & 0 \\
\hline 32 & 1 & $F$ & $\Delta$ & 33 & $t$ & $F$ & & 34 & $t$ & $F$ & 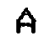 & 35 & 1 \\
\hline 36 & 7 & $F$ & $A$ & 37 & + & $\mathbf{F}$ & & 38 & $t$ & $F$ & 7 & 39 & \\
\hline 40 & $7:$ & $F$ & $A$ & 41 & $f$ & $F$ & & 42 & $t$ & $F$ & $A$ & 43 & 8 \\
\hline 46 & 7 & $F$ & $A$ & 45 & 68.7 & $F$ & & 46 & 69.0 & $F$ & A & 47 & 68.9 \\
\hline 48 & & $F$ & f & 49 & 76.5 & $F$ & r & 50 & 79.0 & $F$ & 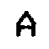 & 51 & 69.1 \\
\hline $5:$ & & $F$ & $A$ & 5.3 & 73.8 & $F$ & $\boldsymbol{H}$ & 54 & 73.8 & $F$ & 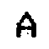 & 55 & 0.017 \\
\hline 56 & .4058 & $v$ & $A$ & 57 & +3.2085 & V & $A$ & 58 & -0.0000 & $v$ & $A$ & 59 & -0.0008 \\
\hline
\end{tabular}
Y225:02:29:59

$\times 080480$

\begin{tabular}{|c|c|c|c|}
\hline A & 0 & 68.6 & $F$ \\
\hline$A$ & 4 & 69.1 & $F$ \\
\hline$A$ & 8 & 71.1 & $F$ \\
\hline A & 1.2 & 73.5 & $F$ \\
\hline A & 16 & 71.2 & $F$ \\
\hline A & 20 & 75.3 & $F$ \\
\hline$A$ & 24 & $+7777.7 *$ & $* * \mathrm{EBT}$ \\
\hline$A$ & 28 & 70.2 & $F$ \\
\hline A & 32 & $71 \cdot 1$ & $F$ \\
\hline$A$ & 36 & $71 \cdot 9$ & $F$ \\
\hline$A$ & 40 & 72.5 & $F$ \\
\hline$A$ & 44 & 71.1 & $F$ \\
\hline$A$ & 48 & 69.7 & $F$ \\
\hline$A$ & 52 & $71 \cdot 4$ & $F$ \\
\hline A & 56 & 5653 & U \\
\hline & 25 & $85 \%$ & \\
\hline
\end{tabular}

A $1+67.9 F$

$\mathrm{A} 5 \mathrm{~F}+70.3 \mathrm{~F}$

A $9+68.4 \mathrm{~F}$

A $13+71.5 \mathrm{~F}$

A $17+67.7 \mathrm{~F}$

A $21+77.9 \mathrm{~F}$

A $25+7777.7 *$ सT

A $29+70.0 \mathrm{~F}$

A $33+71.1 \mathrm{~F}$

A $37+72.9 \mathrm{~F}$

A $4.1+72.6 \mathrm{~F}$

A $45+68.5 \mathrm{~F}$

A $49+76.1 \mathrm{~F}$

A $53+.73 .1 \mathrm{~F}$

A $57+3.1600 \mathrm{~V}$
A $2+67.3 \mathrm{~F}$

A $6+70.6 \mathrm{~F}$

A $10-7777.7 * * \mathrm{BT}$

$\mathrm{A} 14+71.3 \mathrm{~F}$

A $18+69.7 \mathrm{~F}$

A $22+74.7 \mathrm{~F}$

A $26+71.4 \mathrm{~F}$

A $30+70.5 \mathrm{~F}$

A $344+70.8 \mathrm{~F}$

A $38+73.2 \mathrm{~F}$

A $42+69.9 \mathrm{~F}$

$A 46+68.6 \mathrm{~F}$

A $50+78.4 \mathrm{~F}$

$A 5 A+73.4 F$

A $58-0.0000 \mathrm{~V}$
A. $3+68.5 \mathrm{~F}$ A $7+70.9 F$

$A 11+77.9 F$

A $15+71.1 \mathrm{~F}$

A $1.9+72.2 \mathrm{~F}$

A. $23+72.3 \mathrm{~F}$

A $27+70.7 \mathrm{~F}$

A $31+71.1 \mathrm{~F}$

A. $35+71.8 \mathrm{~F}$

A $39+72.2 F$

A $43+68.5 \mathrm{~F}$

A $47+68.6 \mathrm{~F}$

A $51+69.0 \mathrm{~F}$

A $55-0.013 \mathrm{MV}$

A $59-0.0020 \mathrm{~V}$

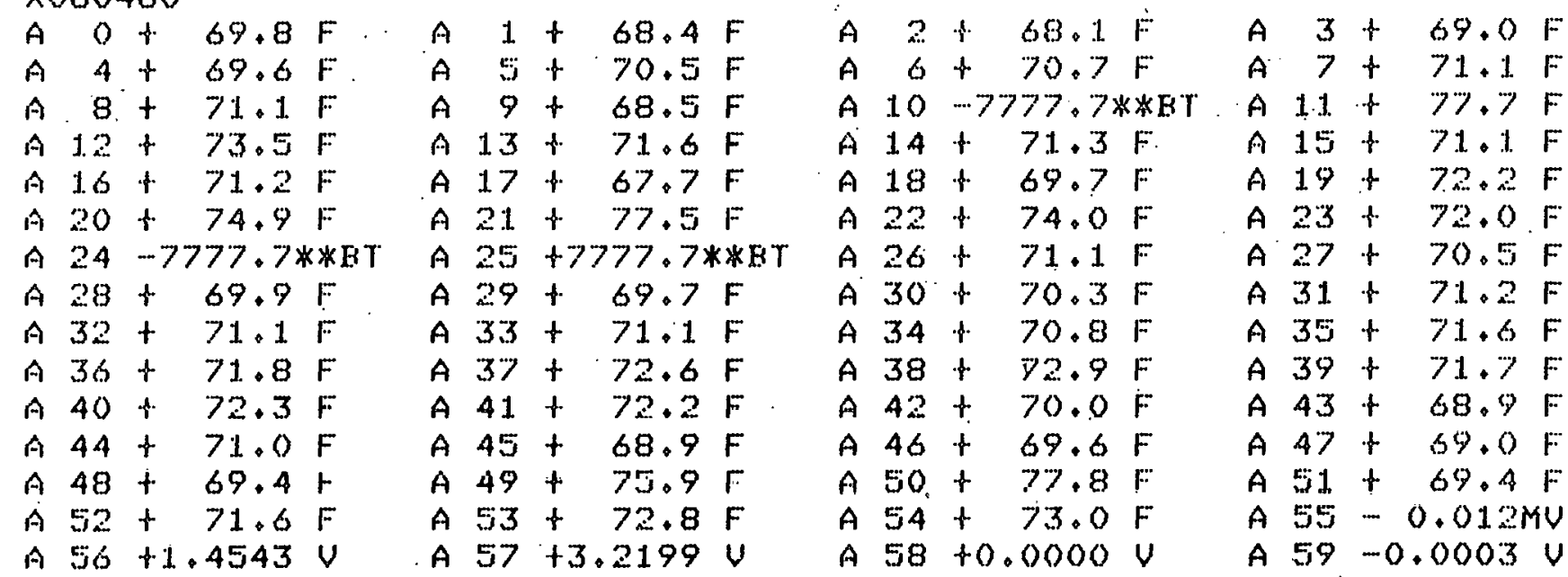


APPENDIX B

Additional Thermal Performance Curves 

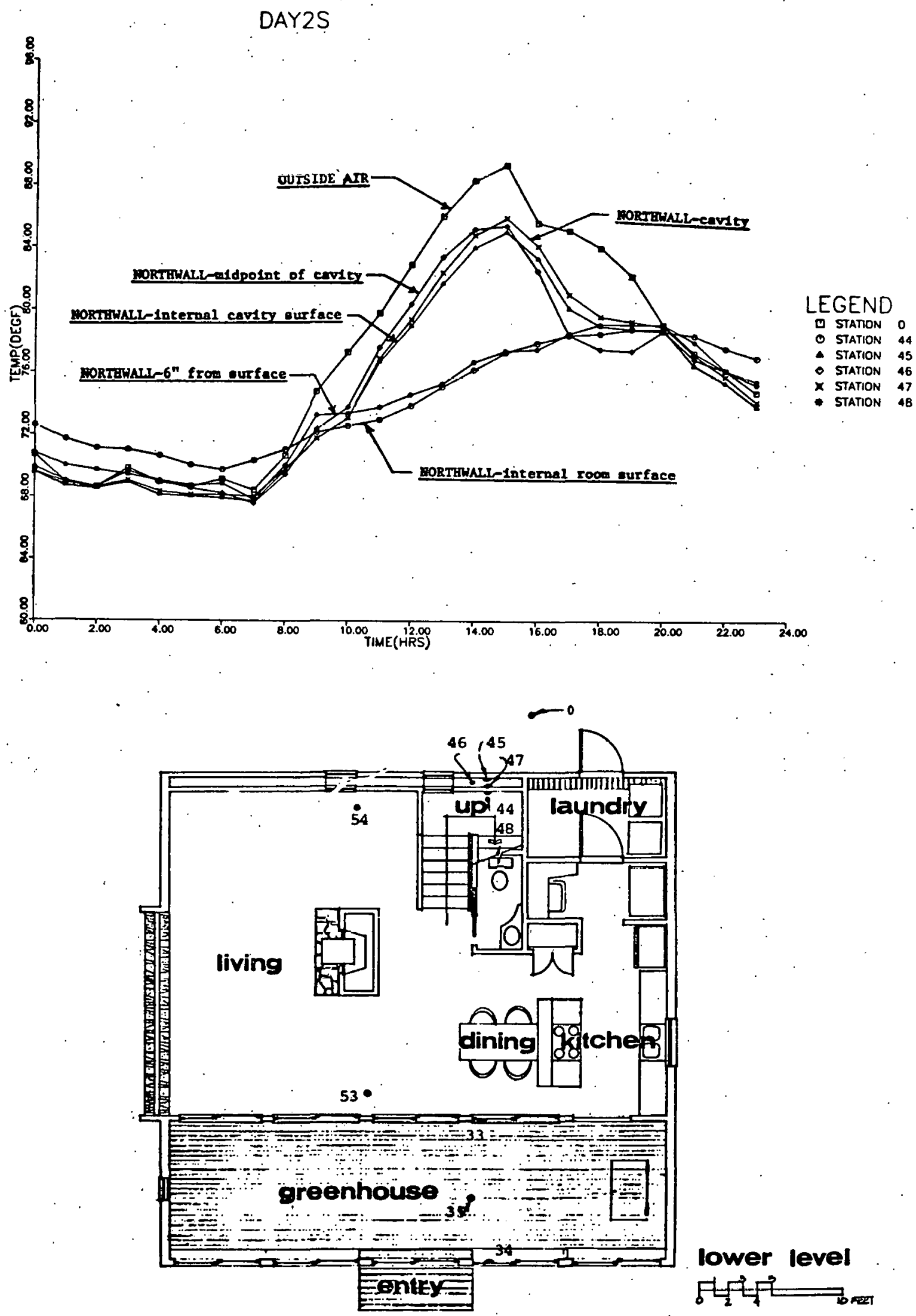

lower level

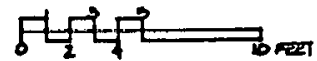


DAY2S
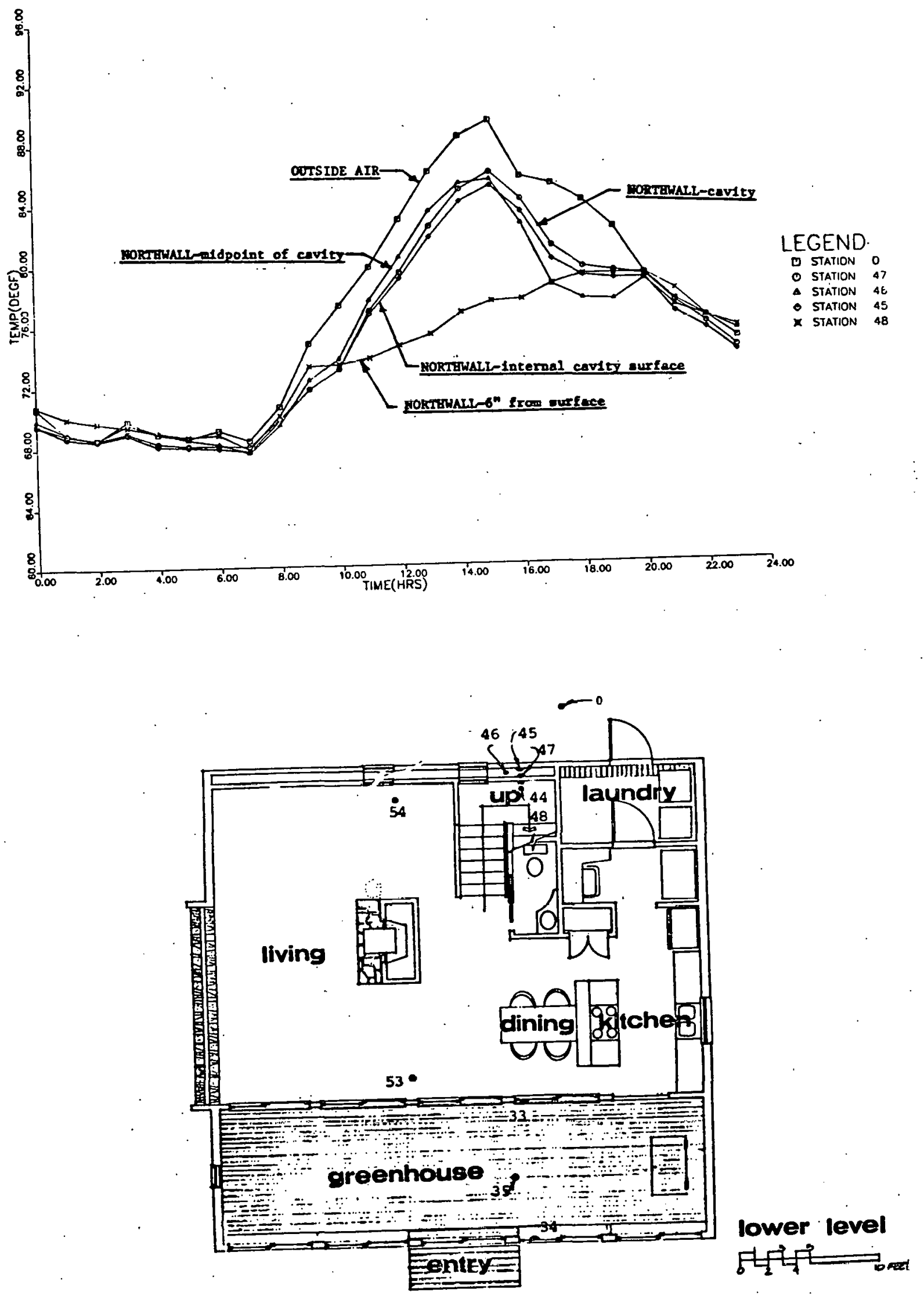
DAYY2S

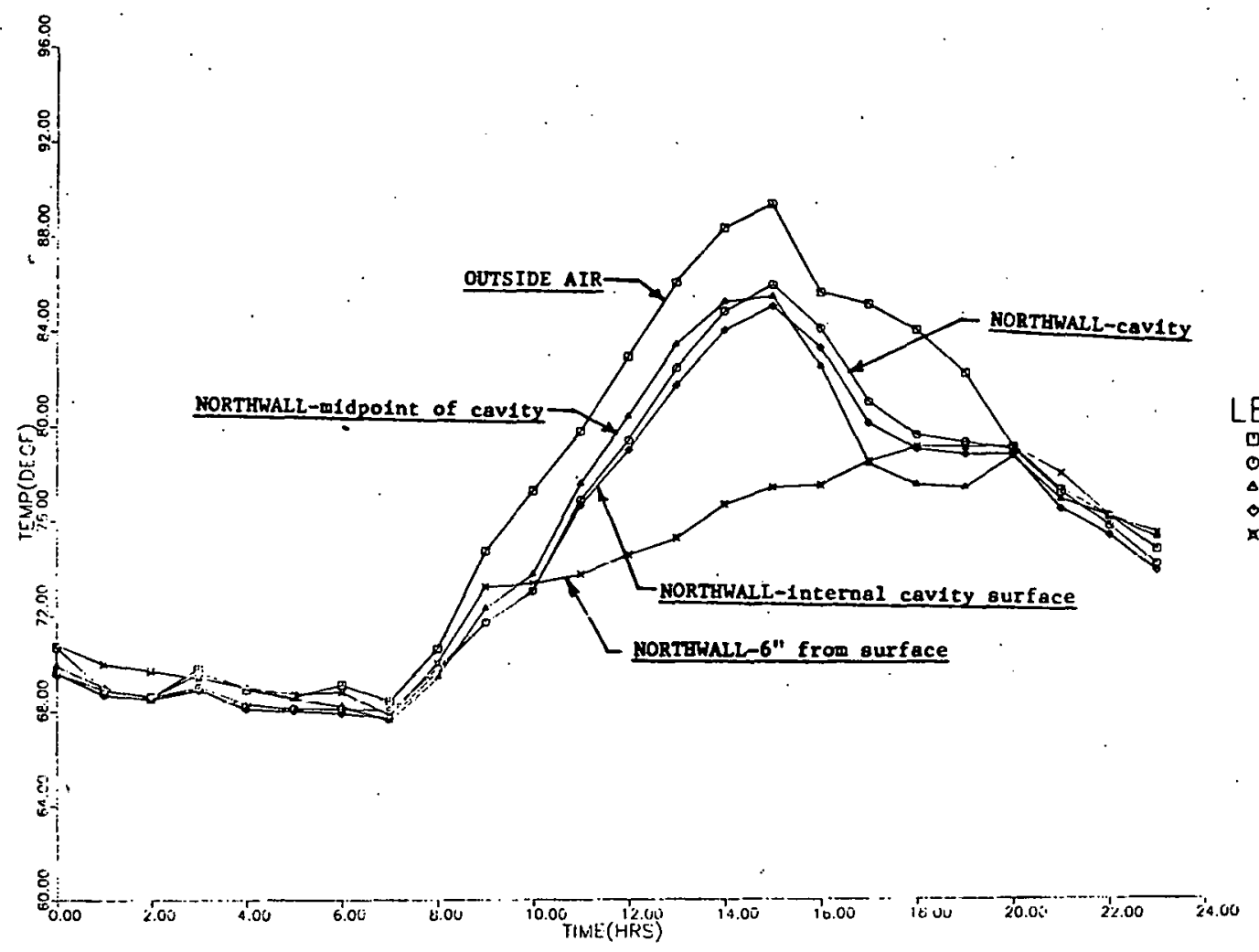

LEGEND

o statio: 6

- statior: 4 i

AT:O:; 4

- STATive.

a station.

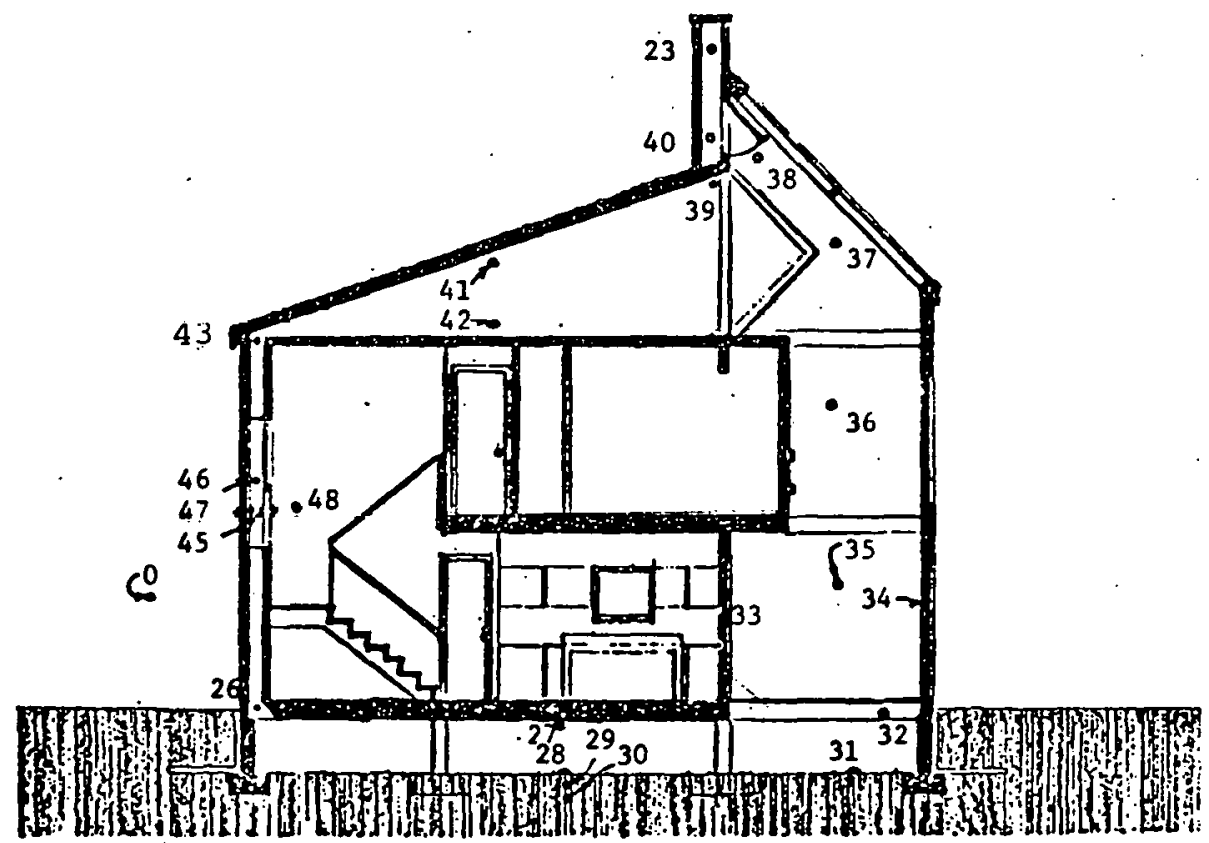

THERMOCOUPLE LOCATION - SECTION THRU STAIR

135

${ }_{0}{ }_{2}=\mathrm{ft}$. 


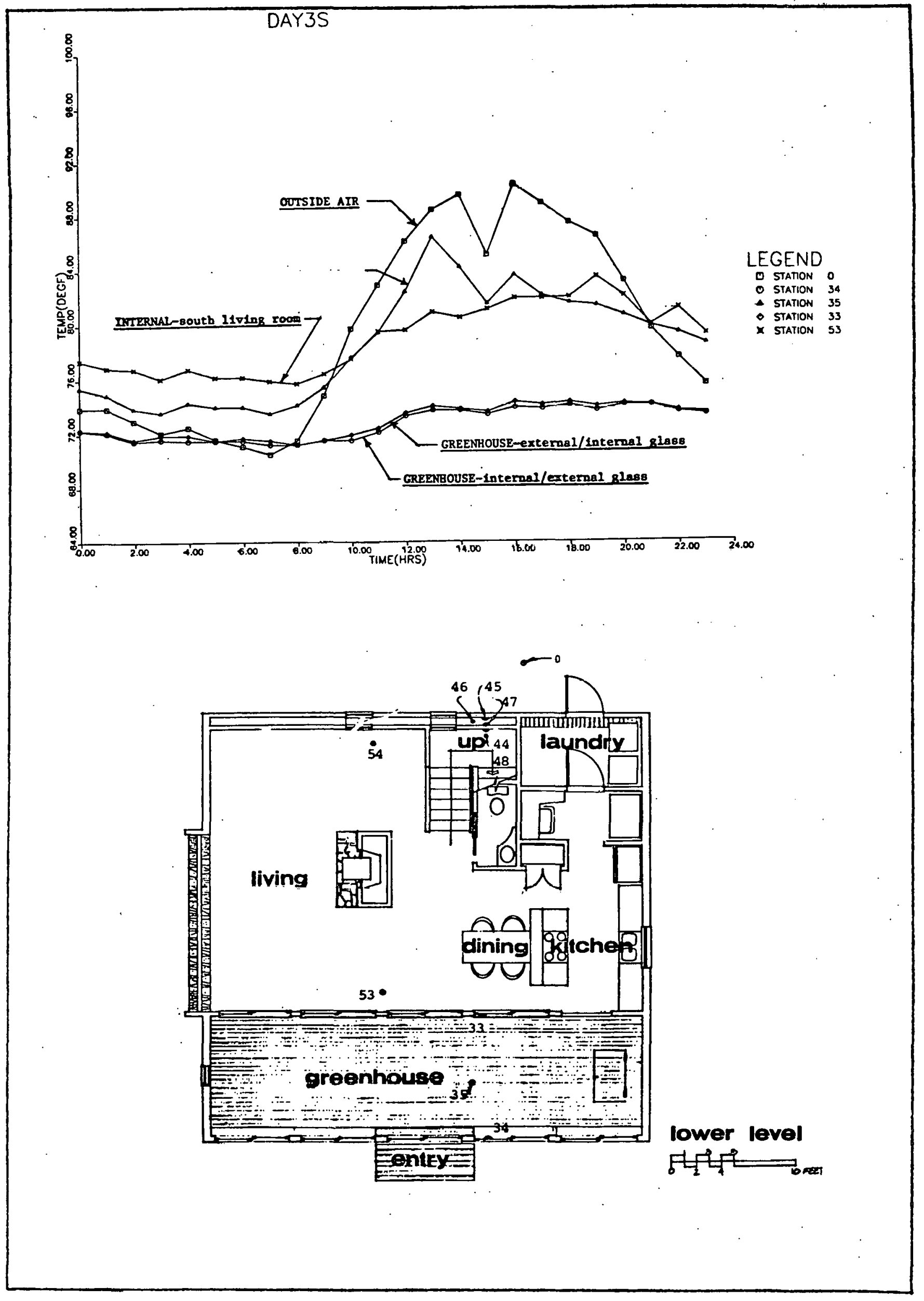



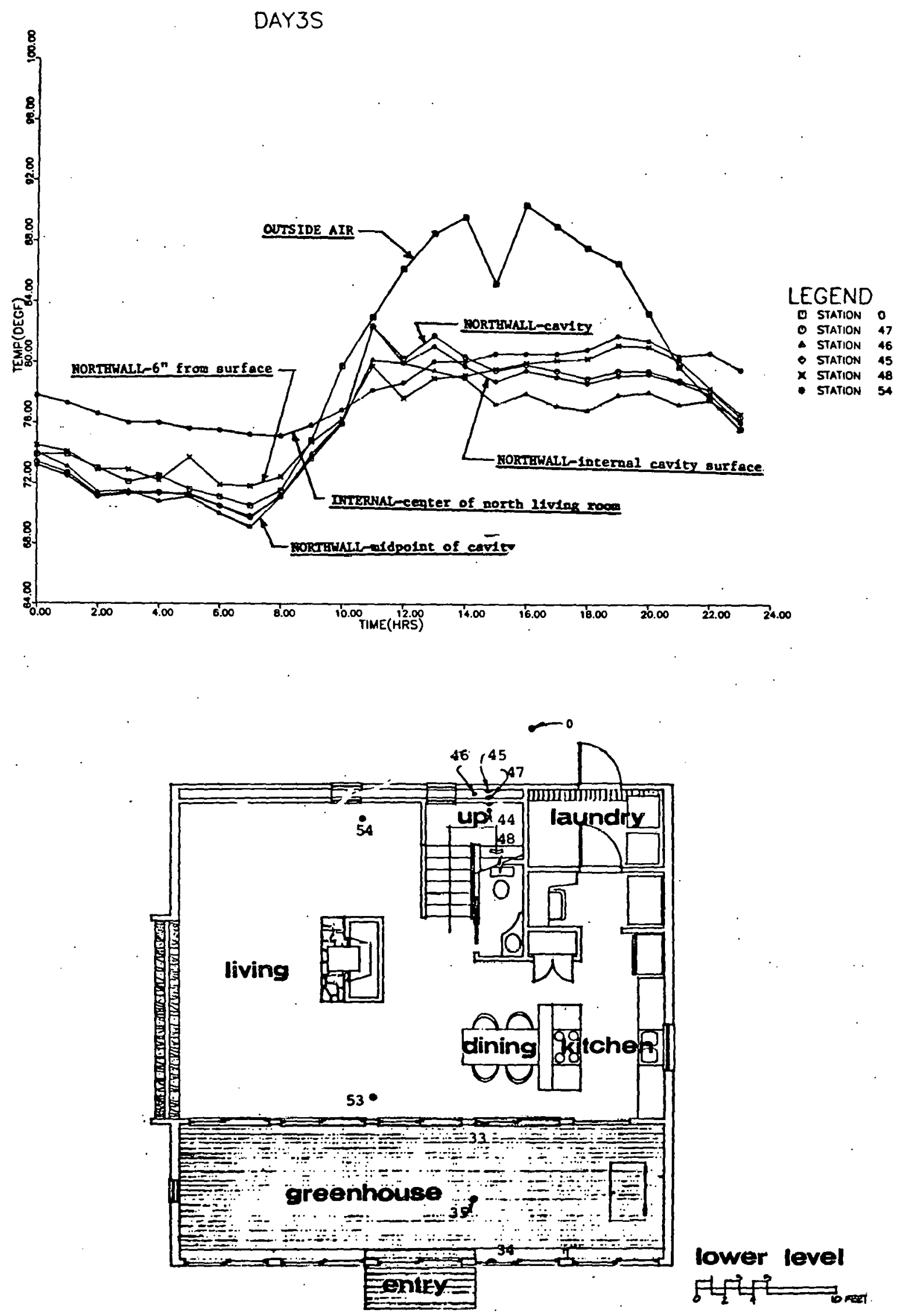

lower level 年证 


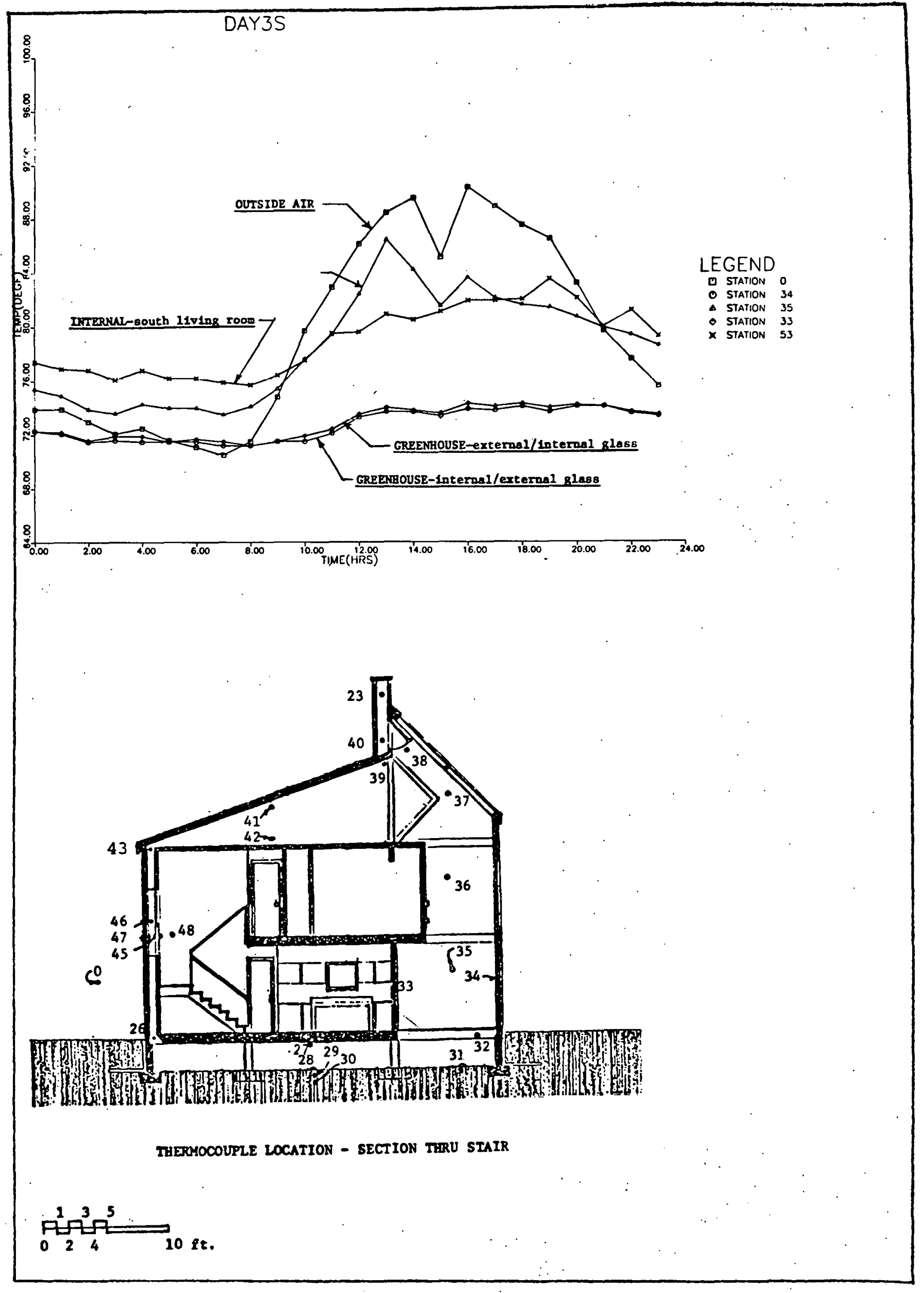




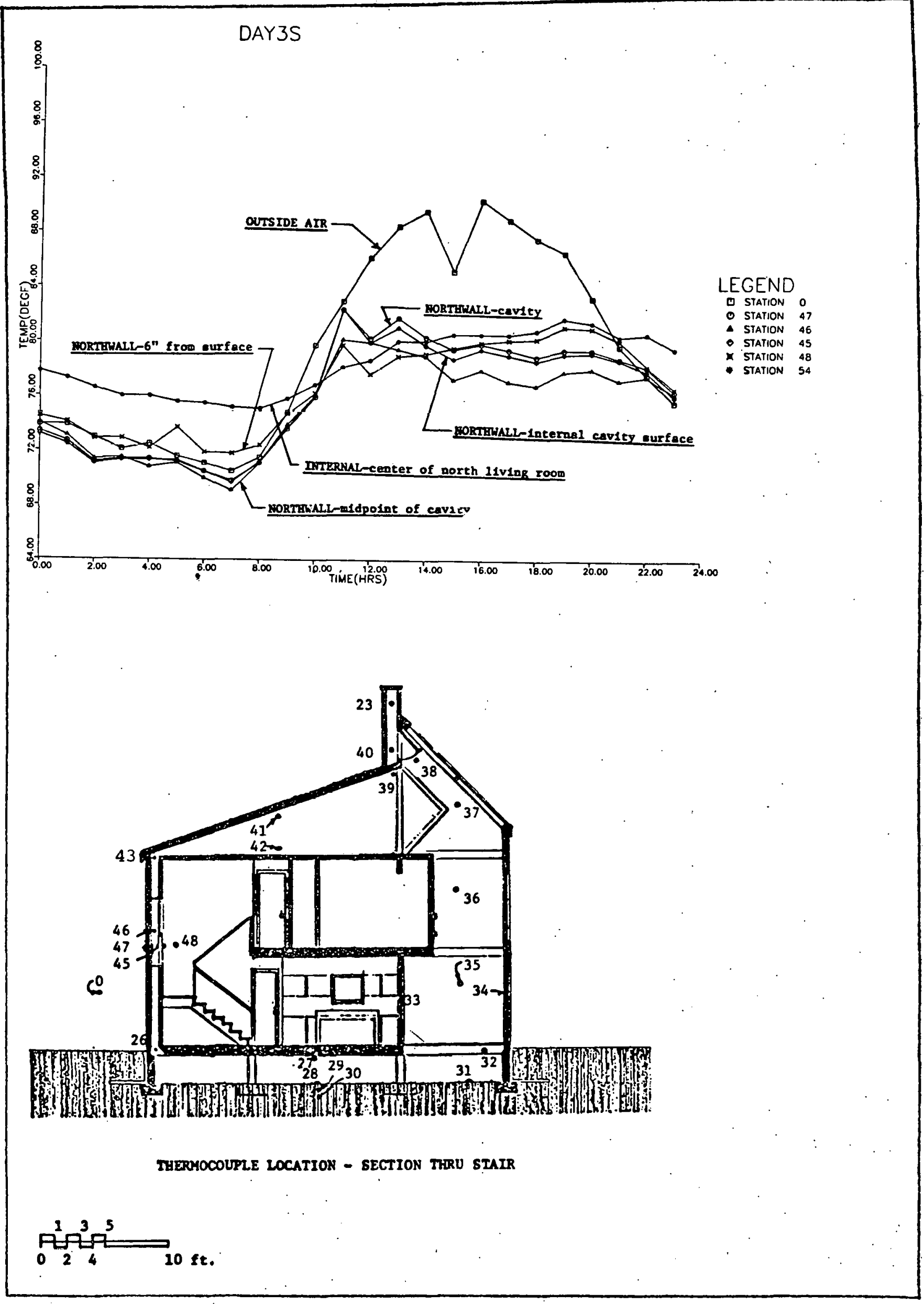




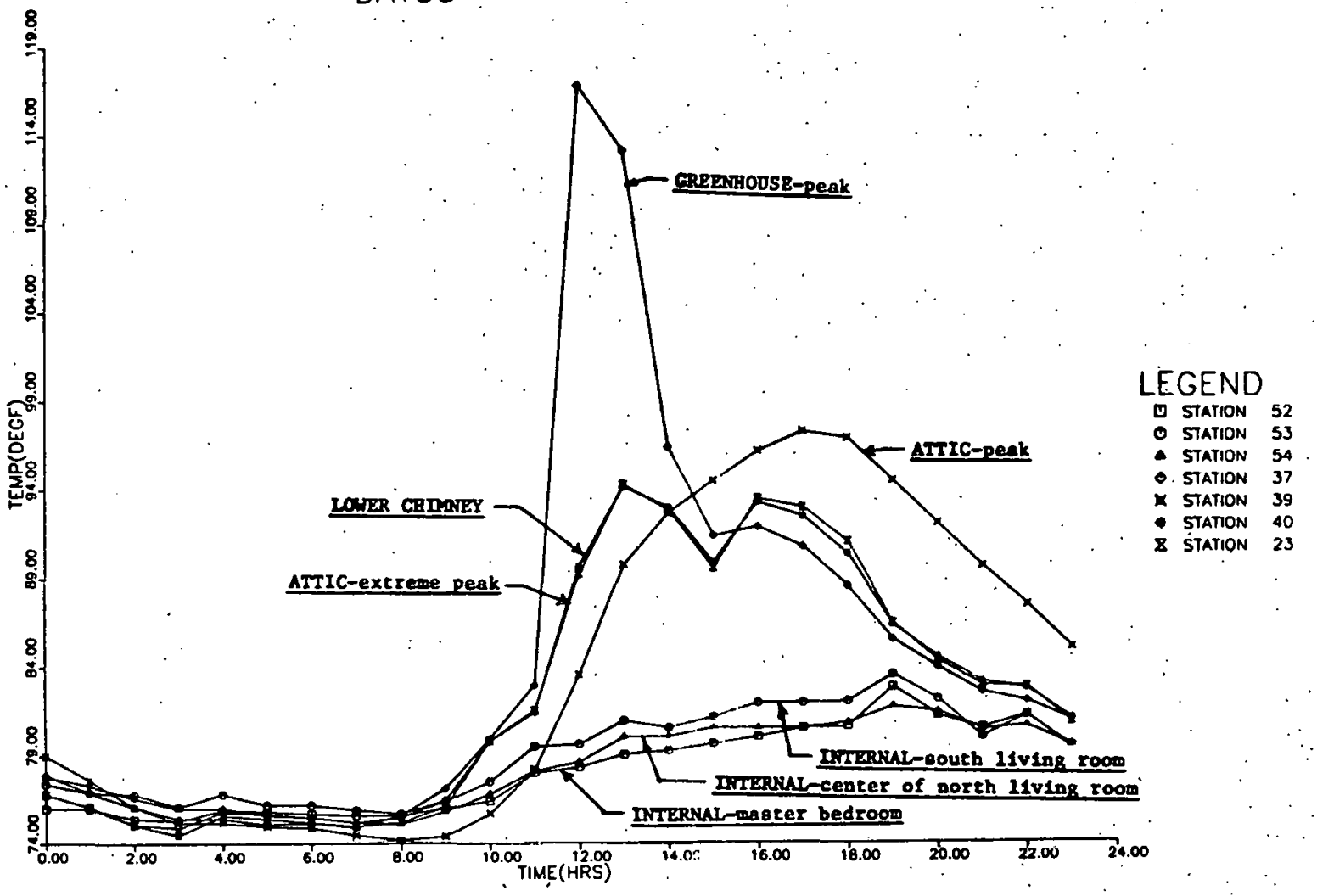

\section{DAY3S}

station 53

station 54

- STATION 40

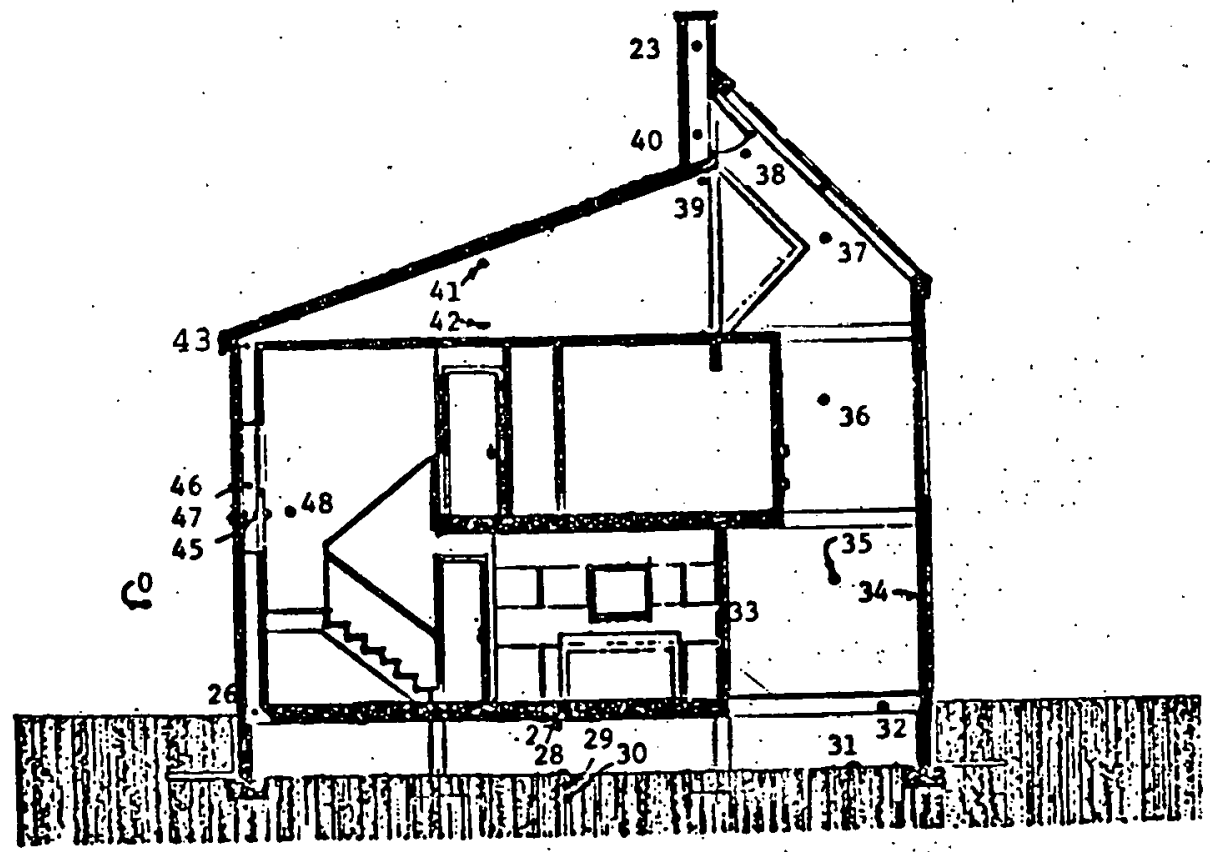

IAERMOCOUPLE LOCATION - EECIION TIRU STATR

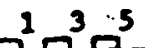

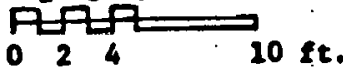




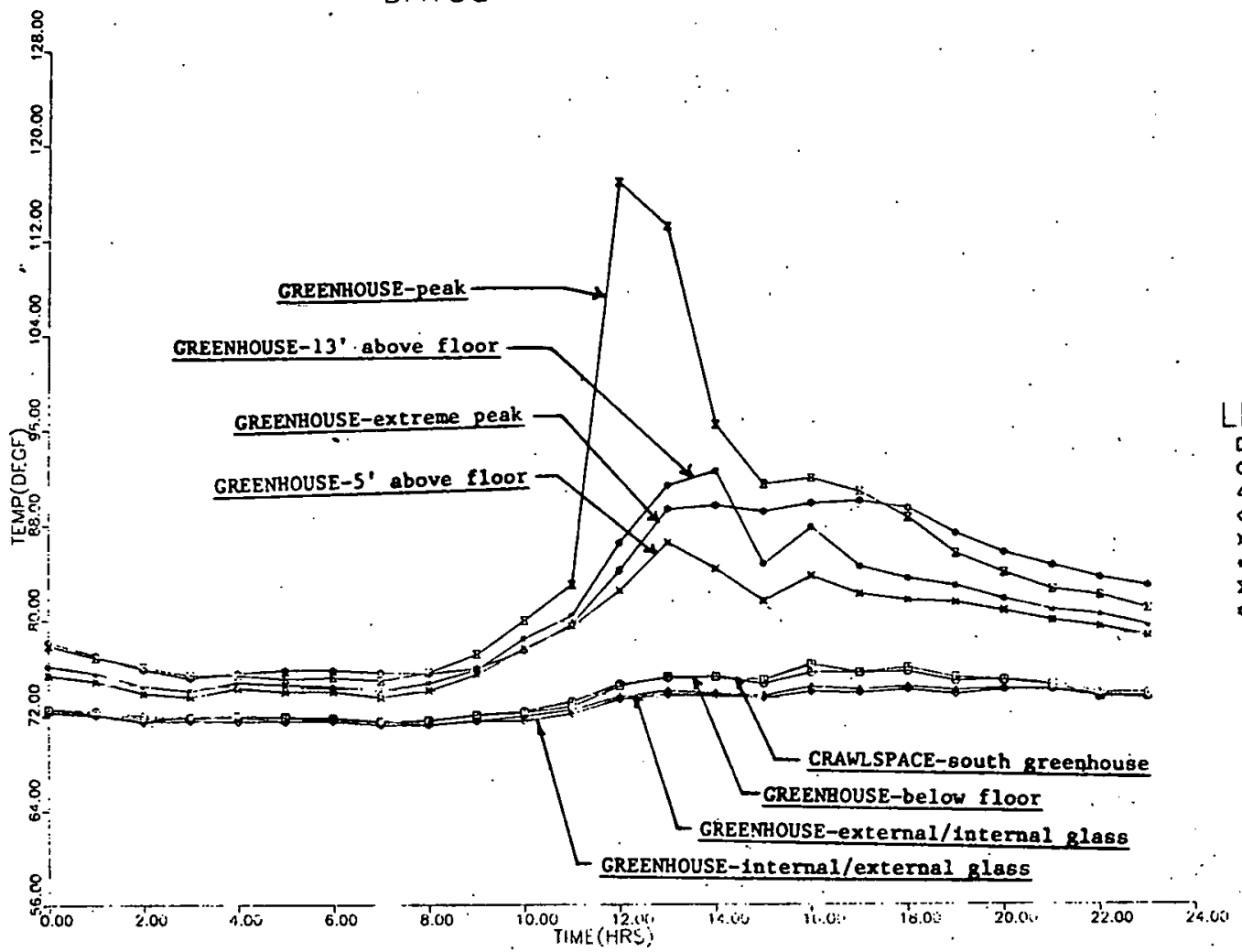

LEGELI: O STALU: : - Staticir je

- STATHE. 33

- STaritis $\because$

a staie: 5 st.

- 5 T2 $\because \quad 3$

8 SIAli: $\quad \therefore$

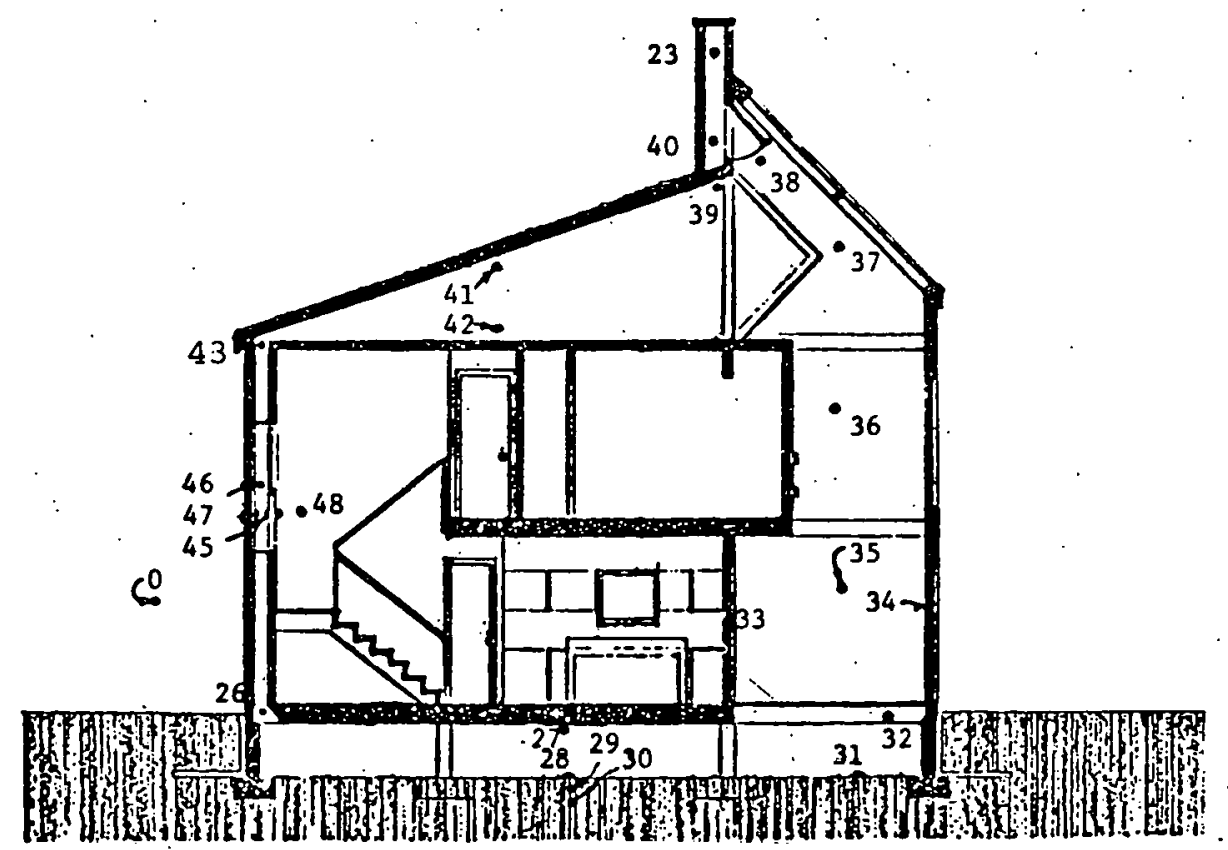

THERMOCOUPLE LOCATION - SECTION THRU STAIR

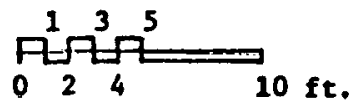



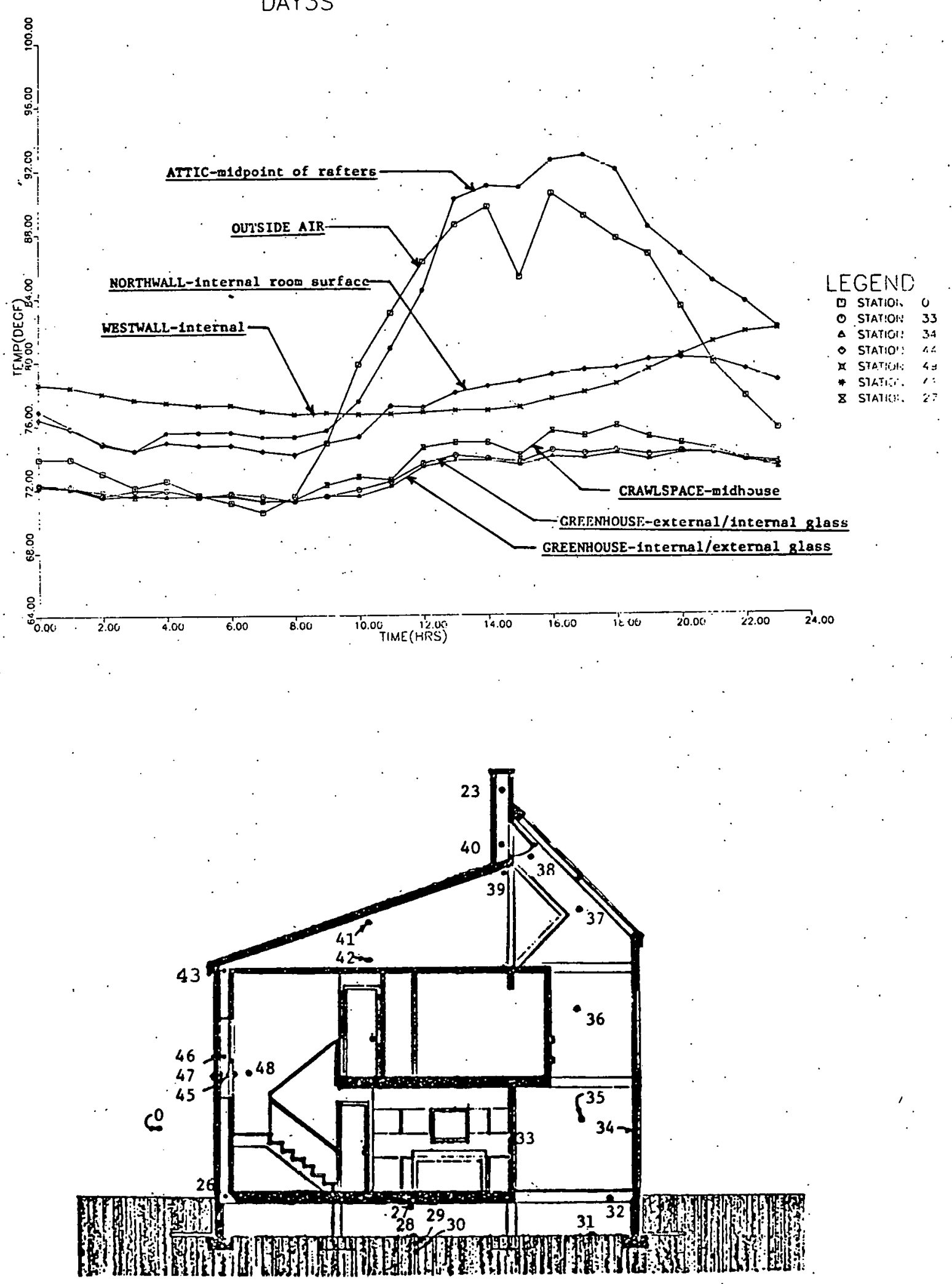

THERMOCOUPLE LOCATION - SECTION THRU STAIR

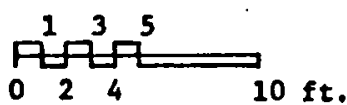


DAY3S
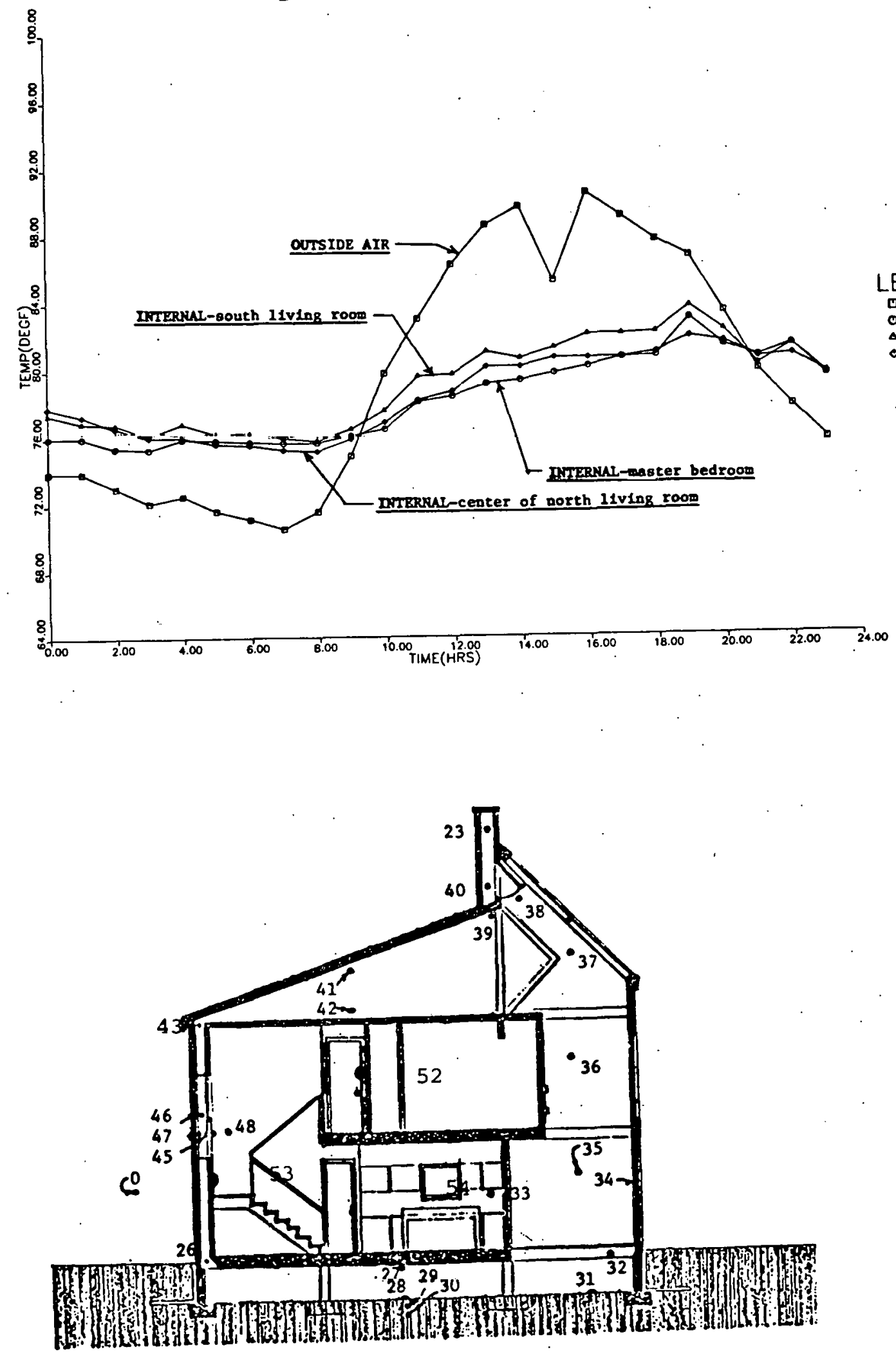

THERMOCOUPLE LOCATION - SECTION THRU STAIR

$1^{3}{ }^{5}$ $\operatorname{lin}_{24} 20$ \&t. 

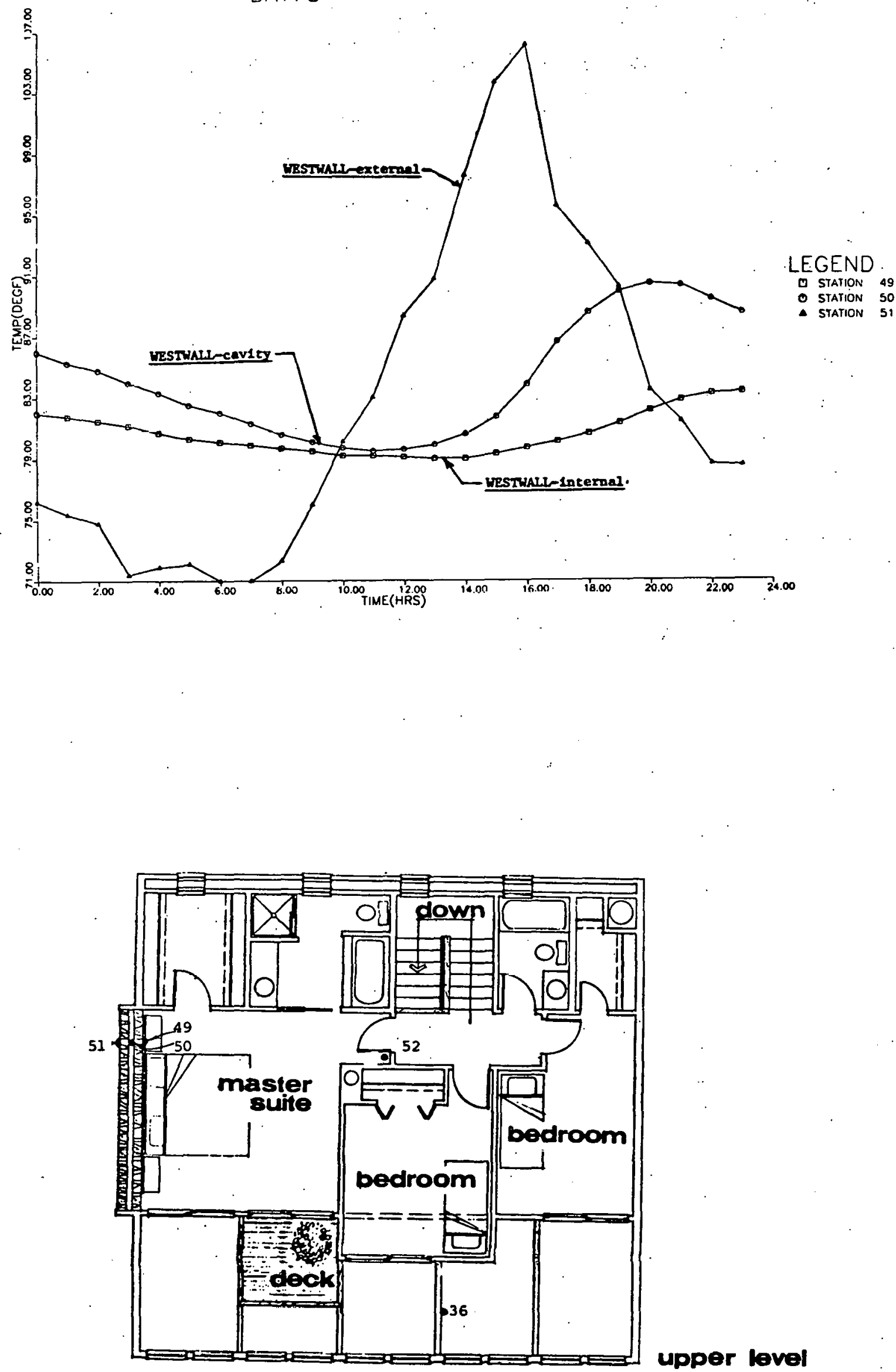

upper level 
DAYTS

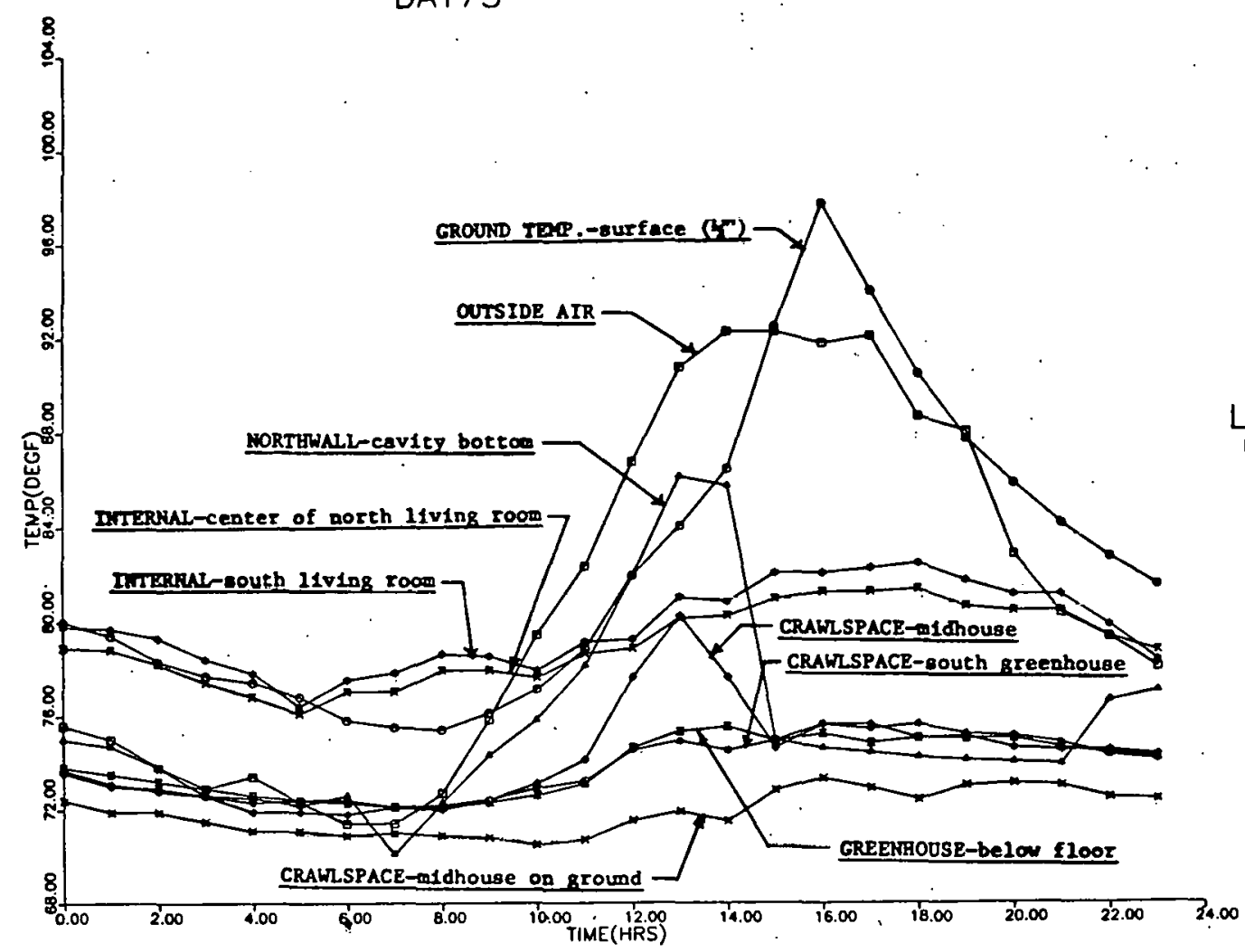

LEGEND

D STATION 0

- station 22

- station 26

- STATION 27

* station 28

- station 31

8 Station 32

- Station 53

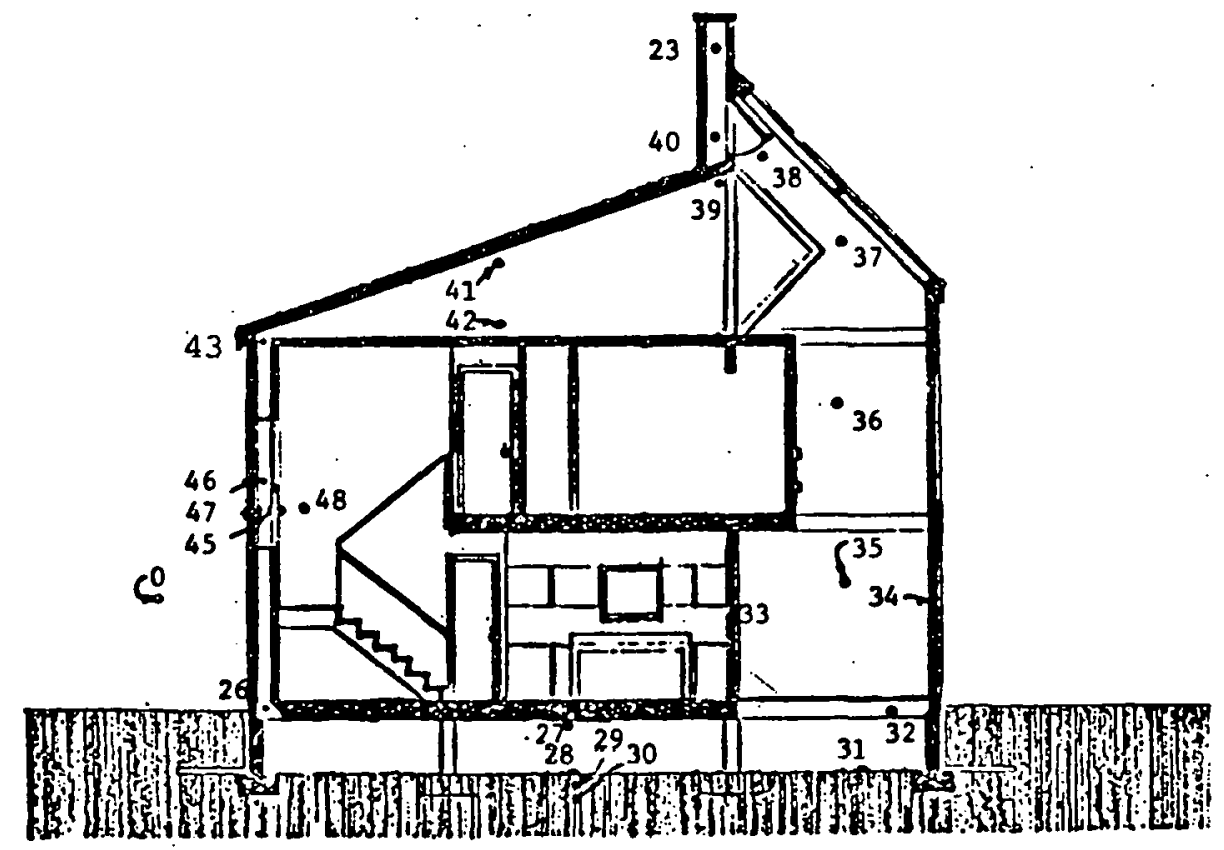

THERMOCOUPLE LOCATION - SECTION THRU STAIR

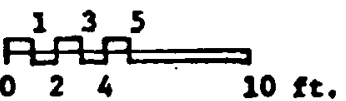




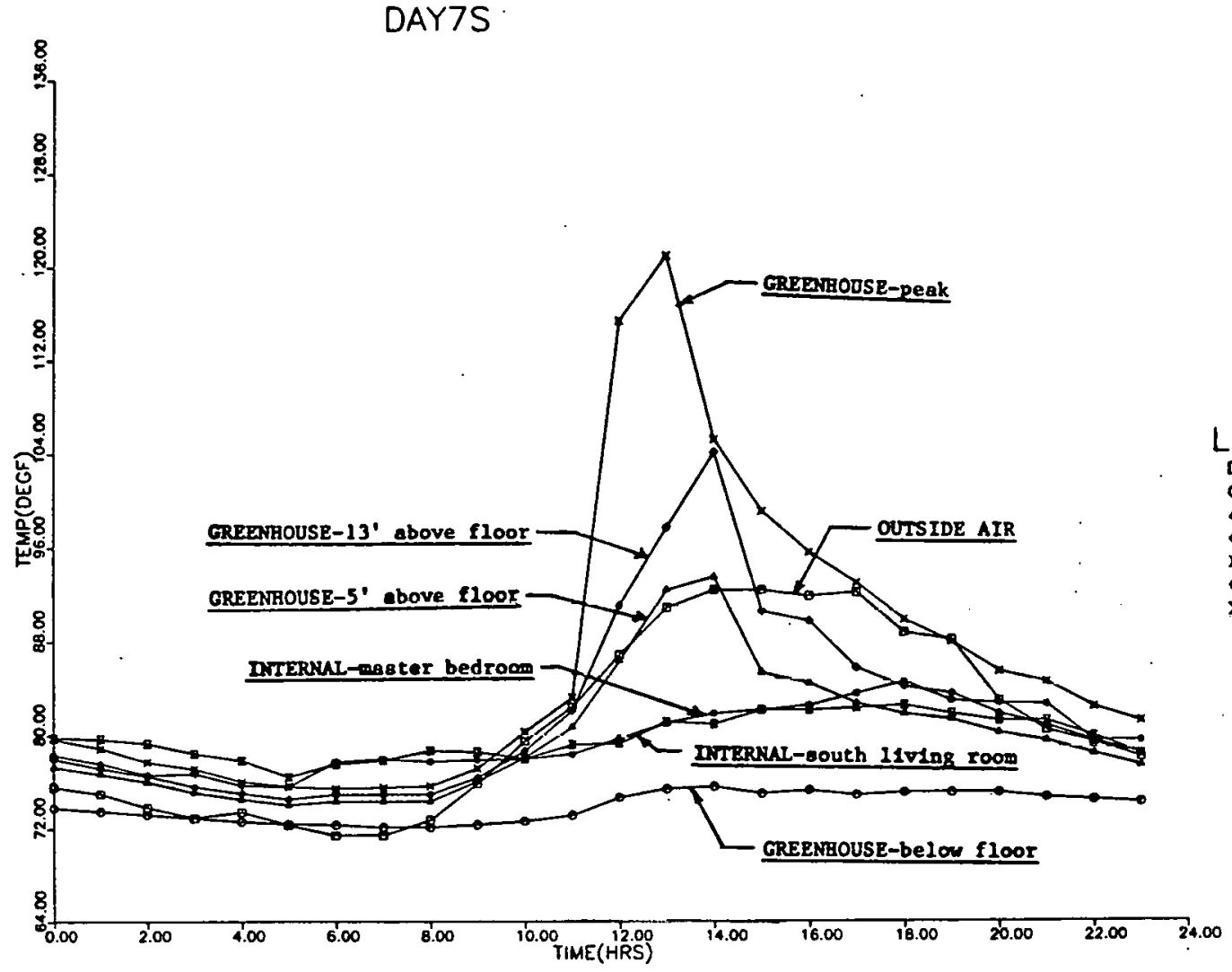

LEGEND

D STATION 0

- STATION 32

- STATION 35

- station 36

X STATION 37

- station 52

8 STATION 53

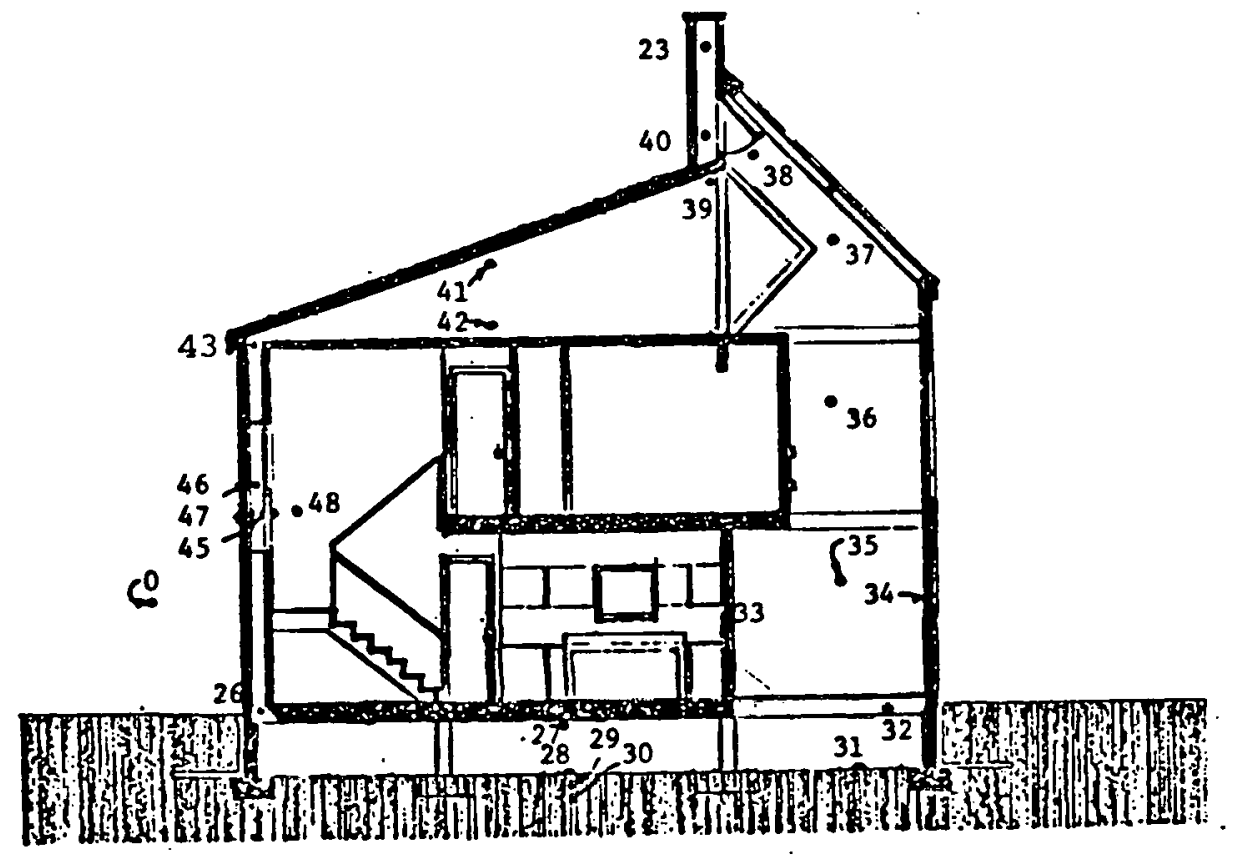

THEPOMOCOUPLE LOCATION - SECTION THRU STATR

135

?2:

024

$10 \mathrm{et}$. 


\section{DAY 45}
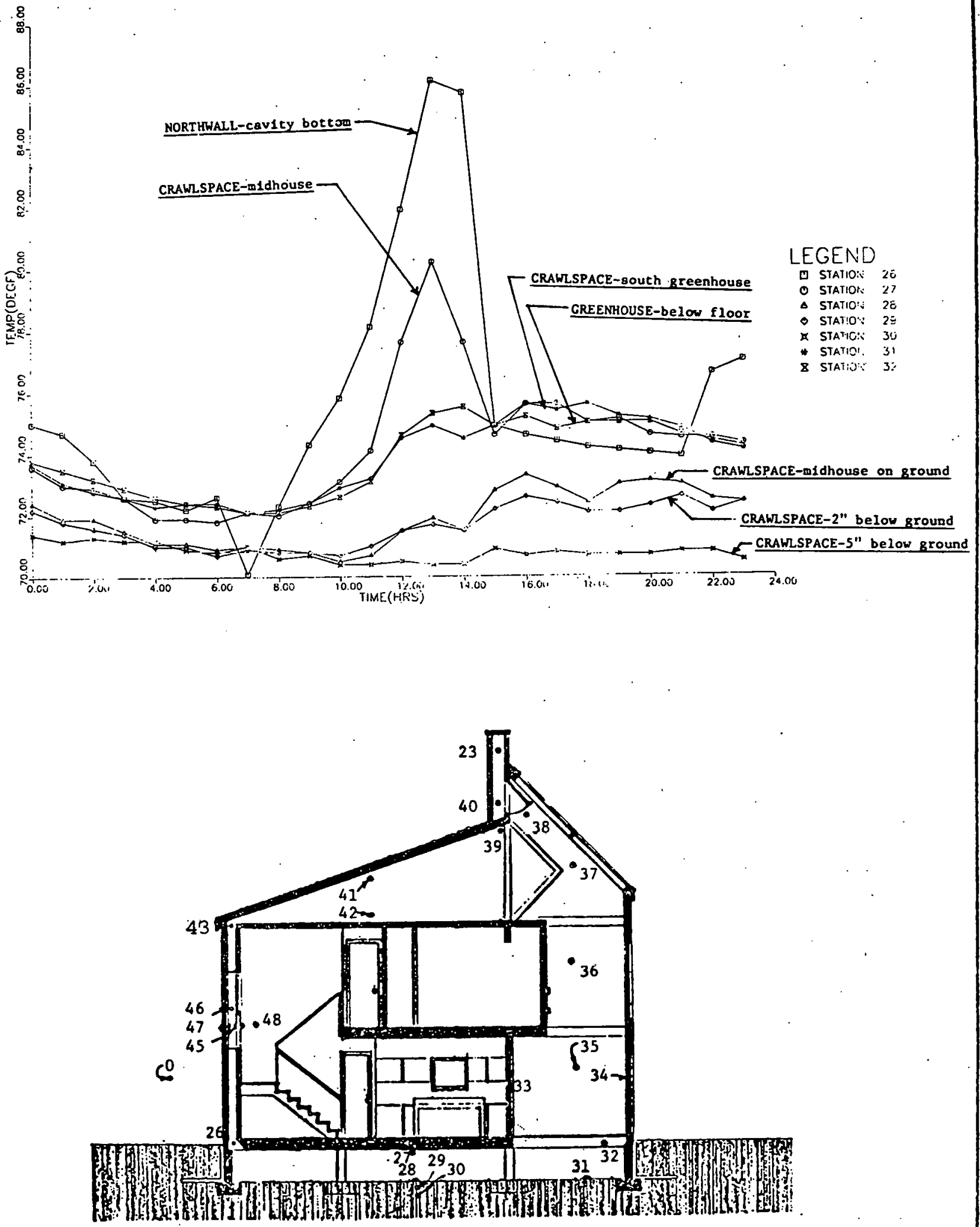

THERMOCOUPLE LOCATION - SECTION THRU STAIR

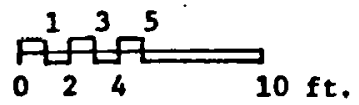




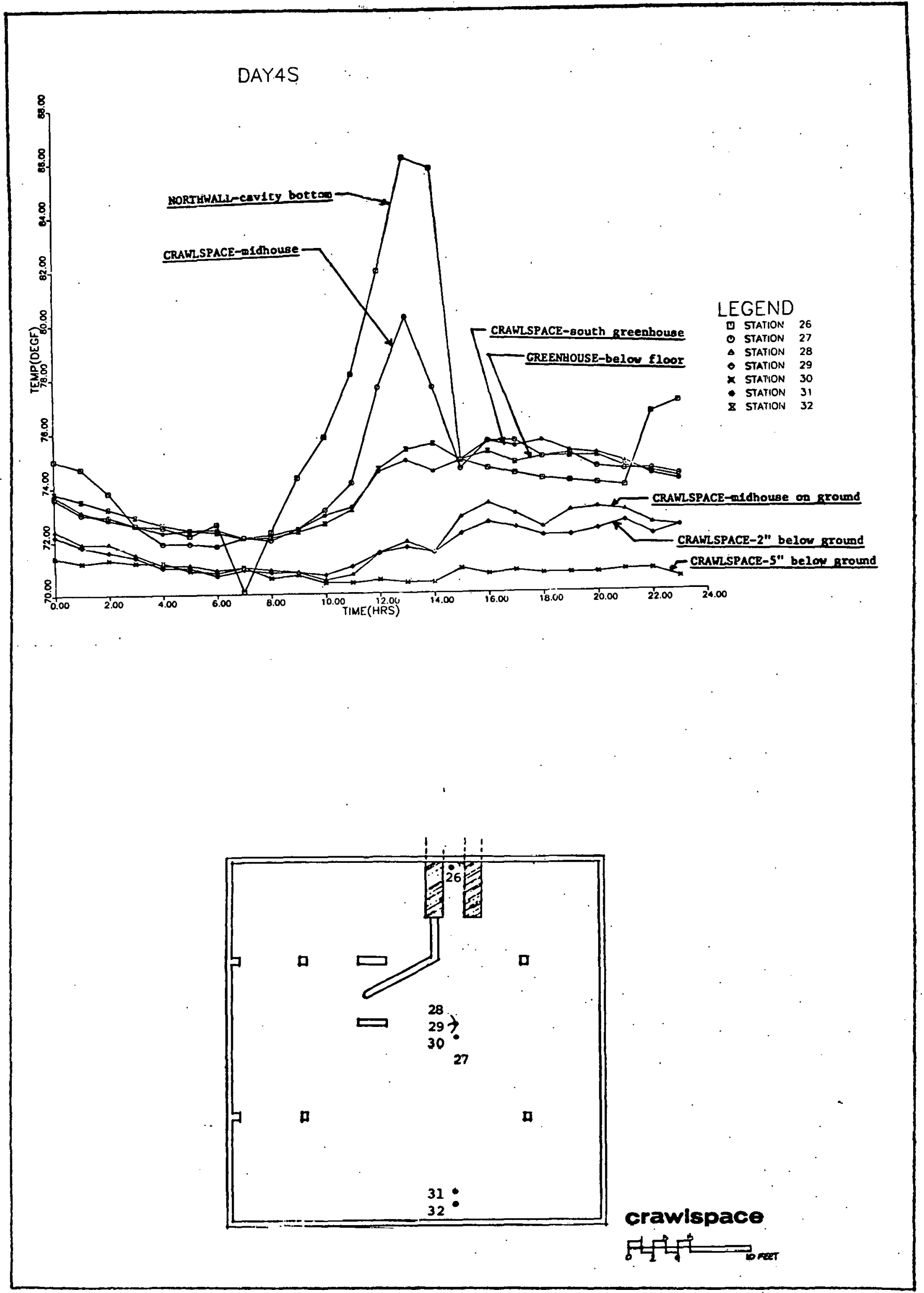




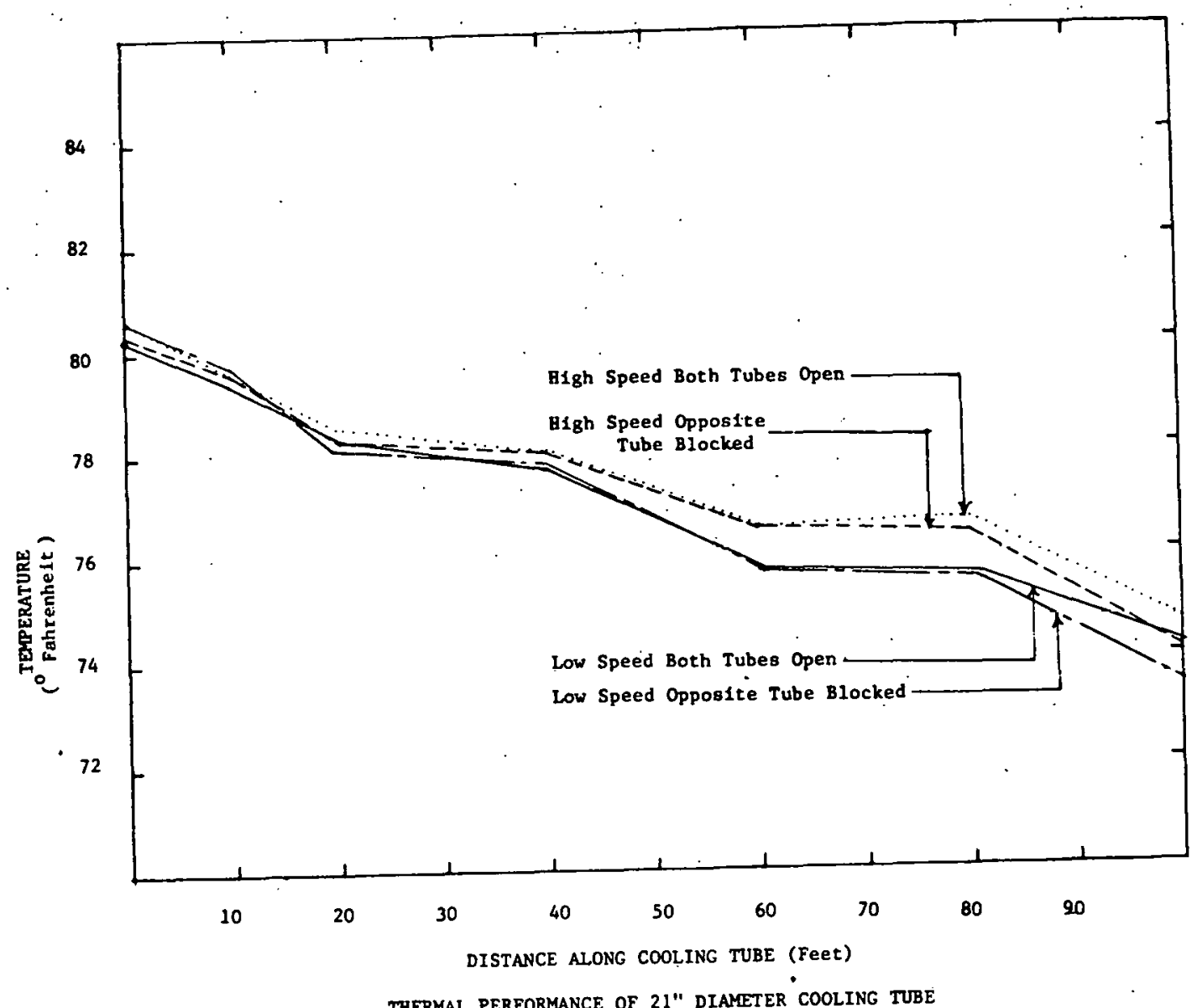

THERMAL PERFORMANCE OF 21 " DIAMETER COOLING TUBE

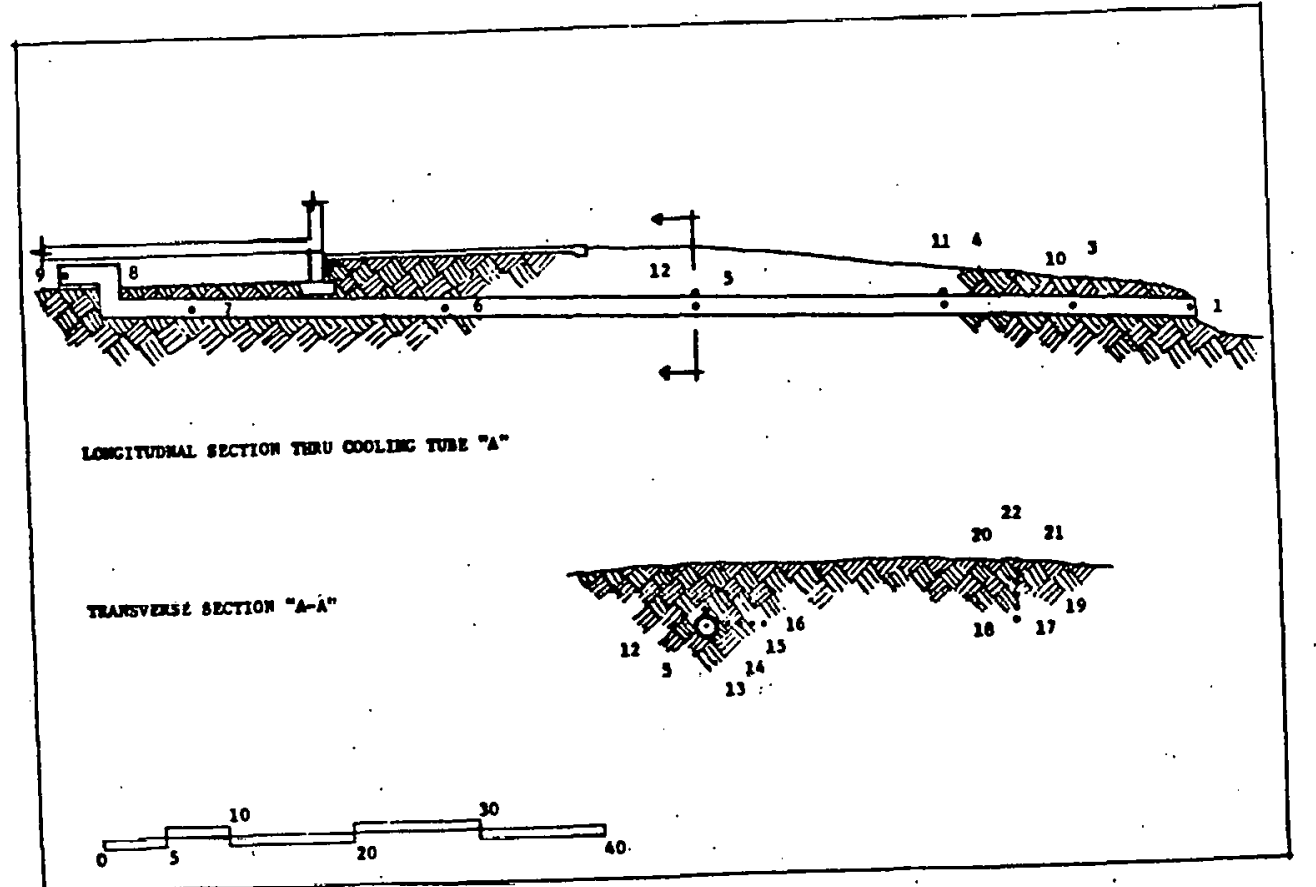




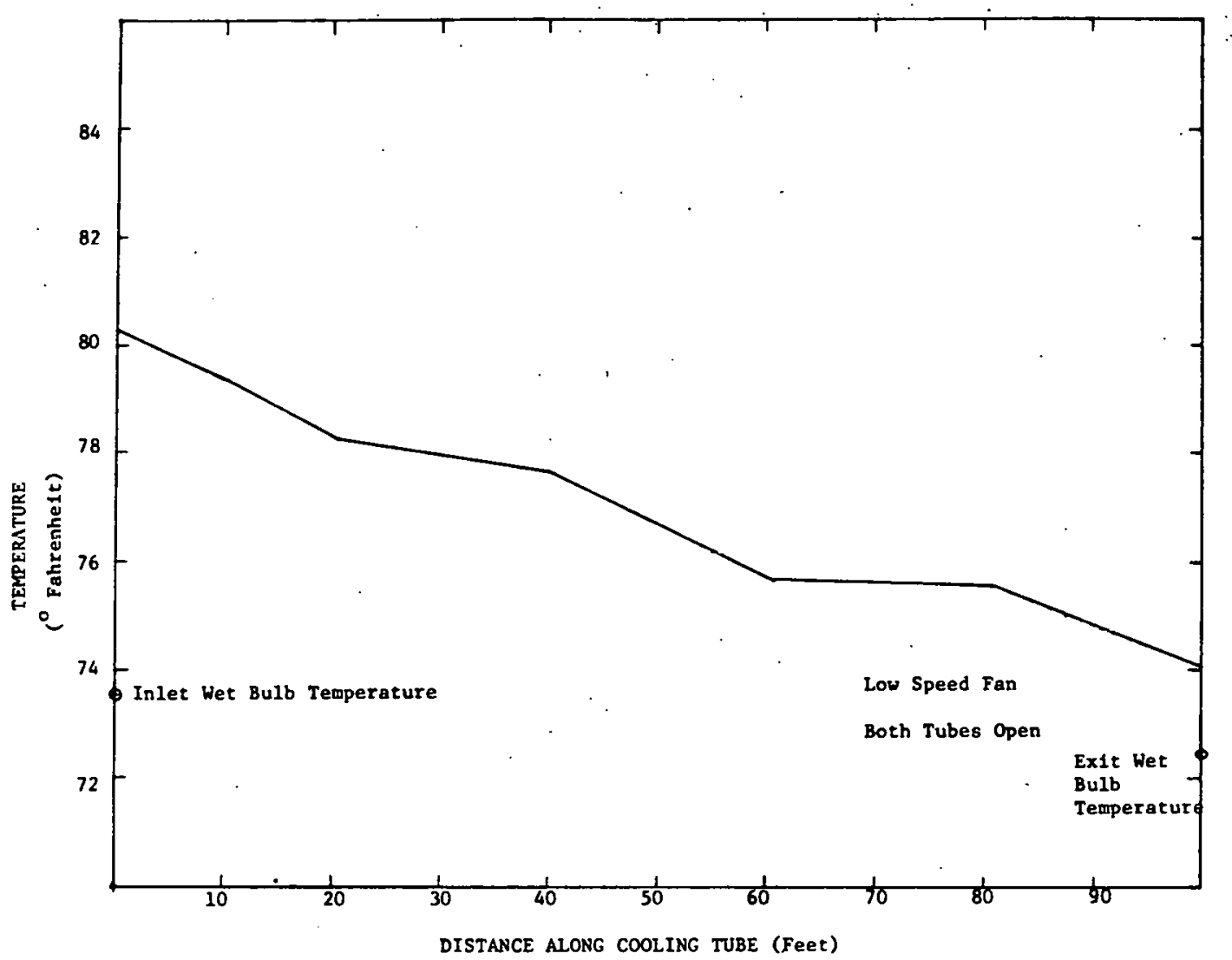

THERMAL PERFORMANCE OF 21" DLAMETER COOLINC TUBE

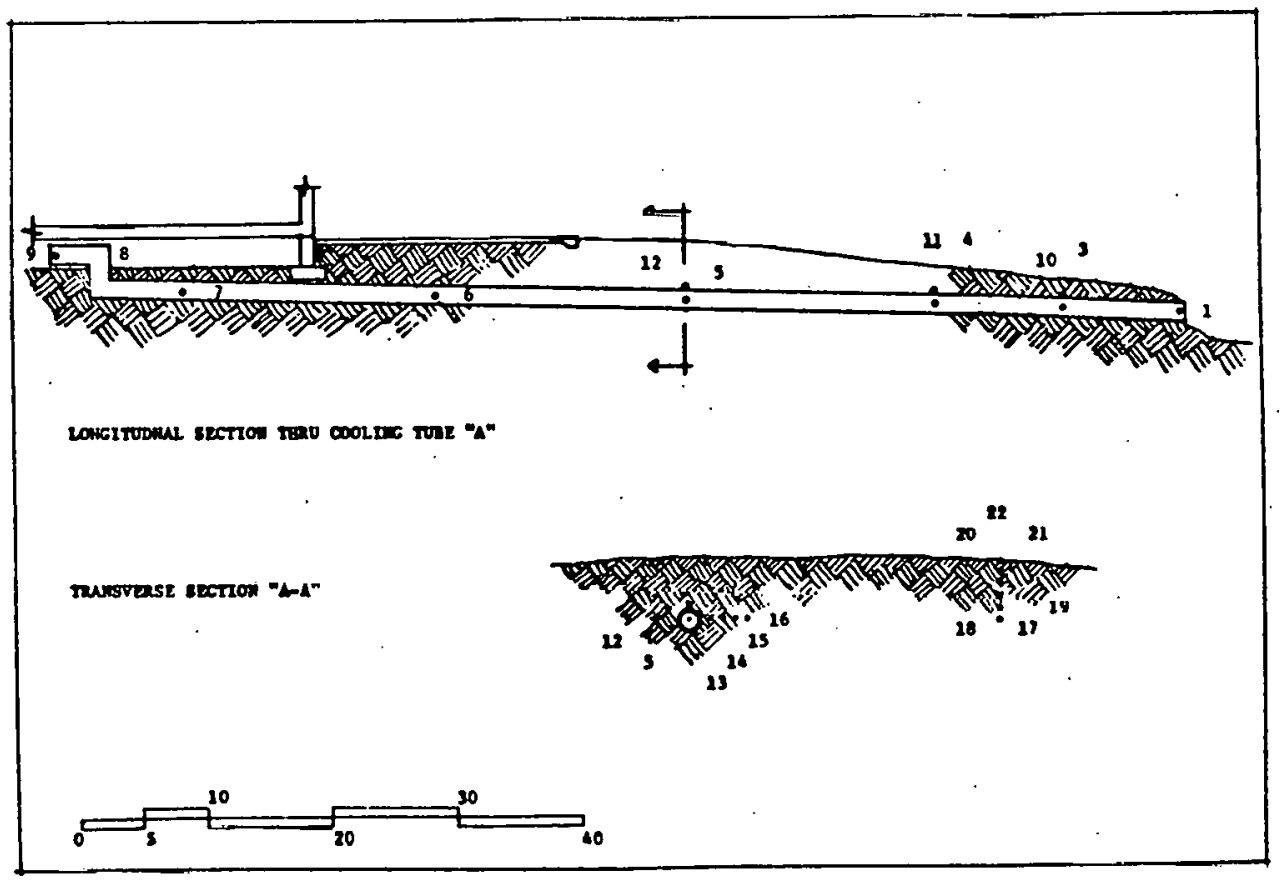




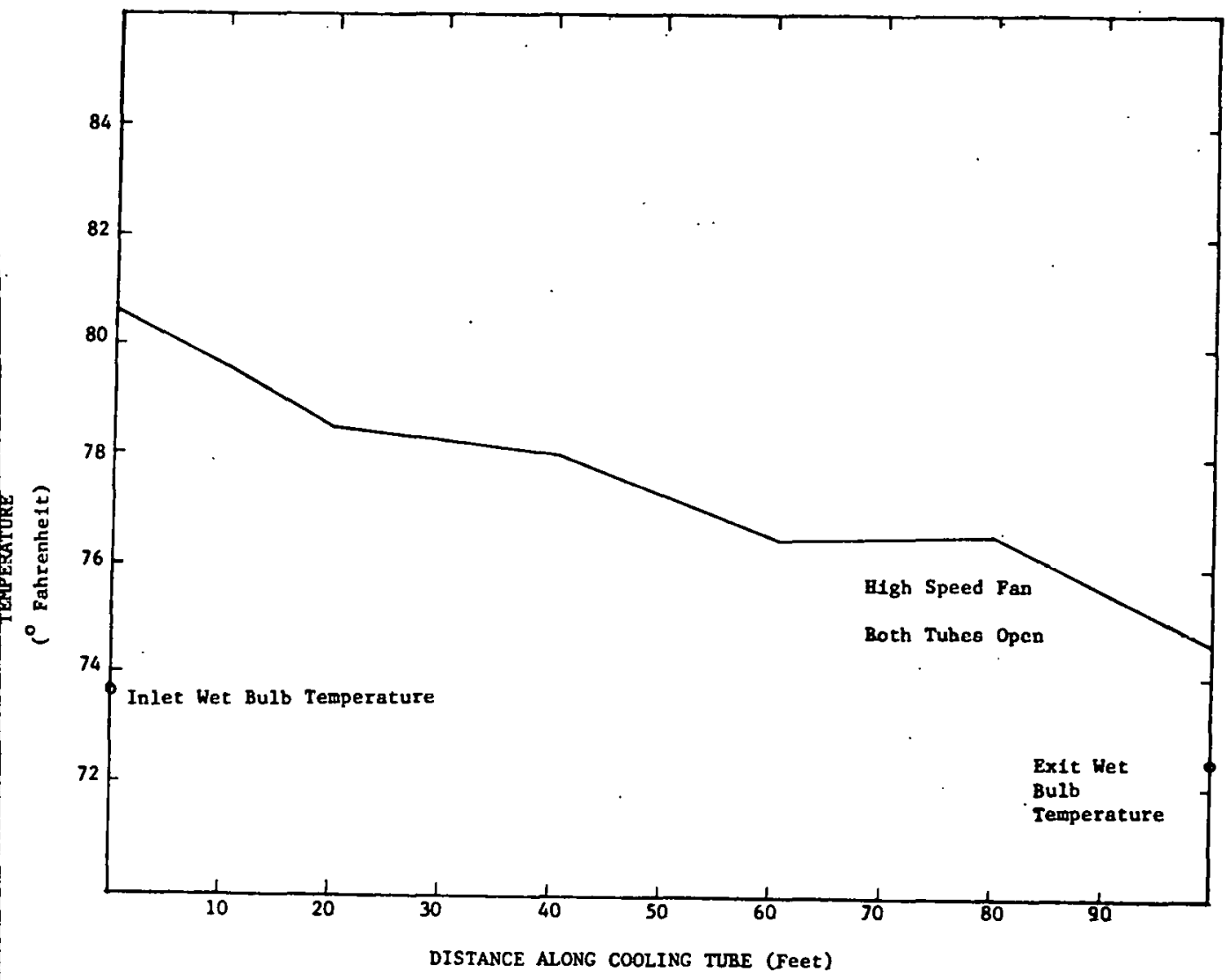

THERMAL PERFORMANCE OF 21" DLAMETER COOLING TUBE

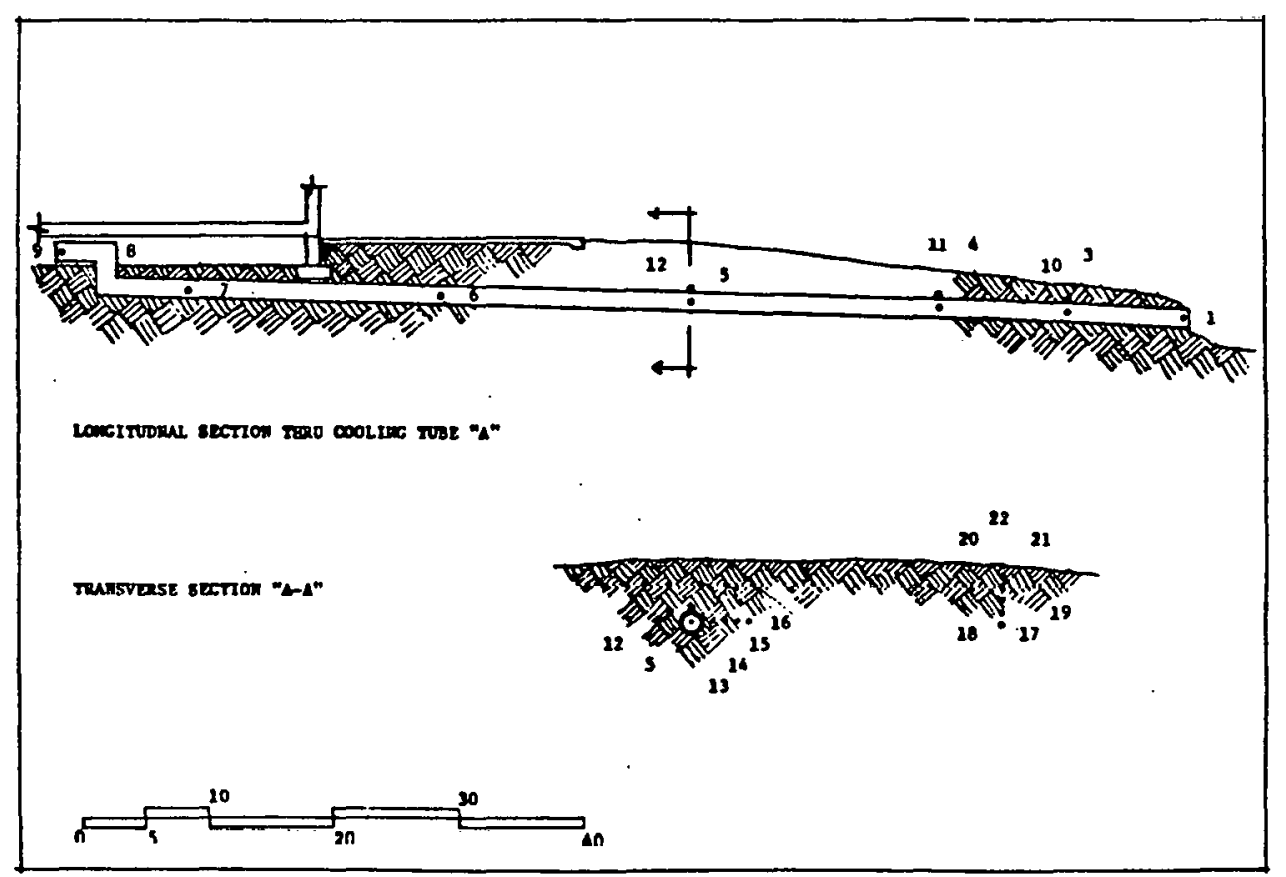




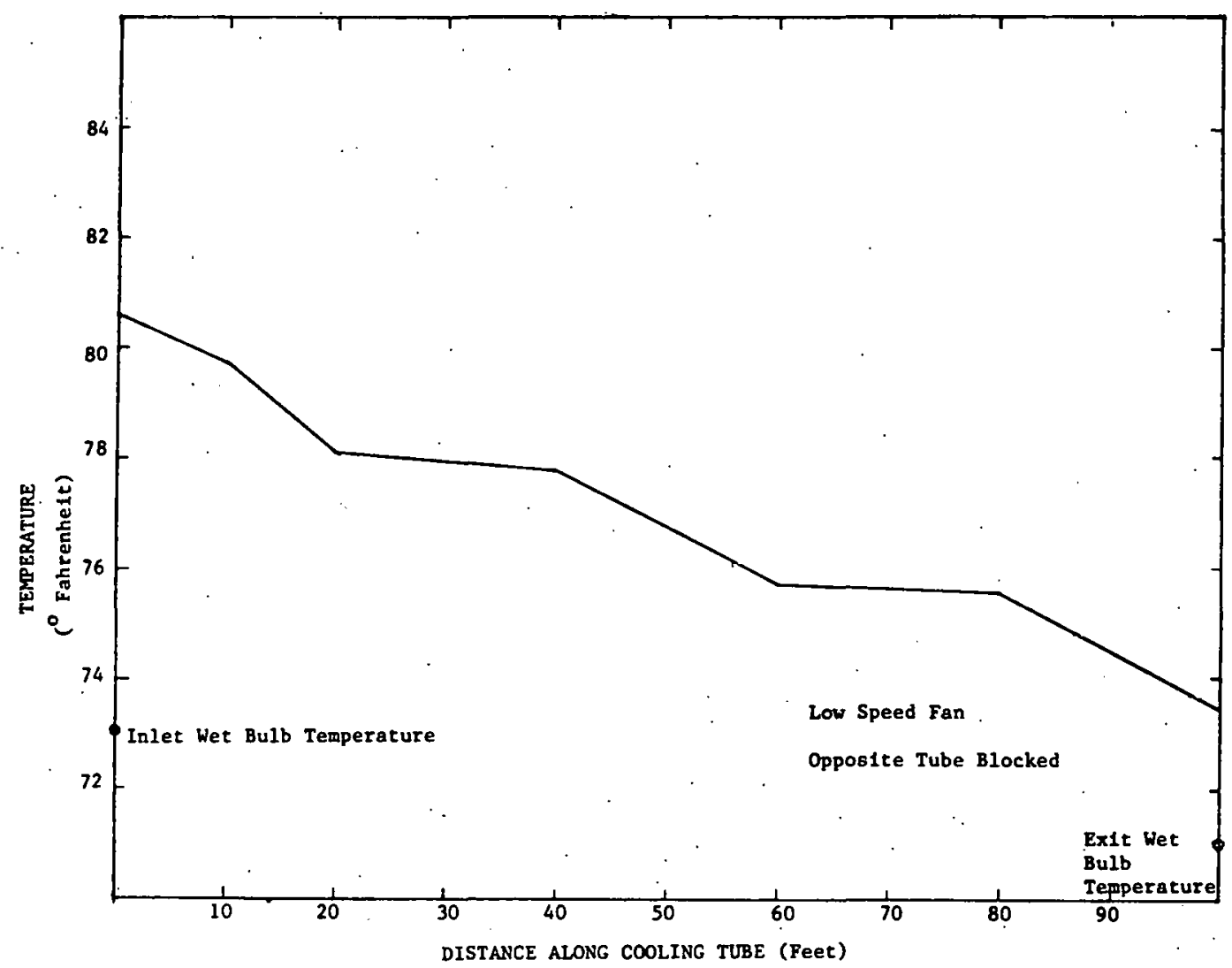

THERMAL PERFORMANCE OF 21" DIAMETER COOLING TUBE

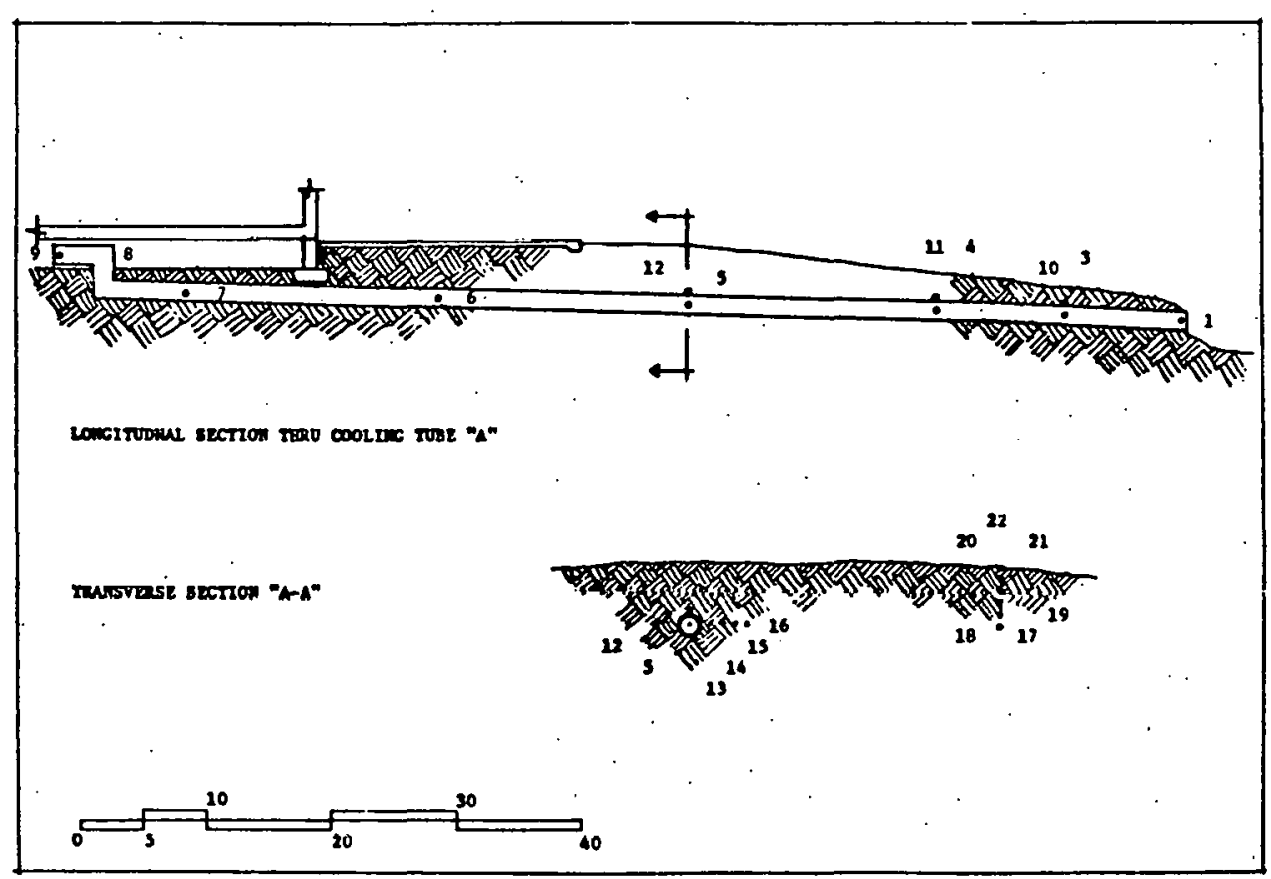




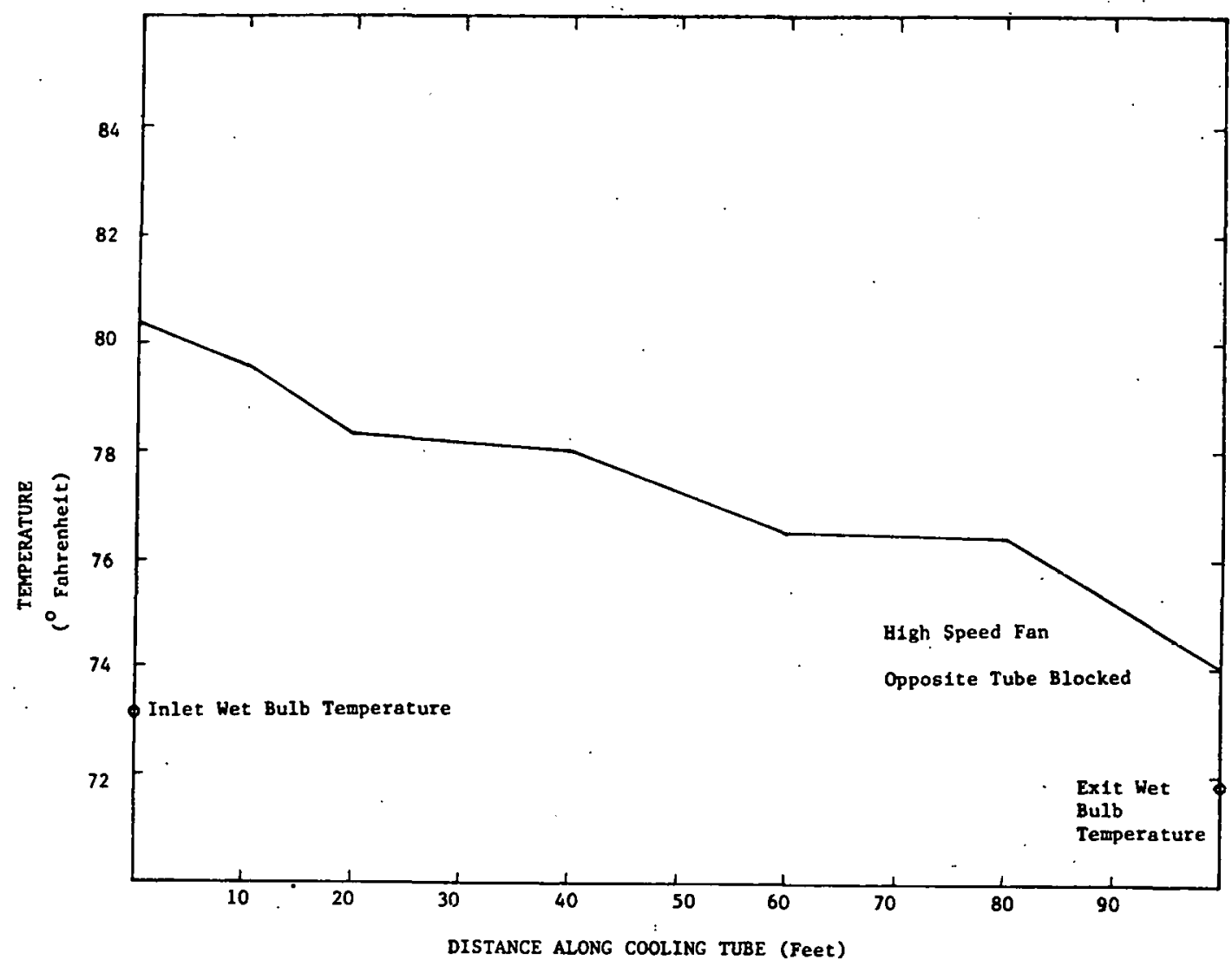

THERMAI. PERFORMANCE OF 21" DLAMETER COOLING TUBE

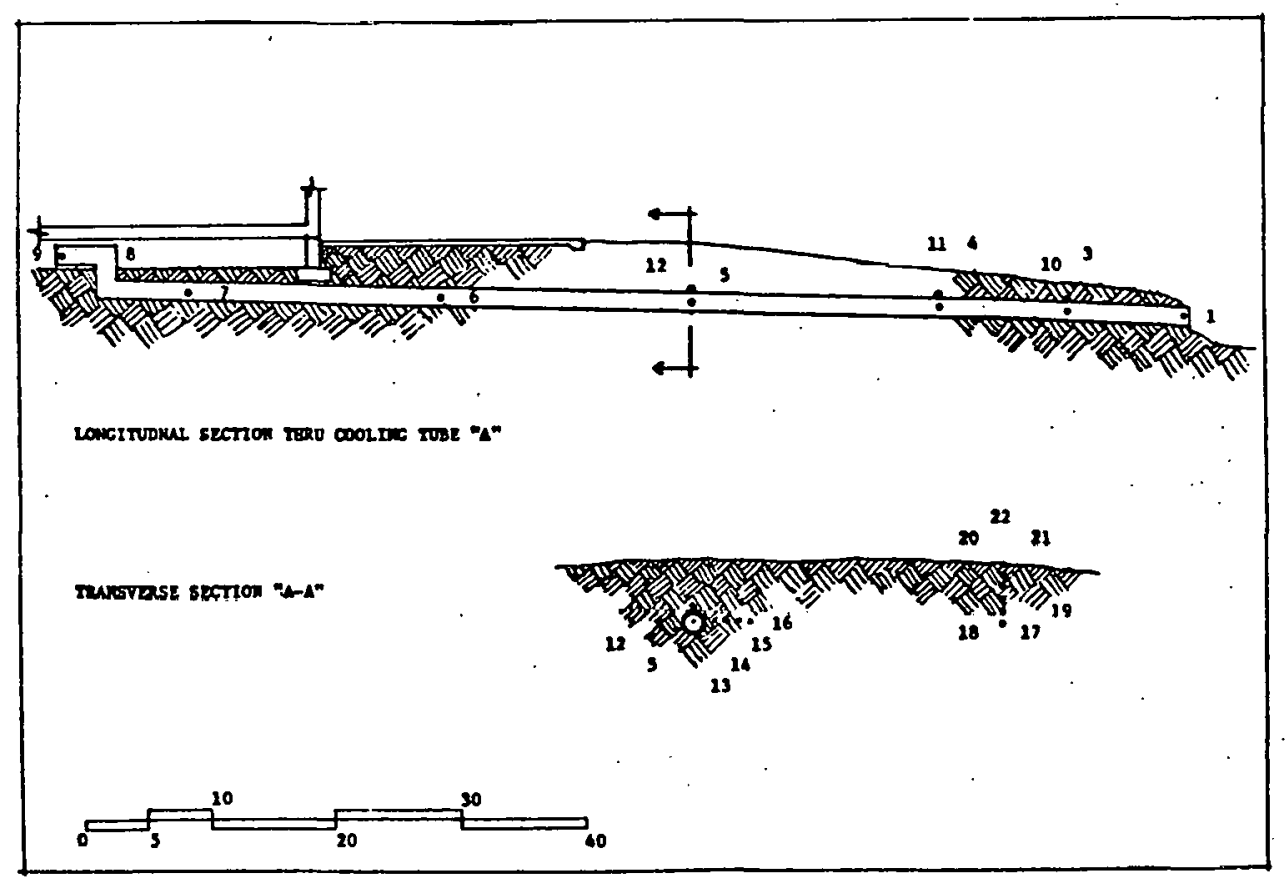




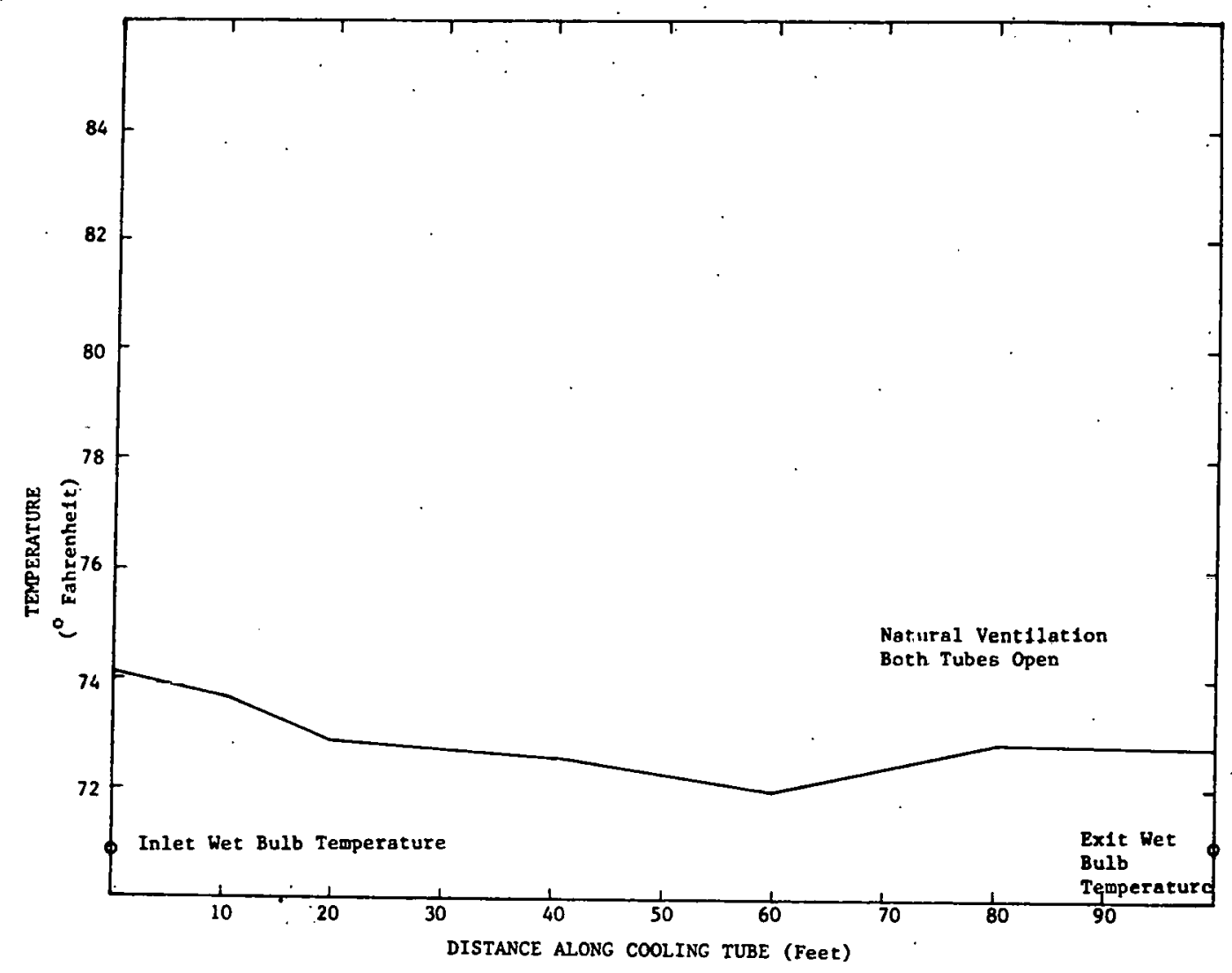

THERMAL PERFORMANCE OF 21" DLAMETER COOLING TUBE

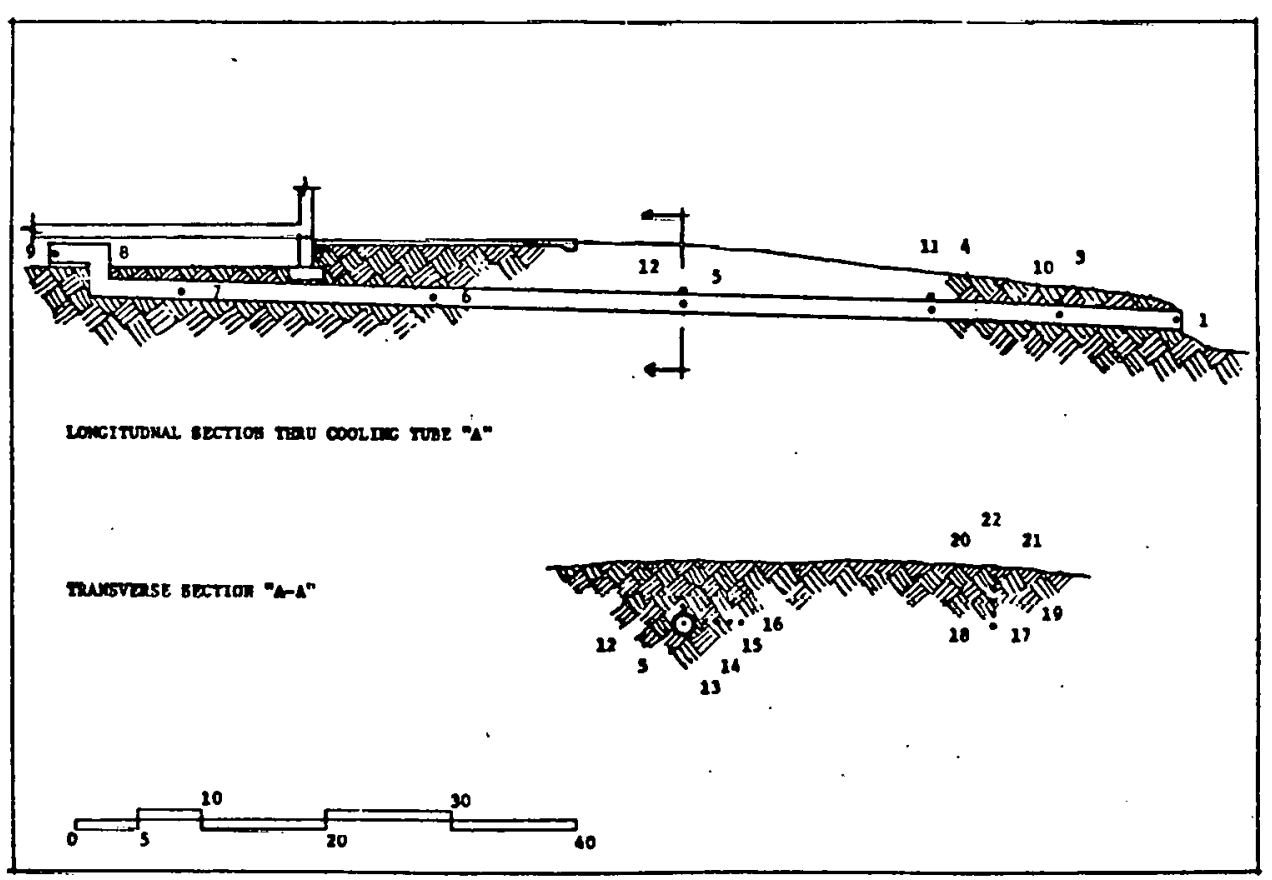




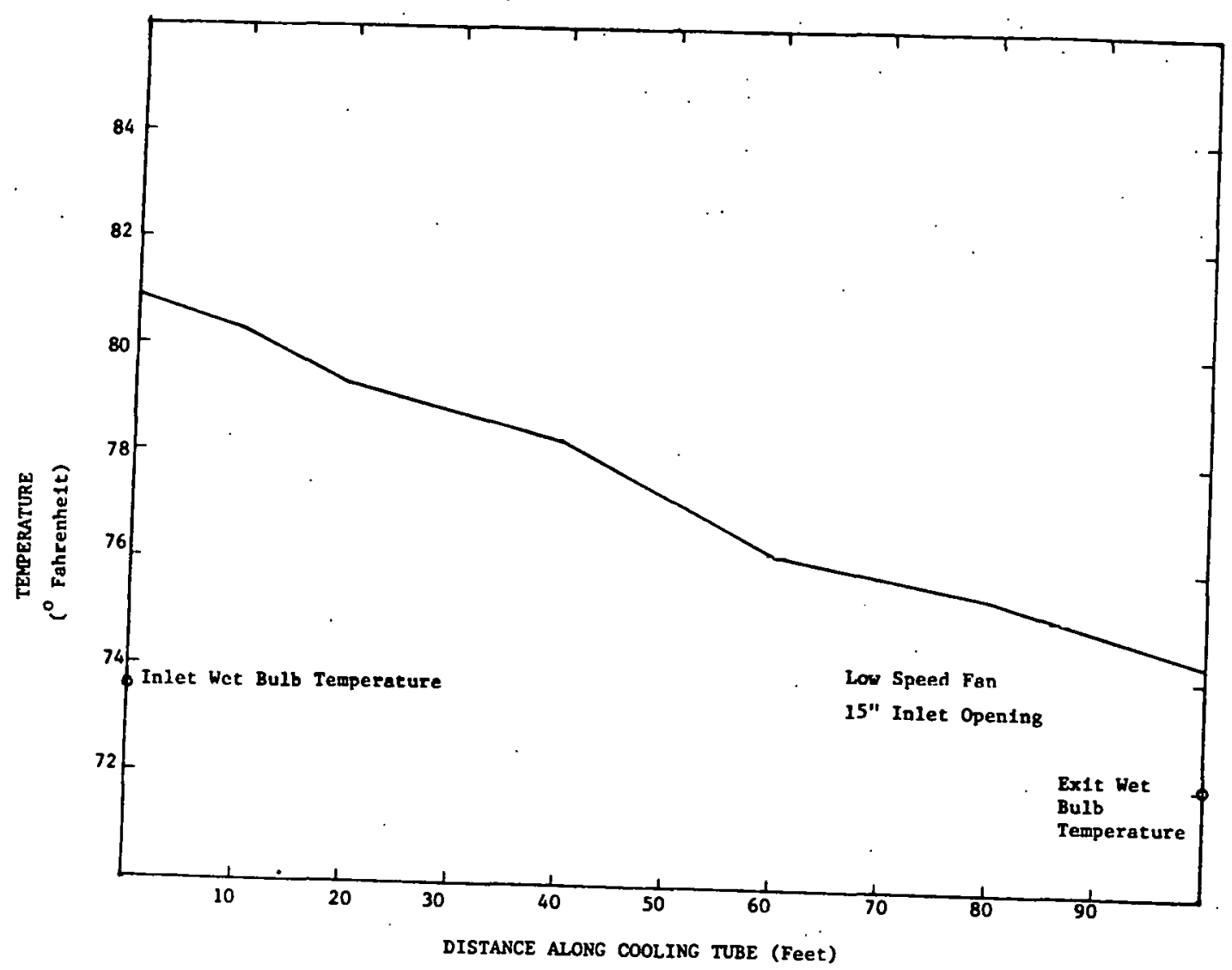

1HERMAL PERFORMANCE OF 21" DIAMETER COOLING TUBE

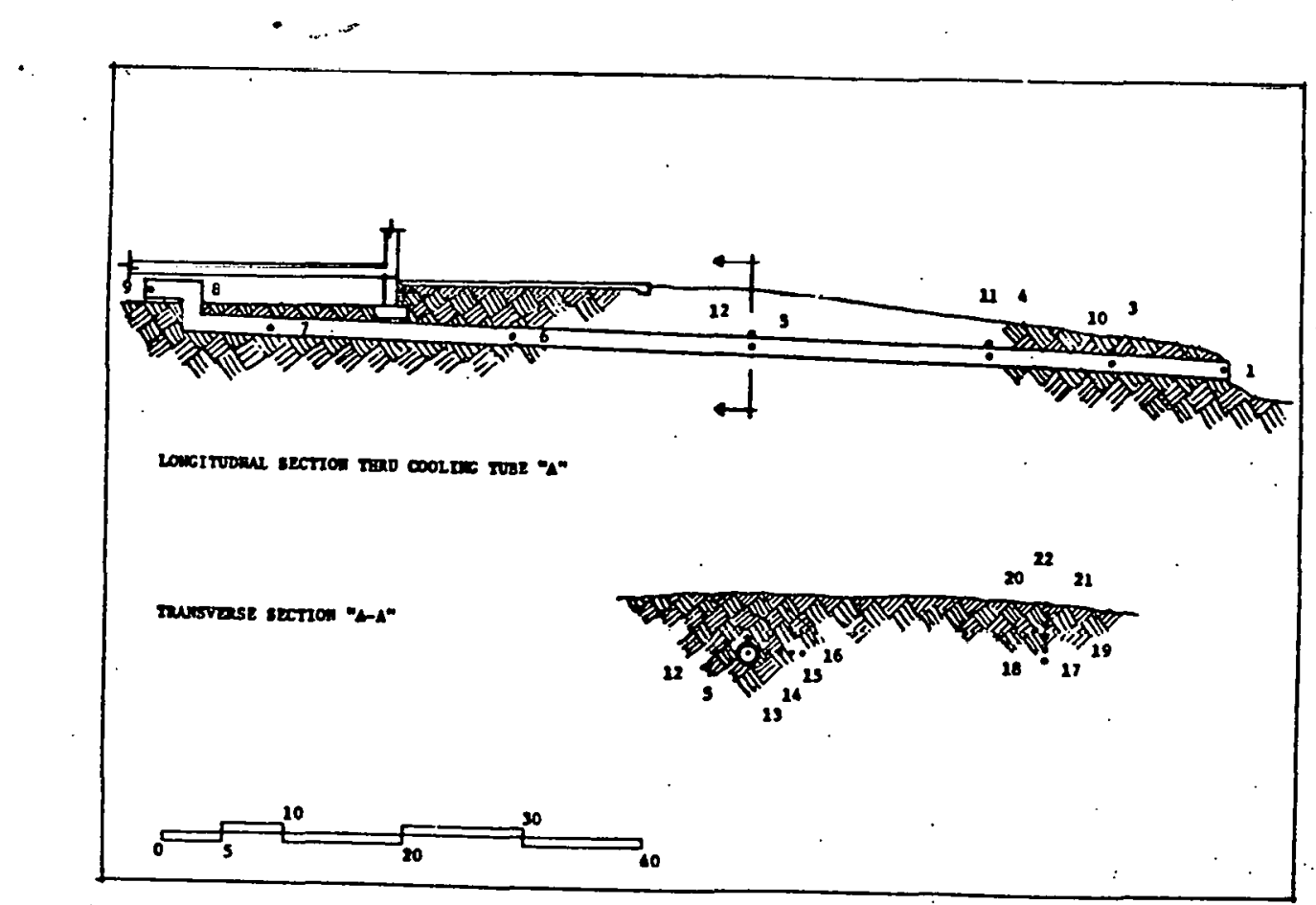




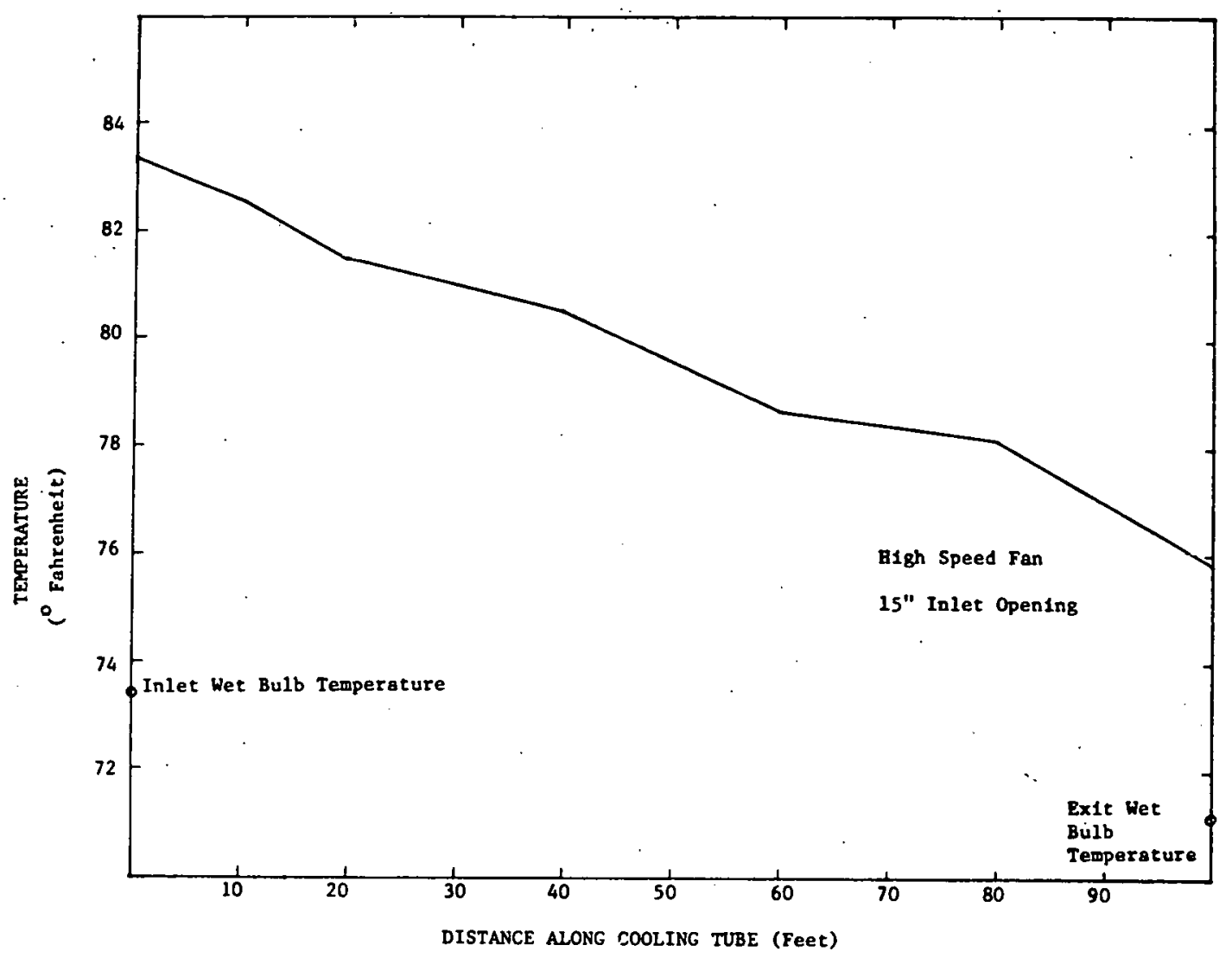

THERMAL PERFORMANCE OF 21" DLAMETER COOLING TUBE

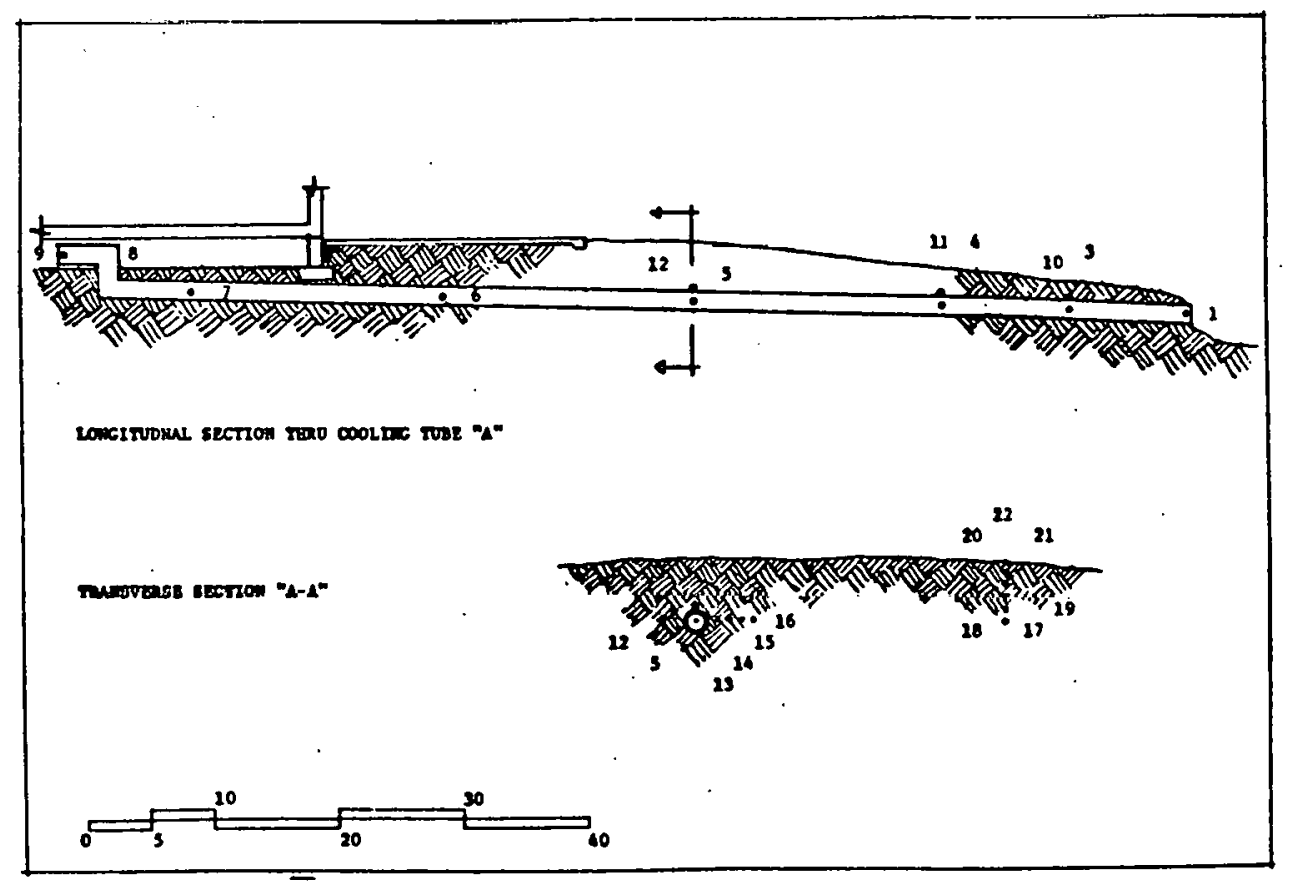




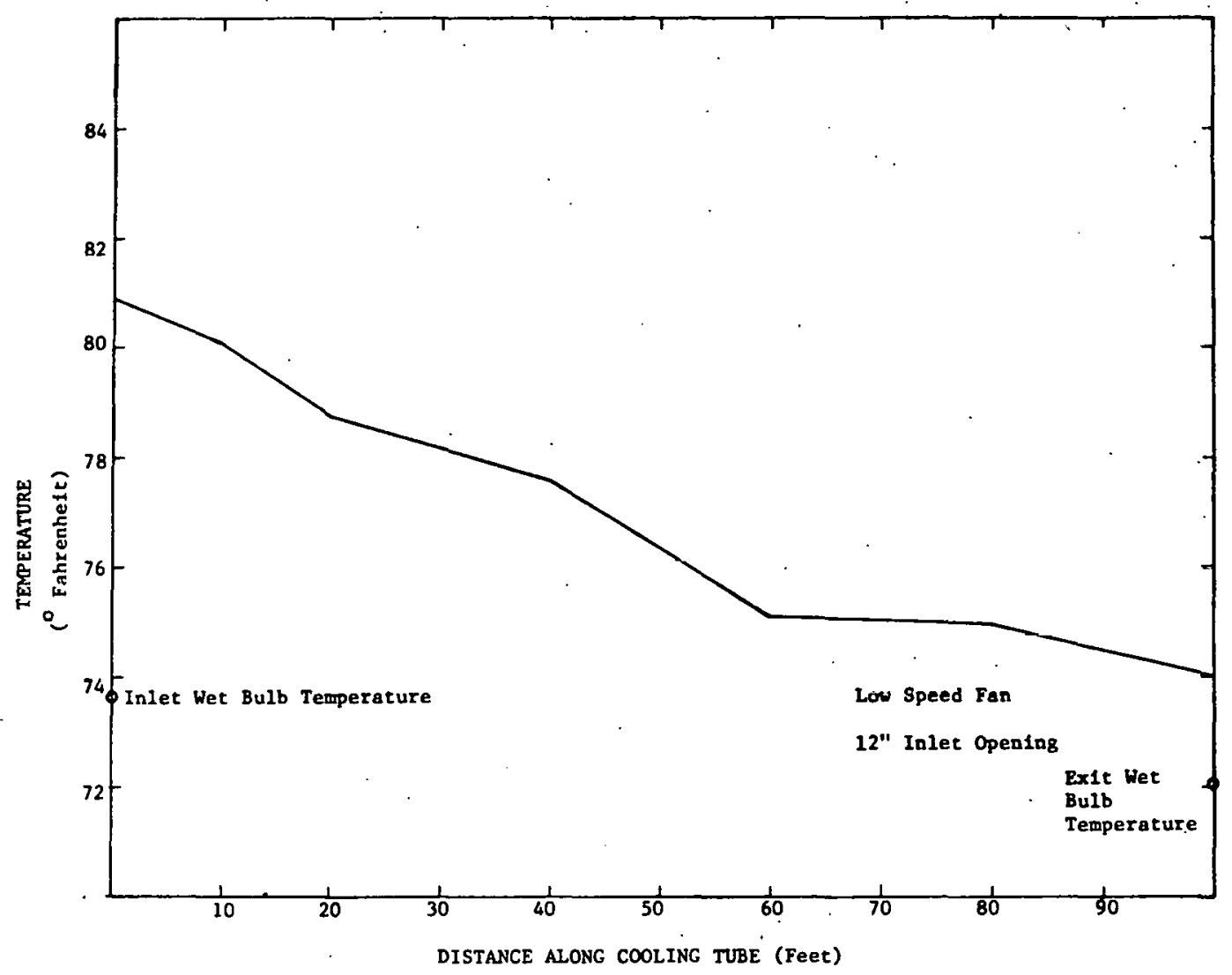

ITERMAI PERFORMANCE OF 21" DLAMETER CPOLING TUBE

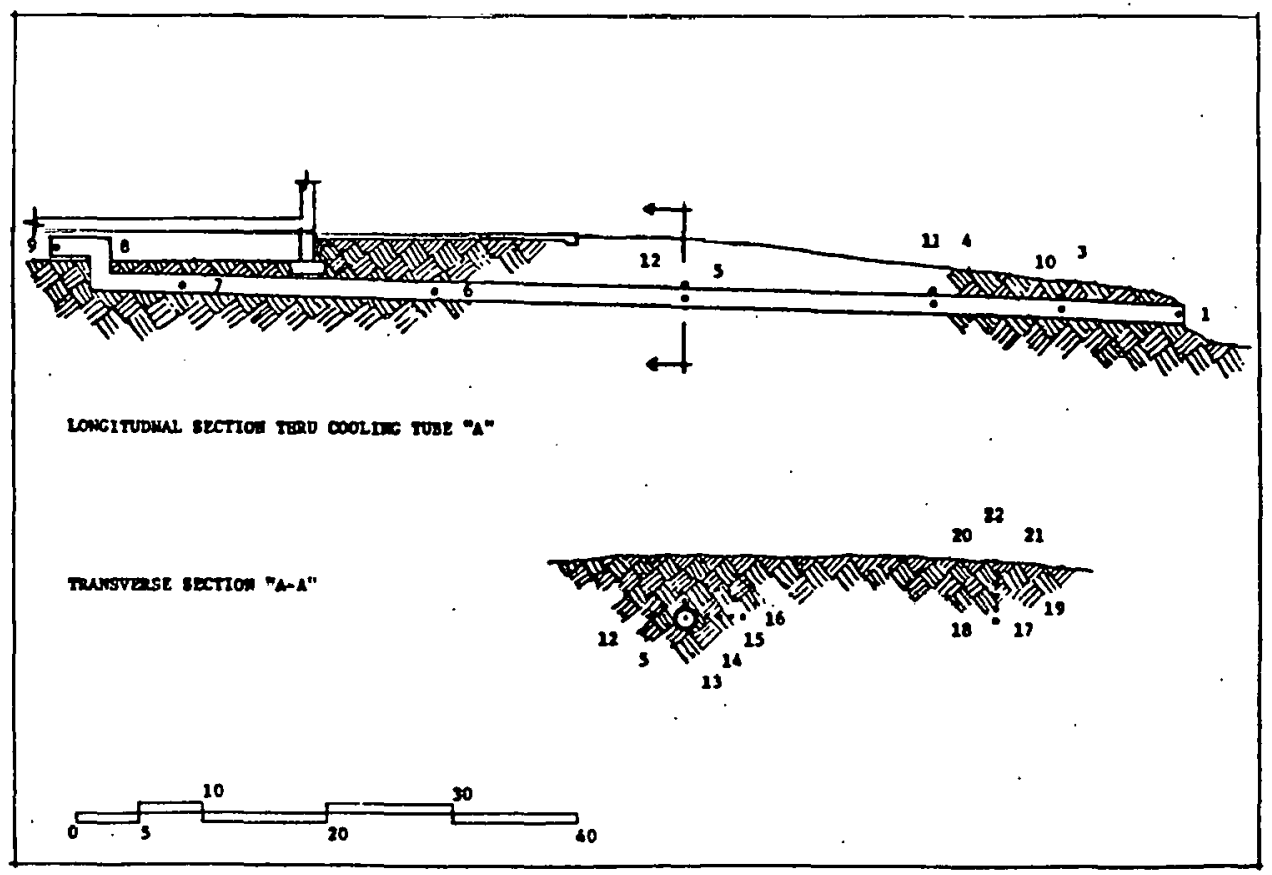




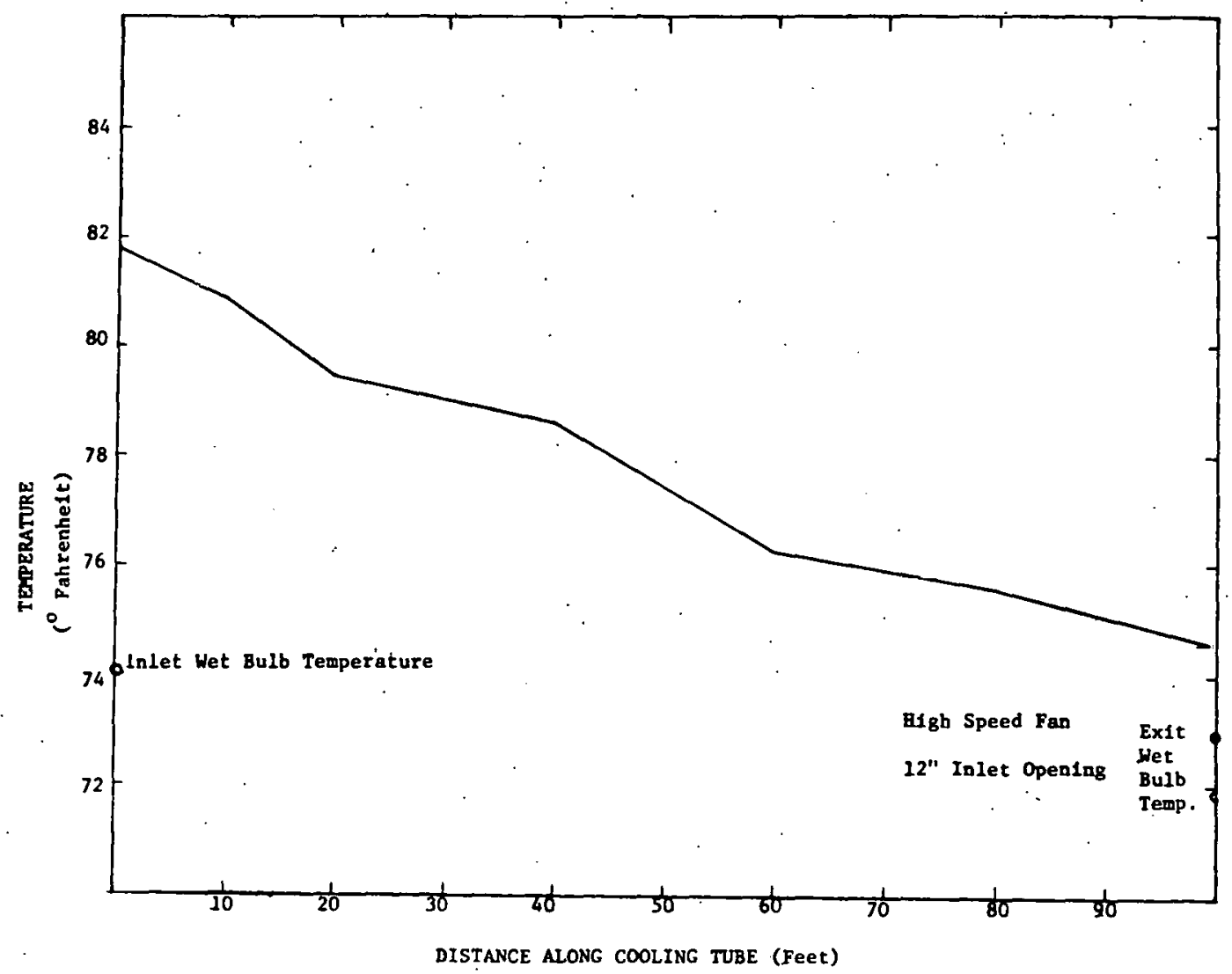

THERMAL PERFORMANCE OF 21" DIAMETER CODLING TUBE

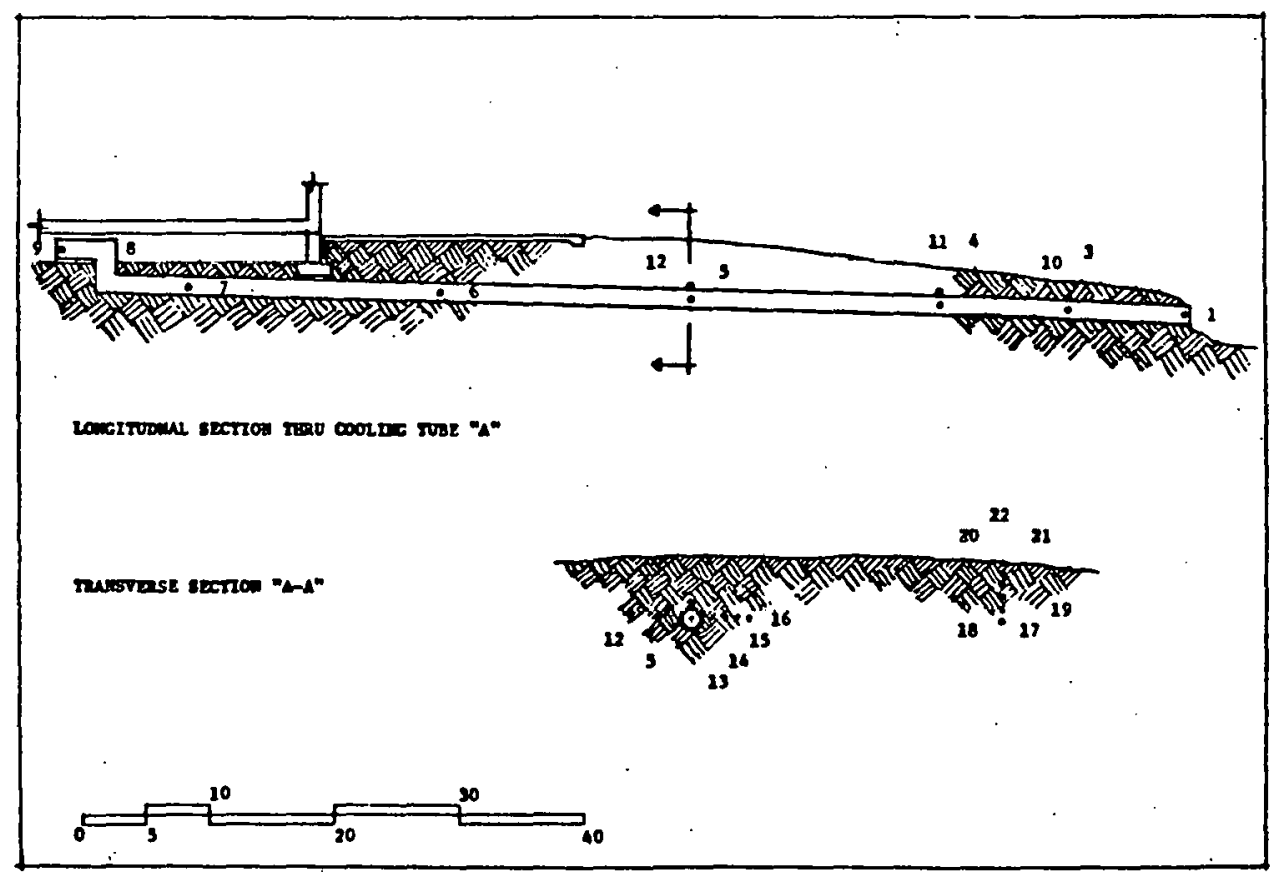




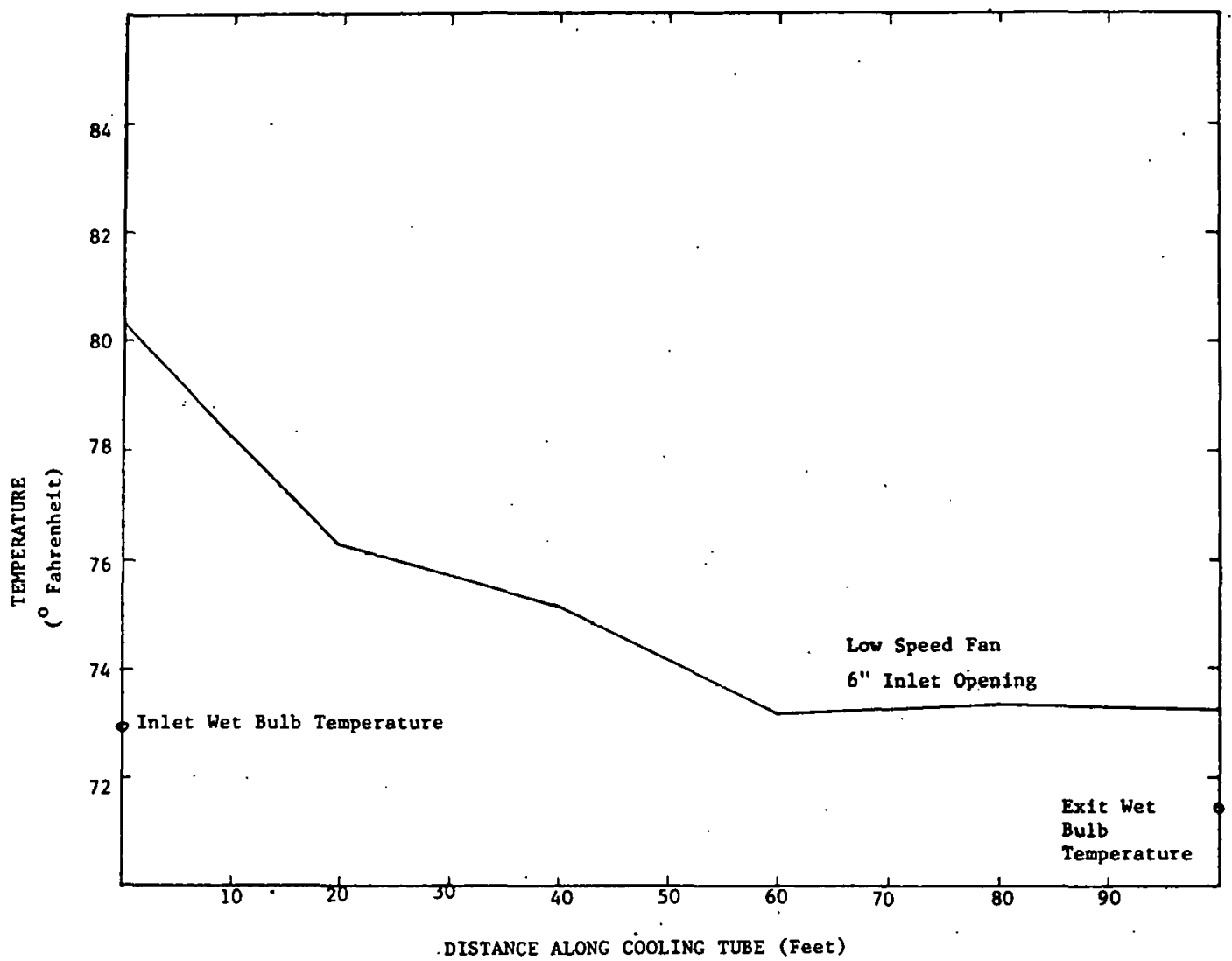

THERMAL PERFORMANCE OF 21" DIAMETER CPOLING TUBE

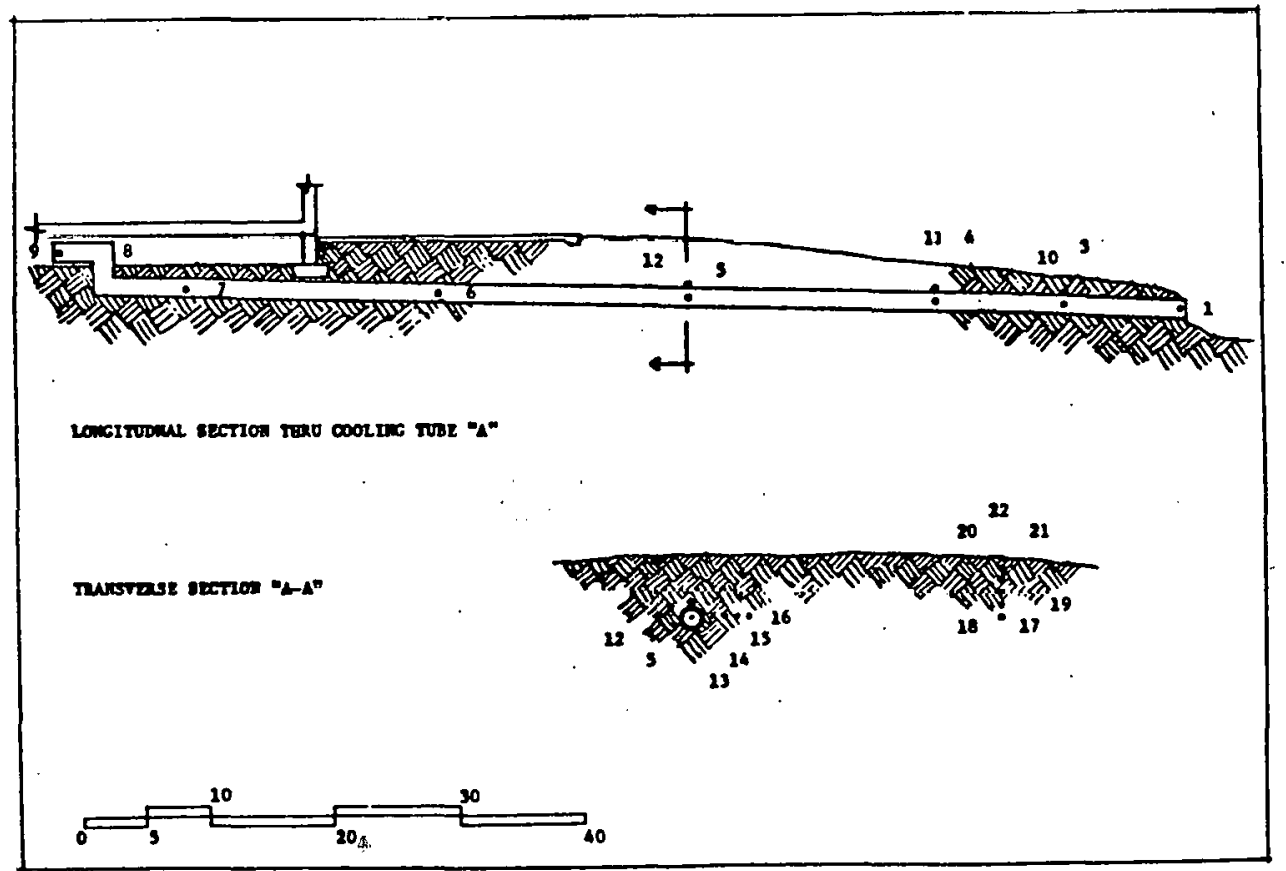




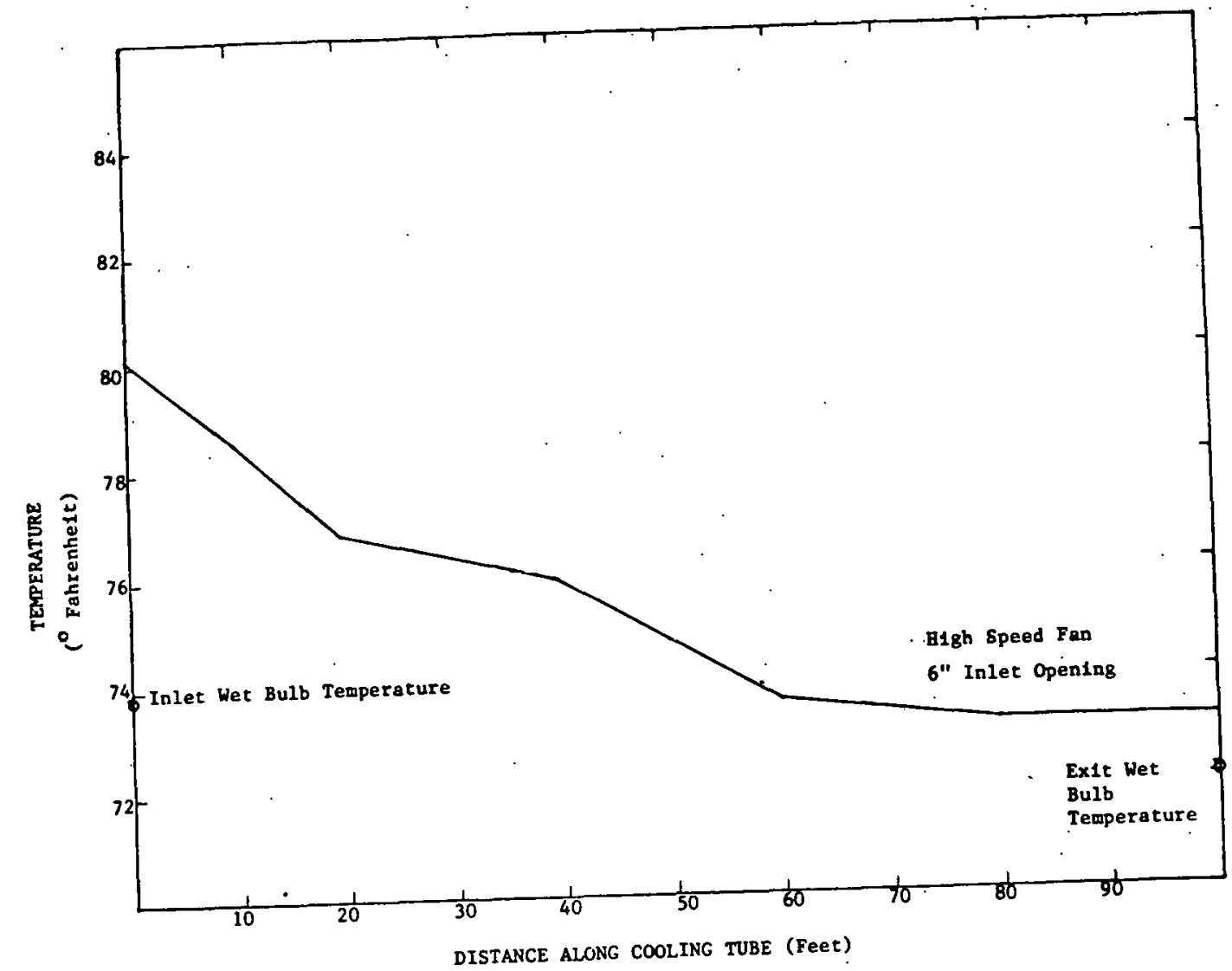

THERMAL PERFORMANCE OF $21^{\prime \prime}$ DIAMETER COOLING TUBE

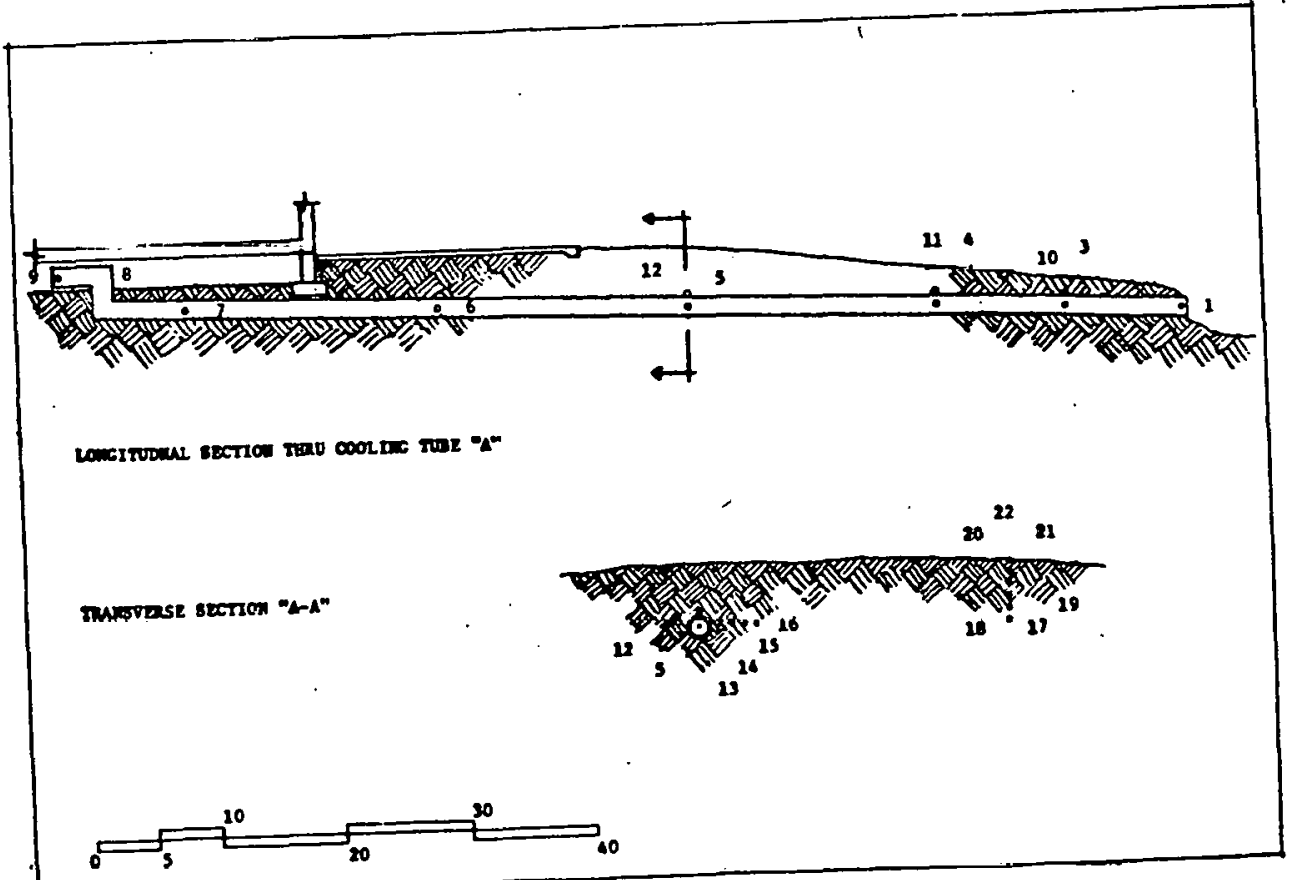


APPENDIX C

Earth Cooling Tube Analytical Performance

Mode1 


\section{EARTH COOLING TUBES}

Earth cooling tubes are popularly touted as a viable method of passive or low-energy space cooling. Despite a lack of basic research, operating experience, and design guidelines, the concept has been well received, resulting in an ever increasing number of new installations.

This appendix presents a performance model of earth cooling tubes in an attempt to arrive at fundamental conclusions about their cooling potential. The applicability and limitations of the model are discussed as are an ongoing field monitoring program and model verification efforts. The results of sensitivity studies on performance variables facilitate consideration of design variations. It is hoped that this discussion will cause more care to be exercised in the design of earth cooling tubes and more restraint to be exercised in their use.

\section{INTRODUCTION}

Four heat sinks are available for use in space cooling processes: the atmosphere, water (surface and subsurface), deep space, and the earth. In many areas, notably the southeastern United States, climatic conditions limit the rejection of heat to those sinks involving radiation, evaporation and diurnal temperature variations.

In such cases, the earth may offer the only sink available at temperatures amenable to "passive" or low-energy space cooling. Architectural designs which incorporate direct building/earth contact and earth cooling tubes which temper air by pulling it through buried tubes, provide two methods of utilizing the earth sink. Earth cooling tubes minimize the impact on the building design and offer retrofit possibilities. Furthermore, they allow the building to be alternately thermally coupled to the earth 
or isolated from it in response to the building's cooling requirements.

Offering the lure of unsophisticated hardware, low operating energy and theoretical simplicity, the earth cooling tube concept has been eagerly embraced by the energyconscious popular media and public. Earth cooling is now viewed by many as an economical means of cooling and dehumidifying.

\section{THERMAL MODEL}

Although a large number of cooling tubes have been installed, few, if any, have been analyzed to determine their performance or optimize their design. The attitude seems to be to install something and take what cooling, if any, results. This has resulted in many thousands of dollars being wasted on designs which have not been optimized and which perform very poorly, leading to many people becoming dissatisfied with cooling tubes.

Until recently, most cooling tube simulation routines were either too simple to be of benefit or too complicated for practical application in design. Historically, accurate simulation routines were based on finite difference nodal solutions which require large expensive computers. Recently, Abrams, Akridge and Benton (1) developed a simplification of a line source equation developed by Ingersoll (2) which can be used with hand held programmable calculators to predict the performance of cooling tubes.

Ingersoll showed that energy transfer from a source can be defined by the following equation:

$$
\left(T_{t s}-T_{e}\right)=\frac{Q_{* r}^{\prime}(2-n)}{2 \pi^{(n / 2)} k} \int_{r n}^{\infty} B^{(n-3)} e^{-B^{2}} d B
$$

where:

$T_{\text {ts }}=$ outside tube surface temperature (OF) 


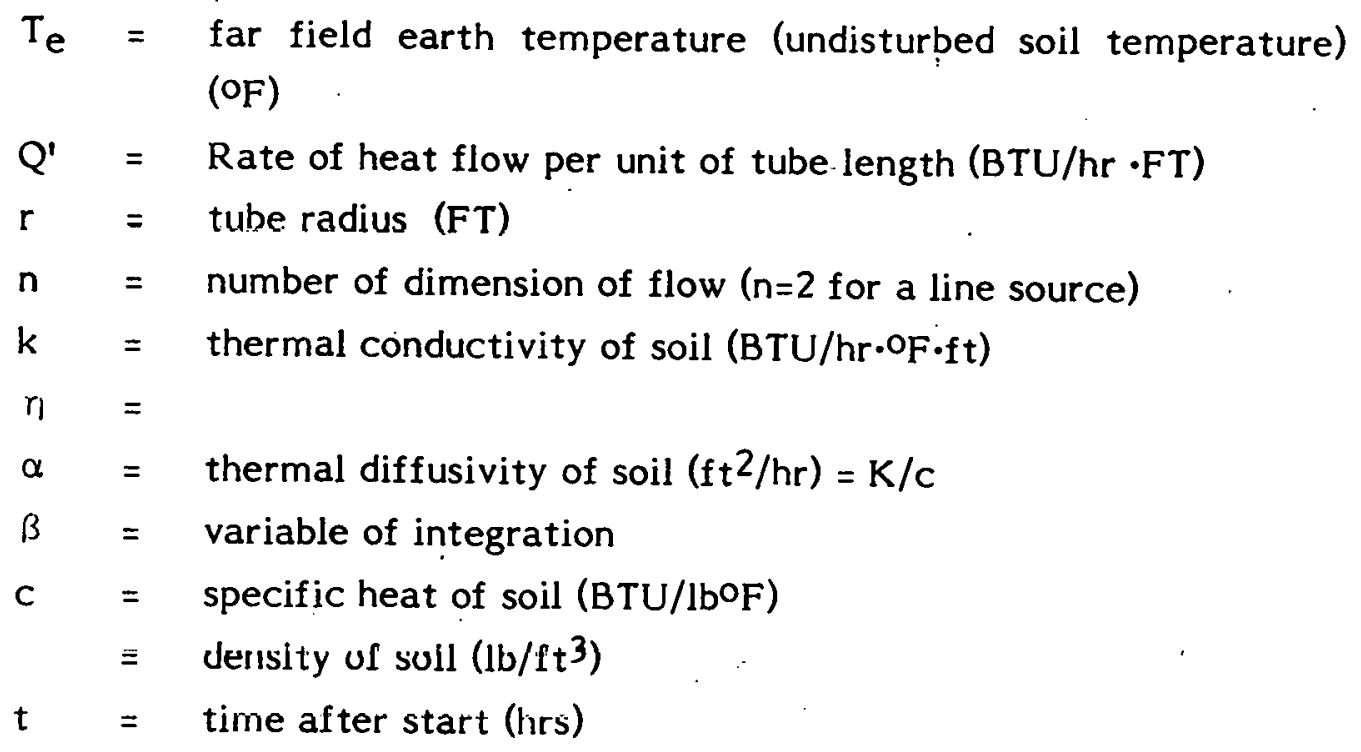

For a line source, equation (1) reduces to:

$$
\left(T_{t s}-T_{e}\right)=\frac{Q^{\prime}}{2 \pi k} \int_{r \eta}^{\infty} \frac{e^{-\beta^{2}}}{\beta} d \beta
$$

Equation (2) treats the energy transfer as a line source and assumes negligible heat transfer along the axis of the tube. Values of the integral may be found in tables of integrals, or for values of $r n$ less than 0.6 , the integral may be represented by:

$$
\int_{r n}^{\infty} \frac{e^{-\beta^{2}}}{\beta} d \beta=\ln \frac{1}{r \eta}+\frac{(r \eta)^{2}}{2}-\frac{(r \eta)^{4}}{8}-0.2886
$$

By substituting equation (3) into equation (2) one obtains: 


$$
\left(T_{t s}-T_{e}\right)=\frac{Q^{\prime}}{2 \pi k} *\left(\ln \cdot \frac{1}{r \eta}+\frac{(r \eta)^{2}}{2}-\frac{(r \eta)^{4}}{8}-0.2886\right)
$$

While equation (4) is useful in calculating the change in temperature of soil adjacent to a tube as a function of energy withdrawal rate ( $\left.Q^{\prime}\right)$, time $t$, and soil properties; it is not in a form that is readily useful for calculating the performance of earth cooling tubes. If one solves for $Q^{\prime}$ and rearranges equation (4) into the form:

$$
Q^{\prime}=U_{g} * A_{p}^{*}\left(T_{t s}-T_{e}\right)
$$

where:

$$
\mathrm{U}_{\mathrm{g}}=\frac{1}{\mathrm{R}_{\mathrm{g}}}=\frac{1}{\frac{\mathrm{r}}{\mathrm{k}} *\left(\ln \frac{1}{\mathrm{r} \eta}+\frac{(\mathrm{r} \eta)^{2}}{2}-{\frac{(\mathrm{r} \eta)^{4}}{8}}^{4}-0.2886\right)}
$$

$$
\begin{gathered}
A_{p}=\quad \text { area of pipe per ft. of length }=2 \pi \gamma * 1 \\
\left(T_{t s}-T_{e}\right)=\quad \text { temperature difference between soil adjacent to } \\
\text { pipe and far field soil temperature. }
\end{gathered}
$$

Equation (4) becomes:

$$
Q^{\prime}=2 \pi k\left(T_{t 3}-T_{e}\right) /\left(\ell n \frac{1}{r \eta}+{\frac{(r \eta)^{2}}{2}}^{2}-\frac{(r \eta)^{4}}{8}-0.2886\right)
$$


Since one is primarily concerned with the energy transferred to the fluid flowing through the pipe, one must also include the thermal resistance through the tube wall and the thermal resistance of the fluid film. These may be expressed as:

Pipe wall resistance may be expressed as:

$$
R p=\frac{t_{p}}{k_{p}}
$$

where:

$$
\begin{aligned}
& t_{p}=\text { pipe thickness in } \mathrm{ft} \text {. } \\
& \mathrm{k}_{\mathrm{p}}=\text { thermal conductivity of pipe } \frac{(\mathrm{BTU} \cdot \mathrm{FT})}{\mathrm{hr} \cdot \mathrm{FT}^{2}{ }^{\circ} \mathrm{F}}
\end{aligned}
$$

Pipe film resistance may be expressed as:

$$
\mathrm{R}_{\mathrm{O}}=\frac{1}{\mathrm{~h}_{\mathrm{O}}} \frac{(\mathrm{BTU})}{{\mathrm{hr} \cdot \mathrm{FT}^{2} \bullet_{\mathrm{F}}}^{\mathrm{N}}}
$$

where:

$$
h_{0}=\text { film transfer coefficient }
$$

- Total thermal resistance to energy flow can now be expressed as:

$$
\begin{aligned}
& R_{t}=R_{g}+R_{p}+R_{0} \\
& R_{t}=\frac{r}{k} *\left(\ln \frac{1}{r \eta}+\frac{(r n)^{2}}{2}-\frac{(r n)^{4}}{8}-0.2886\right)+\frac{t_{p}}{k_{p}}+\frac{1}{h_{0}}
\end{aligned}
$$

Energy transfer for a unit length of pipe can now be expressed in the form:

$$
Q_{x}=A_{p} * \frac{1}{R_{t}} *\left(T_{f x}-T_{e}\right)
$$

where:

$$
T_{f x}=\text { fluid temperature, } o_{F}
$$




$$
T_{e}=\text { far field earth temperature, of }
$$

This gives a final form of the expression:

$$
Q_{x}=2 \pi r * \frac{1}{\left(\frac{r}{k} *\left(\ln \frac{1}{r \eta}+\frac{(r \eta)^{2}}{2}-\frac{(r \eta)^{4}}{8}-0.2886\right)+\frac{t_{p}}{k_{p}}+\frac{1}{h_{0}}\right)} *\left(T_{f x}-T_{e}\right)
$$

Equation (11) allows one to calculațe the energy transfer per foot of pipe length based on far field soil temperatures $\left(T_{e}\right)$ and fluid temperatures $\left(T_{f x}\right)$ at position $x$ along the length of pipe. Obviously as energy is lost or gained at a position $x$, the fluid exit temperature $T_{f x+1}$ will have changed. This change can be calculated by:

$$
T_{f x+1}=T_{f x}+\frac{Q_{x}}{m_{p}}
$$

where:

$$
\begin{array}{ll}
\mathrm{T}_{\mathrm{fx}+1} & =\text { fluid temperature at position } \mathrm{x}+1 \\
\mathrm{~T}_{\mathrm{fx}} & =\text { fluid temperature at position } \mathrm{x} \\
\mathrm{Q}_{\mathrm{x}} & =\text { energy lost or gained between positions } \mathrm{x} \text { and } \mathrm{x}+1 \\
\mathrm{~m} & =\text { fluid mass flow rate (lbs/hr) } \\
\mathrm{C}_{\mathrm{p}} & =\text { fluid specific heat }(\mathrm{BTU} / \mathrm{lb} \text {-F) }
\end{array}
$$

Total energy lost or gained along the length of pipe of length $L$ is:

$$
Q_{T}=\sum_{0}^{L} Q_{x}-\dot{m} C_{P}\left(T_{L}-T_{0}\right)
$$

where:

$Q_{T}$ is total energy transferred (BTU/hr)

$T_{L}$ is fluid temperature at $x=L$

$T_{0}$ is fluid temperature at $x=0$ 


\section{Model Limitations}

The equations developed here to estimate the performance of earth cooling tubes were developed using several simplifying assumptions. First, it is assumed that the soil is an infinite medium at a uniform temperature. At first, this would appear to be a very limiting assumption, since we know that the soil temperature not only changes with depth below the surface but also varies seasonally. The assumption does limit. accuracy if the tube is at a shallow depth or is close to another tube. It is believed that the assumption is reasonably valid providing the tube is greater than six feet below the surface and is separated at least six feet from adjacent tubes. One should use the average monthly soil temperature for a depth comparable to the tube center line for the far field temperature. The best use of these equations lies not in quantifying performance but in parametric studies to determine the effect of different soil properties, pipe diameters, pipe materials and air flow velocities.

A second assumption is that the soil properties are uniform and constant for a particular simulation. In practice we know that these vary both with depth and time. Soil conductivity is highly sensitive to moisture content, becoming much greater at higher moisture contents. If one uses average soil properties for the area where the tubes are installed, this variation averages out over a year.

\section{Parametric Studies}

While it is believed that the equations developed here can provide reasonable estimates of cooling tube performance, their real value lies in parametric studies to determine the effect of tube diameter, tube length, mass flow rate, tube material and thickness, soil properties and time.

Figure $\mathrm{Cl}$ shows the temperature difference between the soil adjacent to the pipe and soil remote (undisturbed) from the pipe for a constant energy input of 50 $\mathrm{Btu} / \mathrm{Hr} \cdot \mathrm{Ft}$ as a function of pipe diameter. Figure $\mathrm{C} 2$ shows the temperature differences if the energy per square foot of pipe is held constant. When one looks at Figure $\mathrm{Cl}$, one might come to the conclusion that larger pipe diameters are desirable. Figure $\mathrm{C} 2$ shows this to not necessarily be the case. A two-inch diameter pipe, two feet long, has much less temperature differential than a four-inch diameter pipe, one 
foot long, for the same total energy transferred. This becomes even clearer on Figure C3 where energy transfer rate (Btu/hr.ft ${ }^{2}$. ${ }^{\circ}$ ) is plotted versus pipe diameter. Figure $\mathrm{C} 4$ shows that smaller pipes have much higher transfer rates for a given wall area.

Basically, Figures $\mathrm{C} 2$ and $\mathrm{C} 3$ show that smaller, long pipes are better than larger; short pipes. This is not unpredictable if one recognizes that energy flow to the pipe is essentially radial and that small, long pipes are exposed to more undisturbed soil than large, short pipes.

While the calculations show that the smaller the pipe, the better its operation from an energy transfer standpoint, there are other factors, such as pressure drop through the pipe, trenching costs, and available space, which will influence pipe diameter selection.

Figure $\mathrm{C} 4$ shows the effect of time on energy transfer rate. This figure shows energy transfer rates to drop quite rapidly during the first 50 hours ( 2 days), drop less rapidly during the next 100 hours ( 4 days), and essentially become constant after 168 hours ( 7 days).

Figure C5 shows the effect of soil diffusivity on temperature difference. Comparison of Figure $\mathrm{Cl}$ and $\mathrm{C} 5$ shows that lower thermal conductivity and diffusivity significantly increase the temperature difference required for a given heat transfer rate. It is believed that the values used to calculate the data used to construct Figure $\mathrm{Cl}$ are more nearly representative of the soil in Atlanta.

Figure $\mathrm{C} 6$ shows the effect of mass flow rate on exit temperature. As one would expect, higher mass flow rates result in higher exit temperatures. Higher flow rates also result in higher energy transfer rates. 


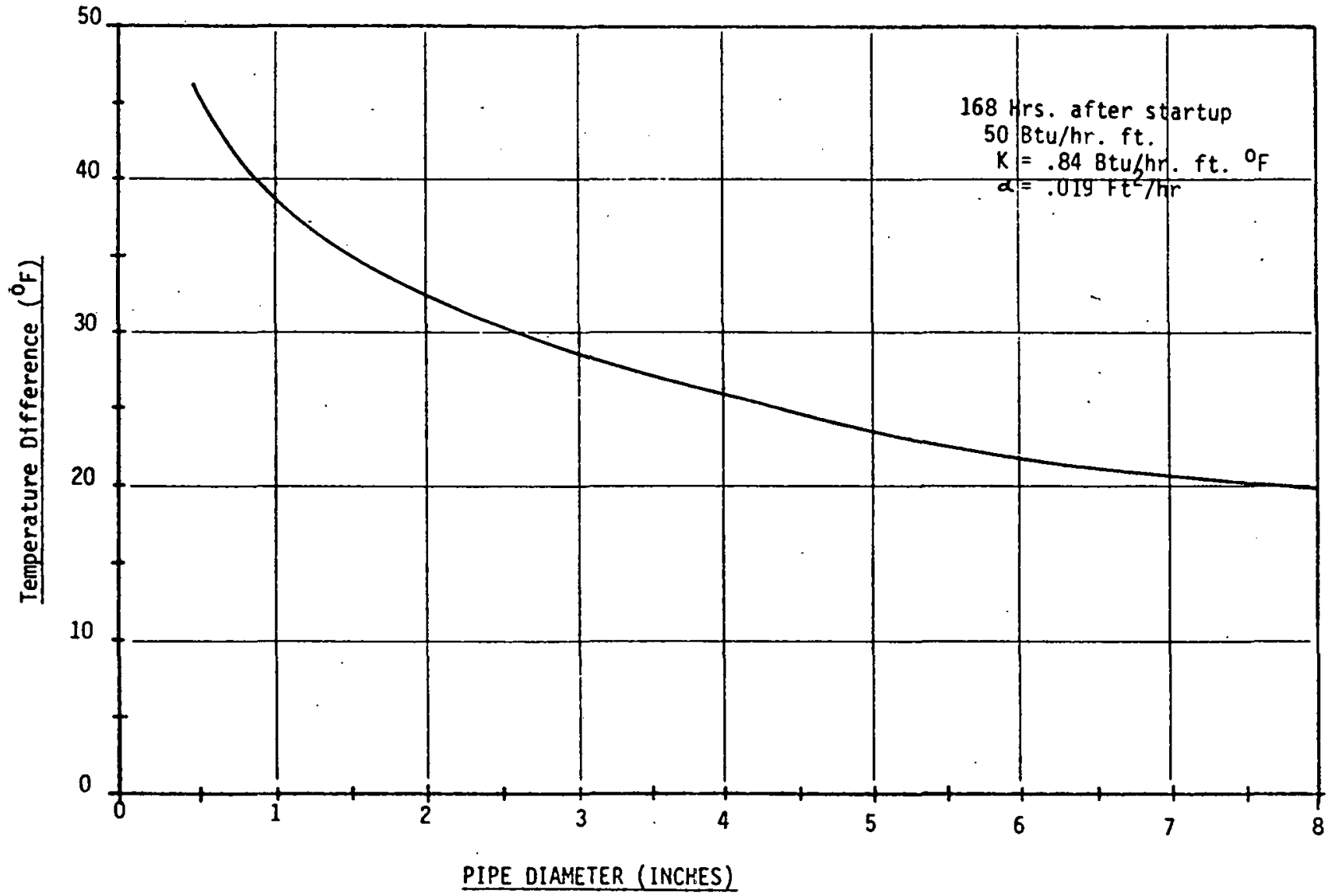

Figure $C_{1}$ Pipe-Far Field Temperature Difference vs Pipe Diameter (in) 


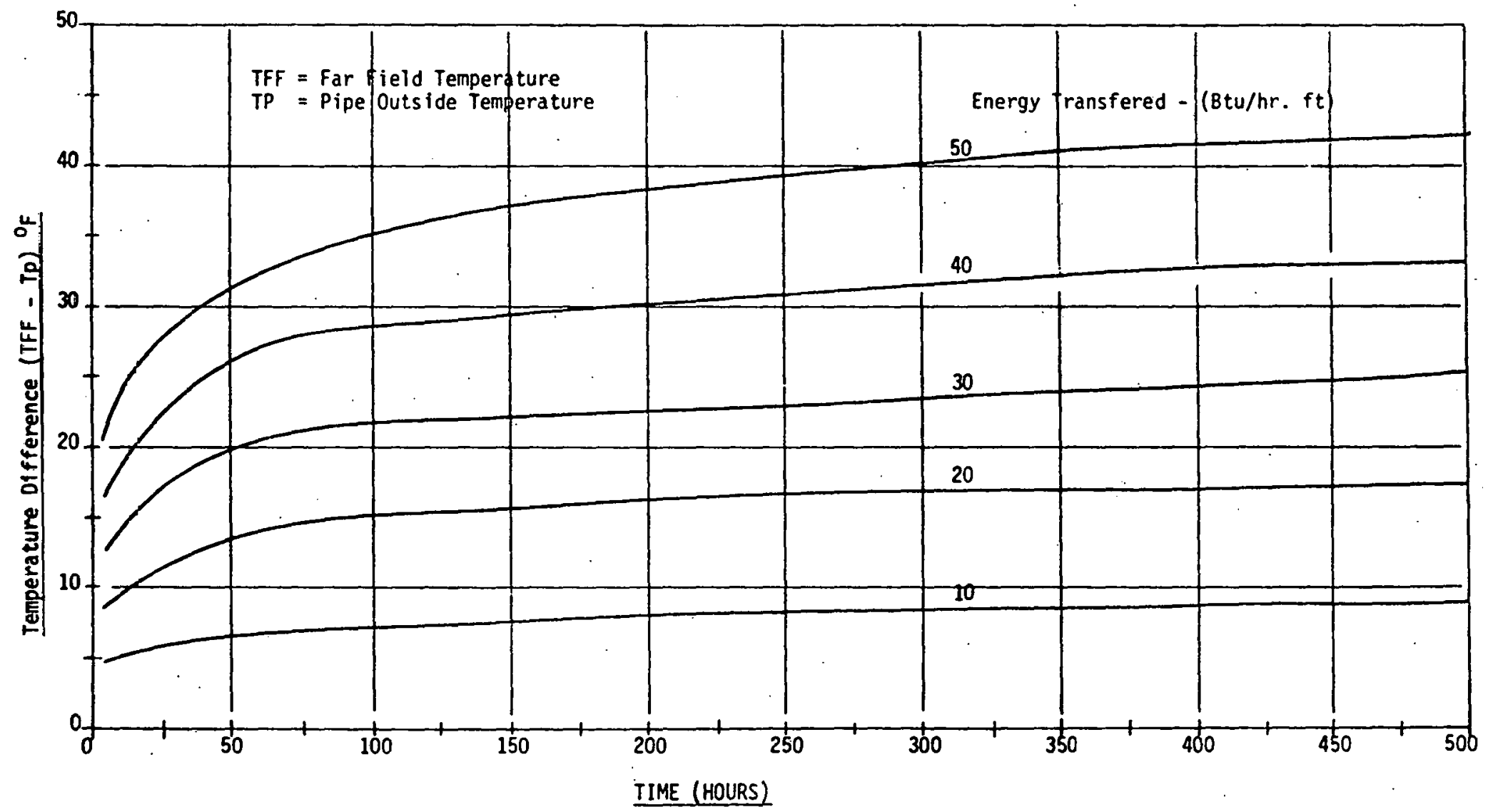

Figure C2 Pipe - Far Field Temperature Difference vs Operating Time 


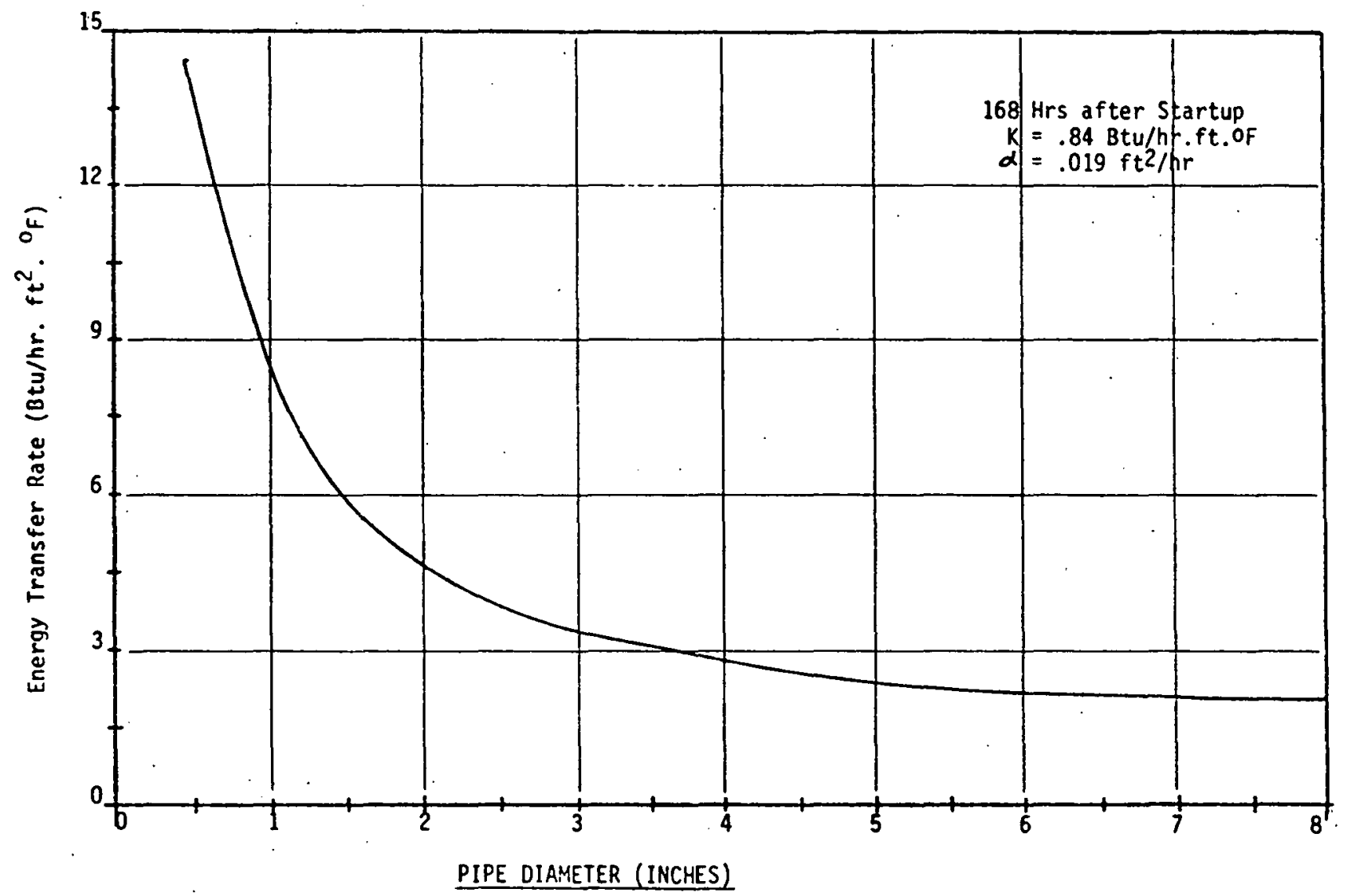

Figure $\mathrm{C}_{3}$ Energy Transfer Rate as a Function of Pipe Diameter 


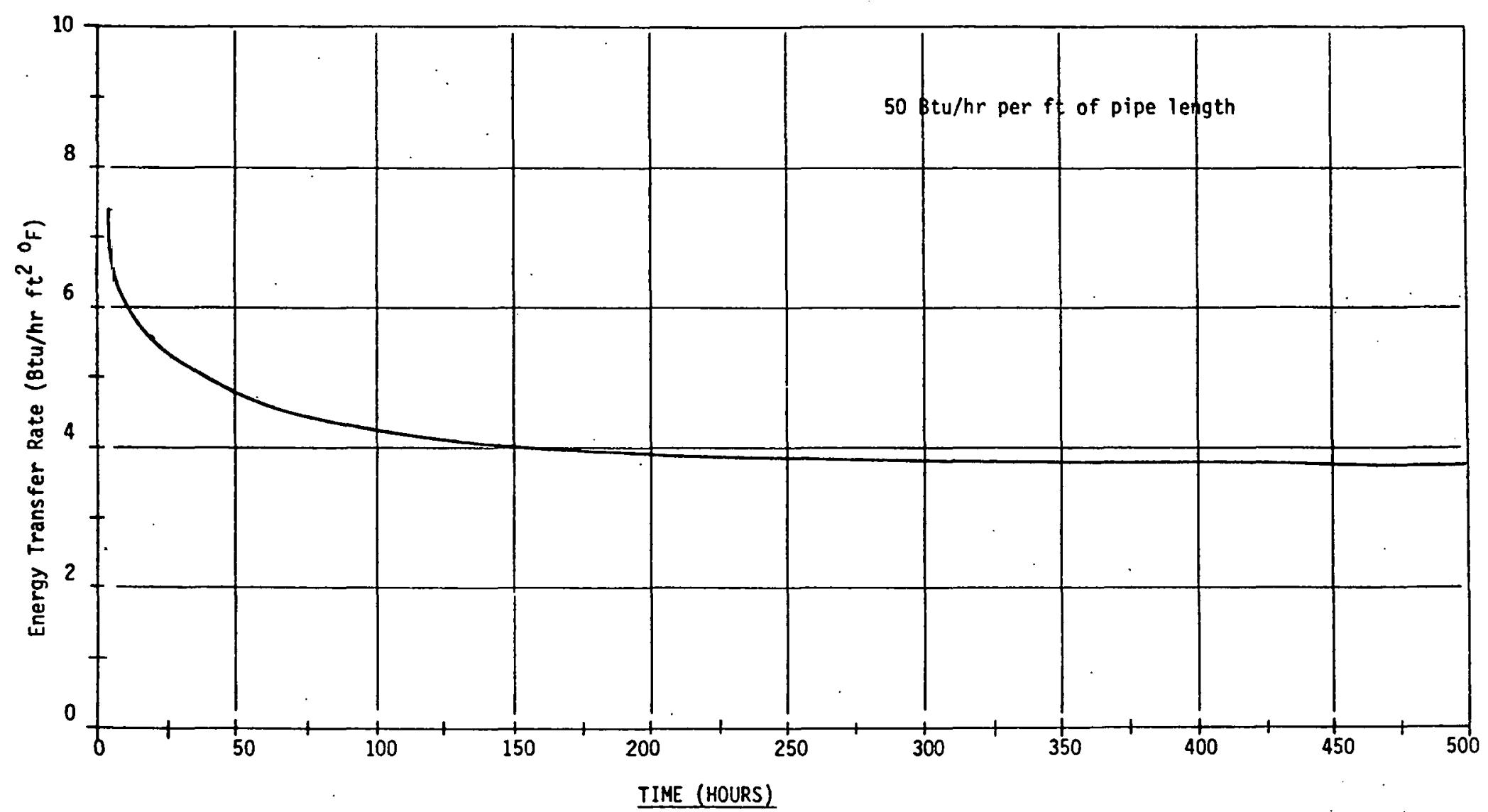

Figure $\mathrm{C} 4$ Energy Transfer Rate as a Function of Operating Time 


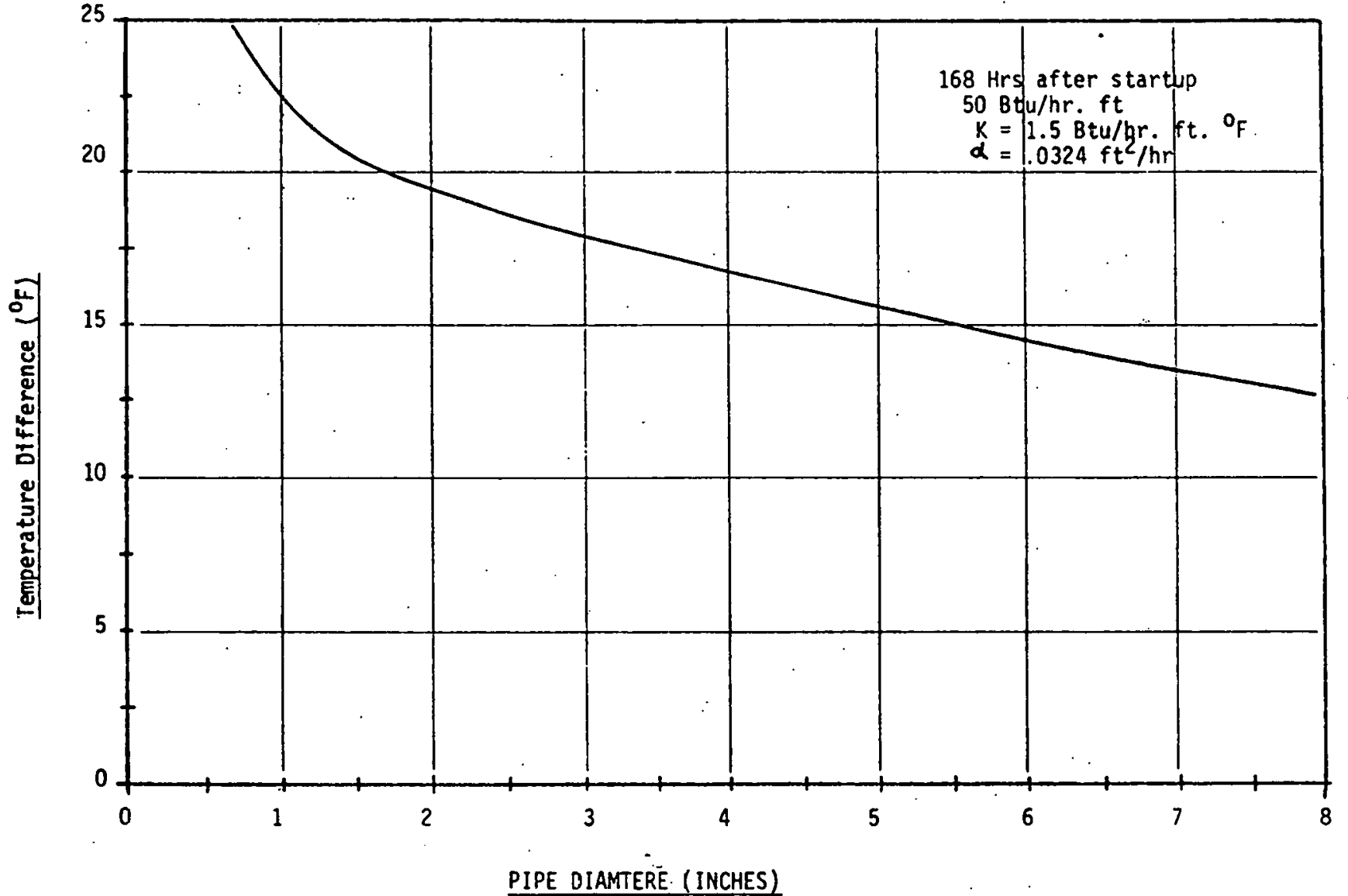

Figure $\underline{\mathrm{C}} 5$ Pipe-Far Field Temperature Difference vs Pipe Diameter (in) 
MASS FLOW RATES

CURVE $\mathrm{A}=100 \mathrm{LBS} / \mathrm{HR}$

" "B $=500 \mathrm{LBS} / \mathrm{HR}$

" " C $=1000 \mathrm{LBS} / \mathrm{HR}$

" $" \mathrm{D}=2000 \mathrm{LBS} / \mathrm{HR}$

" $\quad E=5000 \mathrm{LBS} / \mathrm{HR}$
HEAT TRANSEER AT END OF RUN

TOTAL $Q=1,699 \mathrm{BTU} / \mathrm{HR}$

" " " $=6,766 \mathrm{BTU} / \mathrm{HR}$

" " " $=9,319 \mathrm{BTU} / \mathrm{HR}$

" $" ~ "=11,144 \mathrm{BTU} / \mathrm{HR}$

" " " $=12,483 \mathrm{BTU} / \mathrm{HR}$

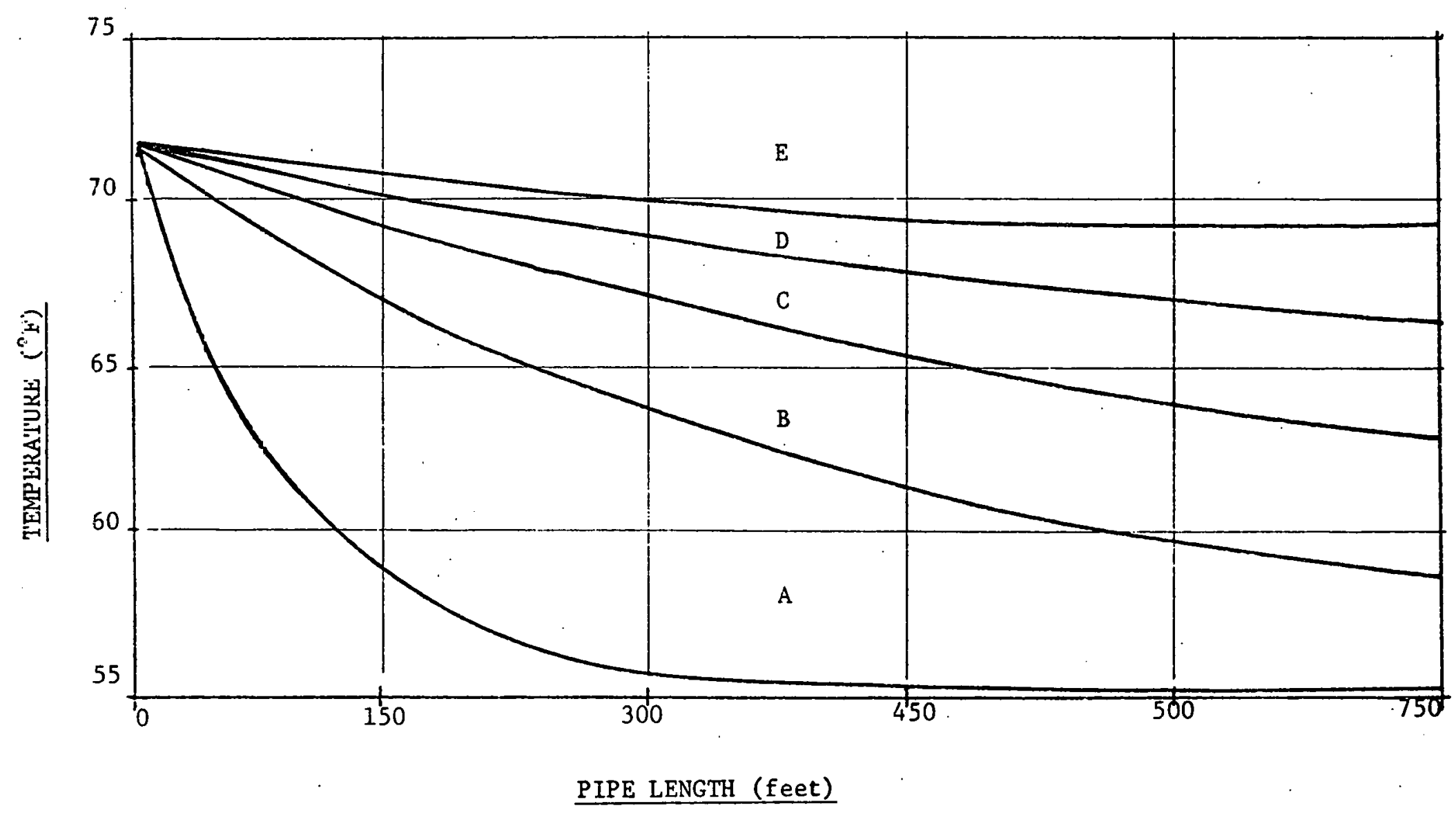

FIG. NO. L 6 TEMPERATURE vS PIPE LENGTH for several values of MASS FLOW 